\title{
CONSERVAÇÃO DE GOIABAS 'KUMAGAI' EM DIFERENTES TEMPERATURAS E MATERIAIS DE EMBALAGEM
}

\section{ANGELO PEDRO JACOMINO}

Engenheiro Agrônomo

\author{
Orientador: Prof. Dr. KEIGO MINAMI
}

Tese apresentada à Escola Superior de Agricultura "Luiz de Queiroz", Universidade de São Paulo, para obtenção do título de Doutor em Agronomia, Área de Concentração: Fitotecnia

P IR A C I C A B A

Estado de São Paulo - Brasil

Maio - 1999 


\title{
Dados Internacionais de Catalogação na Publicação (CIP) DIVISĀO DE BIBLIOTECA E DOCUMENTAÇĀO - Campus "Luiz de Queiroz"/USP
}

\author{
Jacomino, Angelo Pedro \\ Conservação de goiabas "Kumagai"em diferentes temperaturas e materiais de \\ embalagem / Angelo Pedro Jacomino. -- Piracicaba, 1999. \\ $90 \mathrm{p}$. \\ Tese (doutorado) - Escola Superior de Agricultura Luiz de Queiroz, 1999. \\ Bibliografia. \\ 1. Armazenamento 2. Conservação 3. Efeito da temperatura 4.Embalagem \\ 5. Goiaba I. Título
}

CDD 634.421

Termitida a cópia total ou parcial deste documento, desde que citada o fonte 0 artor" 


\section{SUMÁRIO}

Página

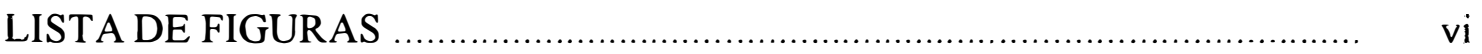

LISTA DE TABELAS .................................................................... vii

RESUMO

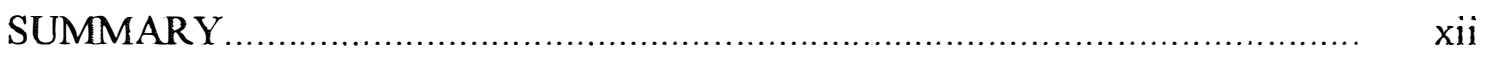

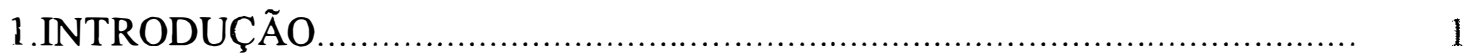

2. REVISÃO DE LITERATURA ....................................................... 3

2.1. Importância econômica....................................................................... 3

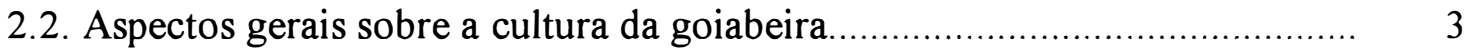

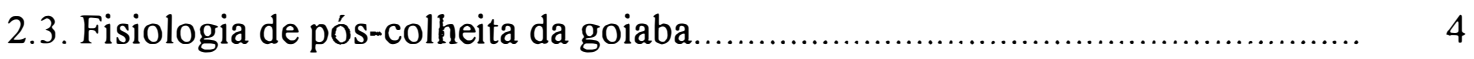

2.3.1. Respiração e evolução de etileno.................................................... 4

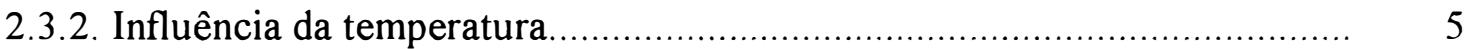

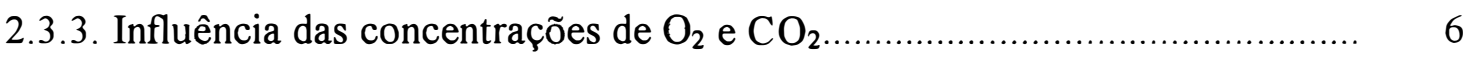

2.4. Uso de atmosfera modificada na conservação de goiabas......................... 7

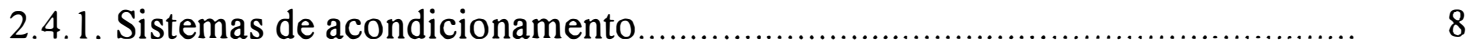

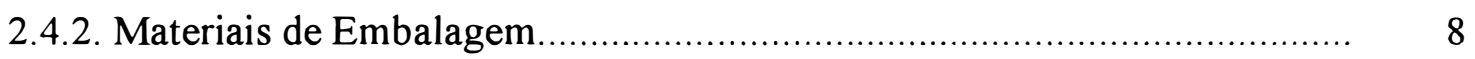

3. COMPORTAMENTO DE GOIABAS 'KUMAGAI' SUBMETIDAS A DIFERENTES TEMPERATURAS DE ARMAZENAMENTO ................... 11

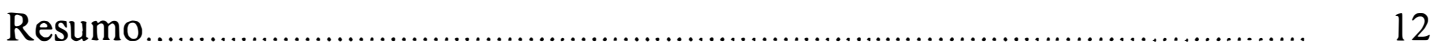

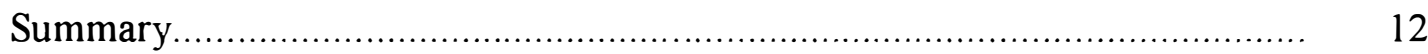

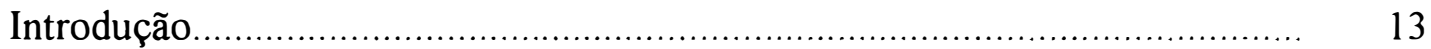

Material e Métodos...................................................................... 14

Resultados e Discussão............................................................. 16

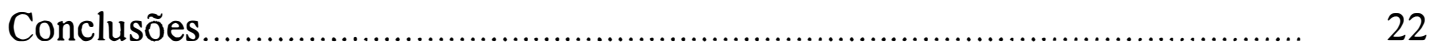

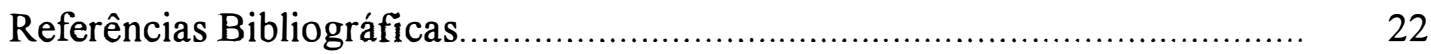

4. MATERIAIS DE EMBALAGEM PARA CONSERVAÇÃO REFRIGERADA DE GOIABAS ‘KUMAGAI’ .............................................. 25

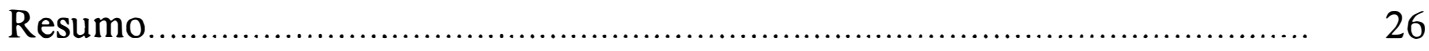




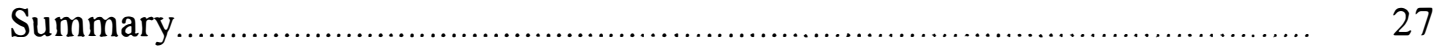

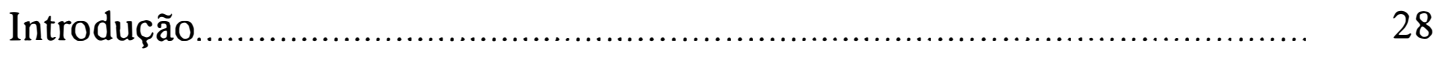

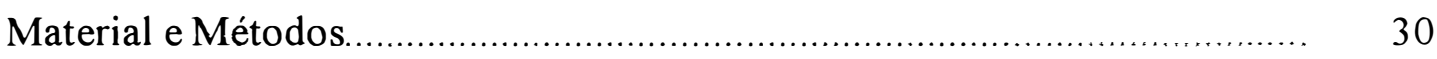

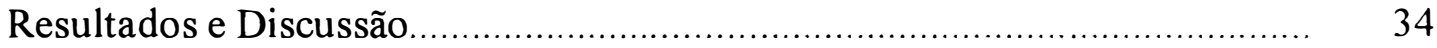

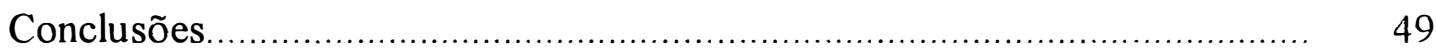

Referências Bibliográficas.............................................................. 50

5. CARACTERÍSTICAS SENSORIAIS DE GOIABAS 'KUMAGAI' SUBMETIDAS A DIFERENTES MATERIAIS DE EMBALAGEM E ARMAZENAMENTO REFRIGERADO............................................. 57

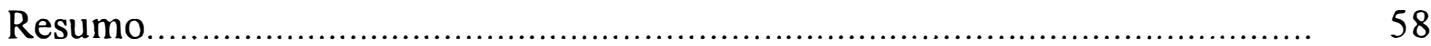

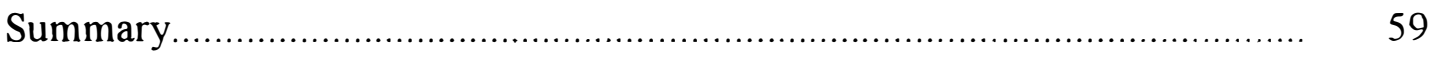

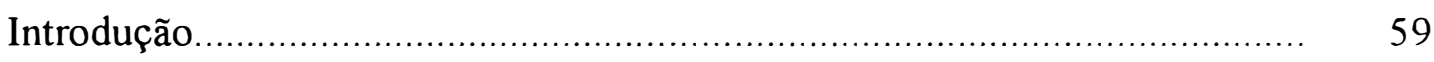

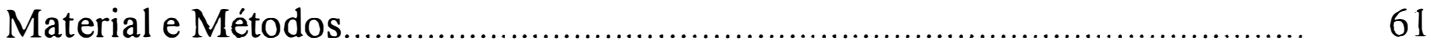

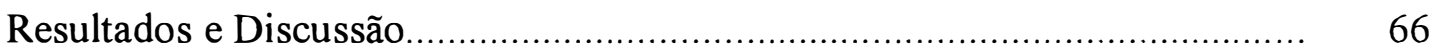

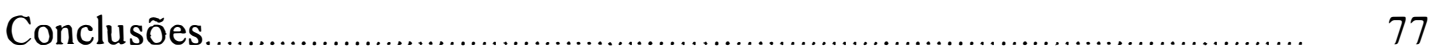

Referências Bibliográficas.................................................................... 77

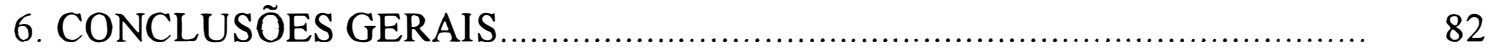

REFERÊNCIAS BIBLIOGRÁFICAS ........................................................ 84 
Ao meu pai Arlindo (in memorian)

e à minha mãe Angela,

que com simplicidade e sabedoria en sinaram-me

as lições do trabalho e da honestidade.

À minha esposa Sandra Mara,

que partilha comigo desta vitória.

Aos meus filhos Rafael e Natália,

que são a alegria da minha vida. 


\section{AGRADECIMENTOS}

A Deus, por ter guiado meus passos e permitido-me atingir mais este objetivo.

À Escola Superior de Agricultura "Luiz de Queiroz", Universidade de São Paulo, pela possibilidade de realização deste curso.

À Fundação de Amparo à Pesquisa do Estado de São Paulo, pelo financiamento da pesquisa.

Ao Prof. Dr. Keigo Minami, pela orientação, amizade e principalmente pela confiança em mim depositada, fundamental para o bom desenvolvimento desta tese.

Ao Engo ${ }^{\circ}$ Agro ${ }^{\circ}$ Dr. José Maria M. Sigrist e Eng ${ }^{\mathrm{a}}$. de Alimentos Dra. Claire I. G. L. Sarantópoulos, pelo apoio, co-orientação e envolvimento efetivo em todas as etapas do planejamento e desenvolvimento das pesquisas que originaram esta tese.

Ao colega e amigo, Eng ${ }^{\circ}$. Agr $^{\circ}$ Dr. Ricardo A. Kluge, pelas frequentes e acertadas sugestões, durante a redação deste trabalho.

Ao Prof. Dr. José Fernando Durigan, que desde o início incentivou-me a trabalhar com pós-colheita de frutas e hortaliças.

À Eng ${ }^{\mathbf{a}}$ Agr $^{\mathbf{a}}$ Dra. Eliane A. B. Rodrigues da Silva, pelo auxilio nas avaliações fitopatológicas.

À Dra. Marta H. F. Spoto e à Eng ${ }^{\mathbf{a}}$ Agr $^{\mathbf{a}}$ MSc. Lucimara Blumer, pelo auxílio na metodologia do artigo referente à análise sensorial.

À Prof ${ }^{\text {. }}$. Dr ${ }^{\mathrm{a}}$ Sônia Maria D. S. Piedade, pelo auxílio na interpretação dos resultados das análises estatísticas.

À bibliotecária Eliana M. G. Sabino, pela revisão das referências bibliográficas.

À Prof ${ }^{\circledR}$ Dra. Fernanda Bacellar, pela revisão dos Summaries.

Aos funcionários do Departamento de Produção Vegetal, especialmente Aparecido, Bete, Célia, Silvia, Ivete e Dona Helena e aos funcionários do ITAL, especialmente Giovana, Carlinhos, Quitéria, Christiane e Adriano, que das mais diversas maneiras colaboraram para a realização desta tese.

Aos colegas professores do Departamento de Produção Vegetal, pelo apoio nesta fase em que desempenhei dupla missão no Departamento.

Aos colegas do curso de Pós-Graduação, pelo convívio e amizade. 


\section{LISTA DE FIGURAS}

Página

\section{Materiais de embalagem para conservação refrigerada de goiaba 'Kumagai'}

1. Evolução da composição gasosa no espaço livre de embalagens contendo goiabas 'Kumagai', durante armazenamento a $10^{\circ} \mathrm{C}$ e $85-90 \%$ UR.

2. Influência de embalagens e períodos de armazenamento na coloração externa de goiabas 'Kumagai' armazenadas a $10^{\circ} \mathrm{C}$ e $85-90 \%$ UR, sendo (A) frutos avaliados imediatamente após retirados da câmara e (B) frutos avaliados após comercialização simulada.

3. Influência de embalagens e períodos de armazenamento no teor de sólidos solúveis totais de goiabas 'Kumagai' armazenadas a $10^{\circ} \mathrm{C}$ e $85-90 \%$ UR, mais 3 dias a $25^{\circ} \mathrm{C}$ e $70-80 \%$ UR.

4. Influência de embalagens e períodos de armazenamento na acidez total titulável de goiabas 'Kumagai' armazenadas a $10^{\circ} \mathrm{C}$ e $85-90 \%$ UR, mais 3 dias a $25^{\circ} \mathrm{C}$ e $70-80 \%$ UR.

5. Influência de embalagens e períodos de armazenamento na firmeza da polpa de goiabas 'Kumagai' armazenadas a $10^{\circ} \mathrm{C}$ e $85-90 \%$ UR, mais 3 dias a $25^{\circ} \mathrm{C}$ e $70-80 \%$ UR

6. Influência de embalagens e períodos de armazenamento no teor de ácido ascórbico de goiabas 'Kumagai' armazenadas a $10^{\circ} \mathrm{C}$ e $85-90 \%$ UR, mais 3 dias a $25^{\circ} \mathrm{C}$ e $70-80 \%$ UR

7. Influência de embalagens e períodos de armazenamento na perda de peso de goiabas 'Kumagai' armazenadas a $10^{\circ} \mathrm{C}$ e $85-90 \%$ UR

Características sensoriais de goiabas 'Kumagai' submetidas a diferentes materiais de embalagem e armazenamento refrigerado

1. Ficha de avaliação e escalas de notas utilizadas para análise sensorial de goiabas.

2. Atmosfera de equilíbrio no interior de embalagens contendo 6 goiabas 'Kumagai', sem evacuação de ar, armazenadas a $10^{\circ} \mathrm{C}$. 
3. Coloração externa de goiabas 'Kumagai', submetidas a diferentes embalagens e períodos de armazenamento a $10^{\circ} \mathrm{C}$ e $85-90 \%$ UR (A), mais 3 dias a $25^{\circ} \mathrm{C}$ e $70-80 \%$ UR (B)

4. Textura da polpa de goiabas 'Kumagai', submetidas a diferentes embalagens e períodos de armazenamento a $10^{\circ} \mathrm{C}$ e $85-90 \% \mathrm{UR}$ (A), mais 3 dias a $25^{\circ} \mathrm{C}$ e $70-80 \%$ UR (B)

5. Qualidade global de goiabas 'Kumagai', submetidas a diferentes embalagens e períodos de armazenamento a $10^{\circ} \mathrm{C}$ e $85-90 \%$ UR (A), mais 3 dias a $25^{\circ} \mathrm{C}$ e $70-80 \%$ UR (B) 


\section{LISTA DE TABELAS}

Página

\section{Comportamento de goiabas 'Kumagai' submetidas a diferentes temperaturas de armazenamento}

1. Perda de matéria fresca de goiabas 'Kumagai' submetidas a diferentes temperaturas de armazenamento......

2. Coloração da casca de goiabas 'Kumagai' submetidas a diferentes temperaturas de armazenamento

3. Dano causado pelo chilling em goiabas 'Kumagai' submetidas a diferentes temperaturas de armazenamento

4. Firmeza de polpa em goiabas 'Kumagai' submetidas a diferentes temperaturas de armazenamento.

5. Teor de sólidos solúveis totais (SST) em goiabas 'Kumagai' submetidas a diferentes temperaturas de armazenamento

6. Acidez total titulável (ATT) em goiabas 'Kumagai' submetidas a diferentes temperaturas de armazenamento

7. Teor de vitamina C em goiabas 'Kumagai' submetidas a diferentes temperaturas de armazenamento.

Materiais de embalagem para conservação refrigerada de goiabas 'Kumagai'

1. Características dos filmes utilizados para o acondicionamento das goiabas e área de permeação das embalagens.

2. Significância do teste $\mathrm{F}$ da análise de variância para os efeitos dos tratamentos, sobre as variáveis analisadas em goiabas 'Kumagai'.....

3. Influência de embalagens e períodos de armazenamento na coloração externa de goiabas 'Kumagai' armazenadas a $10^{\circ} \mathrm{C}$ e 85 $90 \%$ UR

4. Influência de embalagens e períodos de armazenamento no teor de sólidos solúveis totais (SST) de goiabas 'Kumagai' armazenadas a $10^{\circ} \mathrm{C}$ e $85-90 \%$ UR. 
5. Influência de embalagens e períodos de armazenamento na acidez total titulável (ATT) de goiabas 'Kumagai' armazenadas a $10^{\circ} \mathrm{C} \mathrm{e}$ 85-90\% UR.

6. Influência de embalagens e períodos de armazenamento na firmeza da polpa de goiabas 'Kumagai' armazenadas a $10^{\circ} \mathrm{C}$ e $85-90 \%$ UR.

7. Influência de embalagens e períodos de armazenamento no teor de ácido ascórbico de goiabas 'Kumagai' armazenadas a $10^{\circ} \mathrm{C}$ e 85 $90 \%$ UR

8. Influência de embalagens e períodos de armazenamento no índice de doença (ID) em goiabas 'Kumagai' armazenadas a $10^{\circ} \mathrm{C}$ e $85-90 \%$ UR

Características sensoriais de goiabas 'Kumagai' submetidas a diferentes materiais de embalagem e armazenamento refrigerado

1. Características dos materiais de embalagem utilizados para 0 acondicionamento das goiabas e área de permeação das embalagens.

2. Significância do teste $\mathbf{F}$ da análise de variância para os efeitos dos tratamentos sobre as variáveis coloração externa, textura da polpa e qualidade global, analisadas em goiabas 'Kumagai'

3. Influência de embalagens e períodos de armazenamento na coloração externa de goiabas 'Kumagai' armazenadas a $10^{\circ} \mathrm{C}$ e 85 90\% UR

4. Influência de embalagens e períodos de armazenamento na textura da polpa de goiabas 'Kumagai' armazenadas a $10^{\circ} \mathrm{C}$ e $85-90 \%$ UR...

5. Odor estranho em goiabas 'Kumagai' acondicionadas em PPS, PEBD e PBM e armazenadas a $10^{\circ} \mathrm{C}$ e $85-90 \%$ UR

6. Sabor estranho em goiabas 'Kumagai', acondicionadas em polietileno de baixa densidade (PEBD) e armazenadas a $10^{\circ} \mathrm{C}$ e 85 $90 \%$ UR

7. Influência de embalagens e períodos de armazenamento na qualidade global de goiabas 'Kumagai' armazenadas a $10^{\circ} \mathrm{C}$ e 85 $90 \%$ UR 


\title{
CONSERVAÇÃO DE GOIABAS 'KUMAGAI' EM DIFERENTES \\ TEMPERATURAS E MATERIAIS DE EMBALAGEM
}

\author{
Autor: ANGELO PEDRO JACOMINO \\ Orientador: Prof. KEIGO MINAMI
}

\section{RESUMO}

O presente trabalho teve como objetivos verificar os efeitos de diferentes temperaturas de armazenamento e materiais de embalagem na conservação de goiabas 'Kumagai', caracterizar os materiais de embalagem utilizados e avaliar a composição gasosa no interior das embalagens. No primeiro experimento as goiabas foram submetidas a quatro temperaturas de armazenamento $\left(2,8,10\right.$ e $\left.12^{\circ} \mathrm{C}\right)$ e $85-90 \%$ UR por períodos de 7, 14 e 21 dias ( +3 dias de comercialização simulada a $25^{\circ} \mathrm{C}$ e $70-80 \%$ UR). No segundo experimento as goiabas foram acondicionadas em diversos materiais de embalagem e armazenadas a $10^{\circ} \mathrm{C}$ e $85-90 \%$ de UR, durante $7,14,21$ e 28 dias $(+3$ dias de comercialização simulada). Os materiais de embalagem utilizados foram: filme poliolefínico com permeabilidade seletiva (PPS), filme de polietileno de baixa densidade (PEBD), filme de PEBD com incorporação de mineral (PBM) e filme poliolefinico termo-encolhível (ENC). Goiabas sem embalagem foram utilizadas como Controle. No primeiro experimento foram determinadas as características físico-químicas das goiabas ao final de cada período de armazenamento. No segundo determininou-se também as características sensoriais das frutas, as taxas de permeabilidade ao $\mathrm{O}_{2}$ e ao $\mathrm{CO}_{2}$ em cada um dos filmes e as composições gasosas no interior das embalagens. As frutas armazenadas a $2^{\circ} \mathrm{C}$ apresentaram danos severos ocasionados pelo frio a partir dos 14 dias de estocagem. Aquelas armazenadas a $10 \mathrm{ou} 12^{\circ} \mathrm{C}$, embora não tenham apresentado danos pelo chilling, não apresentaram condições de comercialização após 21 dias de estocagem, devido à alta incidência de podridões. $\mathrm{O}$ armazenamento refrigerado a $8^{\circ} \mathrm{C}$ apresentou os melhores resultados para esta variedade, ao final de 21 dias de conservação. O filme PEBD com $69 \mu \mathrm{m}$ de espessura apresentou baixa taxa de 
permeabilidade aos gases $\left(\mathrm{TPO}_{2}=2.115\right.$ e $\left.\mathrm{TPCO}_{2}=4.434 \mathrm{~cm}^{3} \cdot \mathrm{m}^{-2} \cdot \mathrm{dia}^{-1}\right)$, promoveu anaerobiose e elevada concentração de $\mathrm{CO}_{2}$ no interior das embalagens, além de alterações no odor e no sabor dos frutos. O filme ENC mostrou-se muito permeável aos gases $\left(\mathrm{TPO}_{2}=6.366\right.$ e $\left.\mathrm{TPCO}_{2}=34.864 \mathrm{~cm}^{3} \cdot \mathrm{m}^{-2} \cdot \mathrm{dia}^{-1}\right)$, promoveu pouca modificação da atmosfera no interior das embalagens e antecipou a senescência dos frutos em relação ao Controle. $\mathrm{O}$ filme PBM apresentou taxas de permeabilidade ao $\mathrm{O}_{2}$ e ao $\mathrm{CO}_{2}$ iguais a 6.366 e $34.864 \mathrm{~cm}^{3} \cdot \mathrm{m}^{-2} \cdot \mathrm{dia}^{-1}$, respectivamente. Proporcionou atmosfera no interior das embalagens com $3 \%$ de $\mathrm{O}_{2}$ e $4,5 \%$ de $\mathrm{CO}_{2}$ e possibilitou a conservação das goiabas por 14 dias. O filme PPS apresentou taxas de permeabilidade ao $\mathrm{O} 2$ e ao $\mathrm{CO} 2$ iguais a 6.827 $21.969 \mathrm{~cm}^{3} \cdot \mathrm{m}^{-2} \cdot \mathrm{dia}^{-1}$, respectivamente. Proporcionou atmosfera no interior das embalagens com $0,5 \%$ de $\mathrm{O}_{2}$ e $4,5 \%$ de $\mathrm{CO}_{2}$ e possibilitou a conservação das goiabas por 28 dias. 


\title{
DIFFERENT TEMPERATURES AND PACKAGING MATERIALS FOR CONSERVATION OF 'KUMAGAI' GUAVAS
}

\author{
Author: ANGELO PEDRO JACOMINO \\ Adviser: Prof. KEIGO MINAMI
}

\section{SUMMARY}

The objective of this work was to verify the effects of different storage temperatures and packaging materials on the shelf life of 'Kumagai' guavas. In the first experiment the guavas were submitted to four storage temperatures $\left(2,8,10\right.$ and $\left.12^{\circ} \mathrm{C}\right)$ and $85-90 \% \mathrm{RH}$, during 7, 14 and 21 days, plus 3 days at $25^{\circ} \mathrm{C}$ and $70-80 \% \mathrm{RH}$ to simulate commercial handling conditions. In the second experiment the guavas were wrapped in several packaging materials and stored at $10^{\circ} \mathrm{C}$ and $85-90 \% \mathrm{RH}$, during 7 , 14,21 and 28 days, plus 3 days at $25^{\circ} \mathrm{C}$ and $70-80 \% \mathrm{RH}$. The packaging materials used were: polyolephinic film with selective permeability (PSP), low density polyethylene film (LDP), LDP film with mineral incorporation (LDPM) and shrink polyolephinic film (SHR). Guavas without packaging were used as Control. The gas permeability of each film, the concentrations of $\mathrm{O}_{2}$ and $\mathrm{CO}_{2}$ inside the packaging and the physical-chemical characteristics of the guavas (skin color, firmness, total soluble solids, total titatrable acidity, ascorbic acid, chilling injury, decay and weight loss) were evaluated. The fruits stored at $2^{\circ} \mathrm{C}$ presented severe chilling injury after 14 days. Those stored at 10 or $12^{\circ} \mathrm{C}$ did not show chilling injury until 21 days, but presented unmarketable because showed high incidence of decay. The cold storage at $8^{\circ} \mathrm{C}$ presented the best conservation for this variety until 21 days. The LDP film with $69 \mu \mathrm{m}$ of thickness presented low permeability for the gases $\left(\mathrm{TPO}_{2}=2.115\right.$ and $\left.\mathrm{TPCO}_{2}=4.434 \mathrm{~cm}^{3} \cdot \mathrm{m}^{-2} \cdot \mathrm{dia}^{-1}\right)$. It promoted anaerobic atmosphere and high $\mathrm{CO}_{2}$ concentration. Furthermore, it induced both off-flavor and physiological disorders in the fruits which caused abnormal ripening. The SHR film with $15 \mu \mathrm{m}$ of thickness presented high permeability for the gases $\left(\mathrm{TPO}_{2}=6.366\right.$ and 
$\left.\mathrm{TPCO}_{2}=34.864 \mathrm{~cm}^{3} \cdot \mathrm{m}^{-2} \cdot \mathrm{dia}^{-1}\right)$ and promoted little modification of the atmosphere inside the packaging. The fruits wrapped in this film presented fast senescence and smaller conservation than fruits controls. The LDPM film with $24 \mu \mathrm{m}$ of thickness presented $\mathrm{TPO}_{2}$ of $4,918 \mathrm{~cm}^{3} \cdot \mathrm{m}^{-2} \cdot \mathrm{dia}^{-1}$ and $\mathrm{TPCO}_{2}$ of $32,937 \mathrm{~cm}^{3} \cdot \mathrm{m}^{-2} \cdot \mathrm{dia}^{-1}$. This film provided atmosphere composition of $3 \%$ of $\mathrm{O}_{2}$ and $4.5 \%$ of $\mathrm{CO}_{2}$ and the fruits could be conserved until 14 days. The film PSP with $35 \mu \mathrm{m}$ of thickness presented $\mathrm{TPO}_{2}$ of $6,827 \mathrm{~cm}^{3} \cdot \mathrm{m}^{-}$ ${ }^{2} \cdot \mathrm{dia}^{-1}$ and $\mathrm{TPCO}_{2}$ of $21,969 \mathrm{~cm}^{3} \cdot \mathrm{m}^{-2} \cdot \mathrm{dia}^{-1}$. This film provided atmosphere composition of $0.5 \%$ of $\mathrm{O}_{2}$ and $4.5 \%$ of $\mathrm{CO}_{2}$ and conservation of the guavas for 28 days. 


\section{INTRODUÇÃO}

A goiabeira (Psidium guajava L.) é originária da América do Sul e encontra-se atualmente muito difundida por todas as regiões tropicais e subtropicais do mundo. Entre as frutas tropicais, a goiaba se destaca por apresentar elevado valor nutritivo, pois é ótima fonte de vitamina $\mathrm{C}$. Além disso, possui excelentes características organolépticas e alto rendimento em polpa, tornando-a muito adequada tanto para o consumo in natura como para a industrialização (Carvalho, 1994).

Atualmente, esta cultura é bastante importante no contexto da fruticultura brasileira e encontra-se em crescente expansão. A maior parcela dos frutos produzidos ainda é destinada à industrialização, entretanto, o mais significativo crescimento tem sido observado no mercado de frutas in natura (Durigan, 1997). A produção brasileira é de aproximadamente 250 mil toneladas, sendo os Estados de São Paulo e Pernambuco os principais produtores. A comercialização da fruta para mesa ocorre o ano todo, havendo maior oferta nos meses de fevereiro e março. São comercializados anualmente na CEAGESP, cerca de 14 mil toneladas, sendo a maior parte de frutas de polpa branca (FNP, 1999). As exportações brasileiras desta fruta foram de 123 mil toneladas, em 1995, sendo alguns países da Europa os principais compradores (FNP, 1997). Segundo Proctor (1990), a goiaba situa-se no grupo das frutas tropicais que ainda apresenta pequeno volume de exportação, mas têm despertado grande interesse e curiosidade nos consumidores, sendo esperada a ampliação de muitos mercados.

Apesar da grande importância que a goiaba vem ganhando no mercado in natura, constitui-se numa fruta altamente perecível que entra em senescência 1 a 2 dias após o amadurecimento. Por este fato, a goiaba precisa ser comercializada rapidamente após a colheita, sob pena de grande perda na qualidade final do produto ofertado ao consumidor. 
Em nível de exportação, o transporte tem sido exclusivamente por via aérea, onerando substancialmente o custo final.

A globalização da economia, a maior oferta de produtos e a maior exigência dos consumidores em termos de qualidade dos produtos fazem necessário não só o emprego de tecnologias eficientes de produção, como também de conservação da qualidade na fase de pós-colheita.

O armazenamento e comercialização de produtos vegetais sob refrigeração é uma das possibilidades. O abaixamento da temperatura resulta em redução da atividade respiratória de frutos e, consequentemente, aumento no período de conservação. Em frutos climatéricos, como a goiaba, o abaixamento da temperatura retarda o pico climatérico e por consequência o amadurecimento (Hardenburg et al.,1986; Kader, 1992a). Os efeitos benéficos da refrigeração podem ser ampliados se esta for associada ao emprego de atmosfera modificada (Gorris \& Peppelenbos, 1992; Kader, 1992b).

A atmosfera modificada compreende o armazenamento de produtos sob concentração gasosa diferente da atmosfera ambiente, que pode ser obtida pelos mais diversos tipos de embalagens ou ceras, aplicadas à superficie dos frutos (Kader, 1986). Trata-se de uma técnica eficiente e muito útil, por não se restringir às câmaras de armazenamento. Existe atualmente grande quantidade de materiais de embalagem (filmes plásticos), desenvolvidos especialmente para proporcionar a atmosfera adequada no interior de embalagens com produtos vegetais. Produtos acondicionados em atmosfera modificada podem ser conservados em câmaras de refrigeração, para posterior comercialização a granel ou comercialização nas próprias embalagens, se estas forem concebidas como embalagens de varejo. Esta tem sido uma estratégia empregada na comercialização de muitos produtos vegetais, que além de conservar, possibilita agregar valor ao produto.

Em face das potencialidades do emprego de refrigeração e atmosfera modificada na conservação de goiabas, o presente trabalho teve por objetivos: a) avaliar os efeitos de diversas temperaturas de refrigeração, na conservação de goiabas 'Kumagai', b) caracterizar diversos materiais de embalagem, c) monitorar a composição gasosa no interior das embalagens com goiabas 'Kumagai', armazenadas a $10^{\circ} \mathrm{C}$ e $85-90 \%$ UR e, d) verificar os efeitos destes materiais de embalagem e períodos de armazenamento sob refrigeração, na conservação das goiabas. 


\section{REVISÃO DE LITERATURA}

\subsection{Importância econômica}

A goiabeira é cultivada no Brasil desde o Rio Grande do Sul até o Maranhão (Pereira, 1995). Estima-se que o país possua aproximadamente 8.800 ha cultivados com esta fruteira, destacando-se os Estados de São Paulo com 4.100 ha e Pernambuco com 1.900 ha (FNP, 1999).

No Estado de São Paulo, a produção destina-se tanto para consumo in natura, quanto para industrialização. A produção de goiabas para consumo in natura é concentrada nas regiões próximas à capital (Valinhos, Vinhedo, Campinas, Atibaia e Mogi das Cruzes), onde são cultivadas principalmente variedades de polpa branca, e nas regiões de Mirandópolis, Pacaembú e Monte Alto, onde são cultivadas variedades de polpa vermelha. Goiabas para industrialização ou com dupla finalidade são cultivadas principalmente nos municípios de Taquaritinga, Monte Alto, Itápolis, Urupês, Vista Alegre do Alto e São Carlos, e são de polpa vermelha (Pereira, 1995).

Foram comercializadas no CEAGESP entre 1995 e 1997, cerca de 9 mil toneladas de goiaba branca e 4 mil toneladas de goiaba vermelha, por ano (FNP, 1999). Em 1995, as exportações brasileiras desta fruta foram de 123 mil toneladas, sendo a França o principal país importador (FNP, 1997).

\subsection{Aspectos gerais sobre a cultura da goiabeira}

As goiabas de polpa branca têm sido preferidas no mercado de fruta in natura, por apresentarem melhor conservação em pós-colheita e por exalarem um perfume discreto, que as torna finas e delicadas. Em São Paulo, a variedade de polpa branca mais 
cultivada é a Kumagai, cujos frutos são grandes, arredondados a oblongos, firmes, com casca lisa e resistente, e de coloração verde-amarelada quando maduros (Piza Jr. \& Kavati, 1994). Essa é também a principal variedade exportada pelo Brasil.

Pomares conduzidos visando produção de fruta para mercado in natura requerem um série de cuidados especiais, tais como: poda, irrigação e raleio e ensacamento dos frutos. A época normal de produção de goiabas em São Paulo vai de janeiro a março. Entretanto, utilizando-se de sistemas de poda e irrigação, tem-se produção o ano todo. A goiabeira floresce após, aproximadamente, 3 meses da realização da poda e os frutos estão aptos a serem colhidos após mais um período de 3 a 6 meses, dependendo da época do ano. O ponto de colheita é reconhecido, na prática, pelo tamanho, consistência e coloração externa da fruta que, para um mesmo local, varia com a variedade e com a época do ano (Piza Jr. \& Kavati, 1994). As frutas para mercado externo são colhidas quando a coloração da casca começa mudar de verde-escuro para verde-claro e a polpa ainda está firme.

\subsection{Fisiologia de pós-colheita da goiaba}

\subsubsection{Respiração e evolução de etileno}

A respiração é um dos principais fatores determinantes do potencial de longevidade das frutas na fase de pós-colheita e está intimamente ligada à temperatura e à concentração gasosa ao redor das mesmas (Kader, 1986; Chitarra \& Chitarra, 1990)

Os dados sobre a fisiologia de pós-colheita de goiabas são bastante limitados, entretanto, permitem-nos concluir que trata-se de uma fruta com padrão de respiração do tipo climatérico, embora algumas cultivares não o sejam.

Akamine \& Goo (1979) analisaram a respiração de duas cultivares de $P$. guajava e duas de $P$. cattleianum, no estádio de plena maturação e verificaram que todas apresentaram respiração climatérica e pico de produção de etileno bem definidos. Brown \& Wills (1983) estudaram o comportamento de 6 cultivares de P. guajava colhidas em quatro diferentes estádios de maturação, desde frutos imaturos a totalmente desenvolvidos. Todas as cultivares examinadas tiveram comportamento respiratório e de produção de etileno do tipo climatérico. Os frutos mais maduros alcançaram o pico 
climatérico 4-6 dias após a colheita, enquanto os frutos menos maduros apresentaram menor produção de etileno e de $\mathrm{CO}_{2}$ e não completaram seu desenvolvimento. Goiabas indianas 'Sardar', colhidas no início da mudança da coloração da casca e armazenadas a $24^{\circ} \mathrm{C}$ e $85 \%$ de umidade relativa, apresentaram elevação da taxa respiratória de $53 \mathrm{mg}$ $\mathrm{CO}_{2} \cdot \mathrm{kg}^{-1} \cdot \mathrm{h}^{-1}$, na colheita, para $82 \mathrm{mg} \mathrm{CO}_{2} \cdot \mathrm{kg}^{-1} \cdot \mathrm{h}^{-1}$, depois de 6 dias (Singh et al., 1981). Castro \& Sigrist (1988) determinaram o comportamento respiratório de goiaba híbrida (branca) e observaram que esta exibiu rápido aumento na taxa de produção de $\mathrm{CO}_{2}$ após a colheita, comportamento característico de fruto climatérico. Oliveira \& Cereda (1996) determinaram a curva de respiração em goiabas dessa mesma variedade e observaram que as mesmas se comportaram como frutos climatéricos, com pico respiratório de $44,98 \mathrm{mg} \mathrm{CO}_{2} \cdot \mathrm{kg}^{-1} \cdot \mathrm{h}^{-1}$ no $9^{\mathrm{o}}$ dia após a colheita, em temperatura ambiente. Lima et al. (1998) observaram pico respiratório em goiabas 'Pedro Sato', entre o $4^{\circ}$ e o 6ํํㅁ dia após a colheita.

\subsubsection{Influência da temperatura}

O abaixamento da temperatura resulta em redução da atividade respiratória de frutos e, consequentemente, aumento no período de conservação. Em frutos climatéricos, o abaixamento da temperatura retarda o pico climatérico e, por consequência, o amadurecimento (Hardenburg et al., 1986; Kader, 1992a).

Pantástico (1975) relata que as frutas tropicais são muito sensíveis ao frio e podem apresentar uma série de características indesejáveis, como alterações na taxa de respiração e de produção de etileno, escurecimento da casca e/ou da polpa, incapacidade para o amadurecimento normal, menor resistência ao ataque de microorganismos e perda do aroma e do sabor.

Segundo Wills et al. (1983), goiabas para industrialização ou para consumo in natura podem ser conservadas por duas a três semanas sob temperatura de $5^{\circ} \mathrm{C}$ a $10^{\circ} \mathrm{C}$ e $90 \%$ de umidade relativa. De acordo com os autores, temperaturas abaixo de $5^{\circ} \mathrm{C}$ causam danos na polpa. Vasquez-Ochoa \& Colinas-Leon (1990) obtiveram os melhores resultados de conservação de goiabas quando estas foram armazenadas a $7^{\circ} \mathrm{C}$. Frutas armazenadas a $3,5^{\circ} \mathrm{C}$ apresentaram danos pelo frio (chilling), enquanto aquelas 
armazenadas a $11^{\circ} \mathrm{C}$ tiveram menor período de conservação. Por outro lado, Gaspar et al. (1997) observaram danos por chilling em goiabas armazenadas a $7^{\circ} \mathrm{C}$, durante 3 semanas.

Durigan (1997) recomenda o uso de temperatura entre 8 e $10^{\circ} \mathrm{C}$, para que haja maior segurança em evitar danos por chilling. Segundo Carraro \& Cunha (1994), a temperatura para transporte dessa fruta, no caso de exportação por via marítima, deve situar-se entre 9 e $10^{\circ} \mathrm{C}$.

Os sintomas de dano fisiológico pelo frio em goiaba branca são inicialmente, caracterizados pela opacidade da coloração verde intensa da casca, seguida por áreas irregulares verde-pardas; enquanto a polpa adquire coloração irregular com manchas escurecidas. Em estágio mais avançado toda a polpa pode tornar-se de coloração parda a escurecida (Castro \& Sigrist, 1988). Segundo estes autores, o armazenamento a $5^{\circ} \mathrm{C}$ por um período de 15 dias é suficiente para causar dano fisiológico.

\subsubsection{Influência das concentrações de $\mathrm{O}_{2}$ e $\mathrm{CO}_{2}$}

A diminuição do nível de $\mathrm{O}_{2}$ ao redor de frutos e hortaliças reduz sua taxa respiratória na proporção da diminuição da concentração de $\mathrm{O}_{2}$, até níveis ao redor de 1$3 \% \mathrm{O}_{2}$, dependendo do produto (Kader, 1986; Wills et al., 1989). Níveis reduzidos de $\mathrm{O}_{2}$ diminuem também a produção de etileno e reduzem a sensibilidade do produto à ação do mesmo. Isto ocorre porque o $\mathrm{O}_{2}$ é requerido tanto para a síntese do etileno quanto para sua ação (Burg \& Burg, 1967). Sob condição de anaerobiose, a conversão do ácido 1 aminociclopropano-1-carboxílico (ACC) em etileno é inibida (Yang, 1985).

Elevadas concentrações de $\mathrm{CO}_{2}$ também reduzem a taxa respiratória de frutos e hortaliças recém colhidos. $\mathrm{O}$ nível crítico de $\mathrm{CO}_{2}$ tolerado pelos produtos é variável. Todavia, concentrações de $\mathrm{CO}_{2}$ ao redor de $20 \%$ ou acima, costumam ser prejudiciais, dependendo do produto e da concentração de $\mathrm{O}_{2}$ (Kader, 1986; Wills et al., 1989). Concentrações elevadas de $\mathrm{CO}_{2}$ podem reduzir, promover ou não ter efeito na produção de etileno, dependendo do produto e da concentração (Kader, 1986). 
Poucos são os trabalhos que fazem referência à atmosfera ideal para conservação de goiabas, entretanto, as concentrações de 7,5-8\% de $\mathrm{CO}_{2}$ e $3 \%$ de $\mathrm{O}_{2}$ têm sido citadas como sendo adequadas (Monzini \& Gorini, 1973; Castro \& Sigrist, 1988).

$\mathrm{O}$ armazenamento de frutos sob concentração de gases diferente da atmosfera ambiente pode ser obtido basicamente de duas formas: atmosfera controlada e atmosfera modificada.

A atmosfera controlada é caracterizada pelo controle preciso da composição da atmosfera durante o armazenamento, além da temperatura e umidade relativa. Envolve o uso de câmaras herméticas a gases e implica na adição ou remoção de gases, principalmente $\mathrm{CO}_{2}, \mathrm{O}_{2}$, etileno e nitrogênio (Chitarra \& Chitarra, 1990). Trata-se de um método bastante eficiente, porém requer altos investimentos de capital. No Brasil, seu uso se restringe à conservação de maçãs nos Estados da Região Sul.

A atmosfera modificada compreende o armazenamento sob concentração gasosa diferente da atmosfera ambiente, porém sem controle preciso das concentrações dos gases. A atmosfera ambiental é alterada, permitindo que a concentração de $\mathrm{O}_{2}$ diminua, à medida que o mesmo é utilizado pelo vegetal no processo de respiração, enquanto os níveis de $\mathrm{CO}_{2}$ elevam-se. É frequentemente obtida pelos mais diversos tipos de embalagens ou ceras, aplicadas à superficie dos frutos. Trata-se de uma técnica aparentemente simples, porém eficiente e muito útil, por não se restringir às câmaras de armazenamento (Kader, 1986; Gorris \& Peppelenbos, 1992).

\subsection{Uso de atmosfera modificada na conservação de goiabas}

Muitos são os trabalhos que evidenciam a eficiência do uso de embalagens plásticas na conservação pós-colheita de goiabas, diminuindo a perda de matéria fresca e retardando o amadurecimento (Yagi, 1976; Khedkar et al. 1982; Adsule \& Tandon, 1983; Singh et al., 1984; Tandon et al., 1984; Augustin \& Azizah, 1988). Na maioria destes trabalhos os autores utilizaram filmes de polietileno e armazeram por períodos de 1 a 3 semanas.

Combrink et al. (1990) obtiveram benefícios significativos na estocagem de goiabas em embalagem de polietileno selada, durante 2 semanas, sendo que os melhores 
resultados foram obtidos em filmes impregnados com mineral absorvedor de umidade. Paro et al. (1996), associando o uso de cera, embalagem de polietileno e refrigeração $\left(9^{\circ} \mathrm{C}\right)$, conservaram goiabas da variedade Paluma por 29 dias. De maneira semelhante, Gaspar et al. (1997) conservaram goiabas da variedade Kumagai por 3 semanas em embalagem selada de polietileno, sob temperatura de $8^{\circ} \mathrm{C}$.

\subsubsection{Sistemas de acondicionamento}

Vários sistemas de acondicionamento em embalagens plásticas são propostos por Sarantópoulos et al. (1996) para preservação de frutas e hortaliças.

$\mathrm{O}$ acondicionamento a vácuo em filmes de alta permeabilidade a gases ou permeabilidade seletiva é uma alternativa. A evacuação leva à diminuição do volume de ar no espaço livre da embalagem, que passivamente é transformado em uma atmosfera modificada com teores de oxigênio e gás carbônico favoráveis à manutenção da qualidade da fruta ou da hortaliça. Essa modificação passiva da atmosfera é controlada pela taxa de respiração do produto e pela taxa de permeabilidade da embalagem, na temperatura de estocagem.

Outra possibilidade é a modificação ativa da atmosfera, pela injeção direta de uma mistura gasosa no interior da embalagem. Neste caso, os beneficios da atmosfera modificada são obtidos mais rapidamente. Este sistema é adequado, por exemplo, para minimizar o escurecimento enzimático em vegetais minimamente processados, que pode ocorrer antes que a atmosfera seja modificada passivamente.

A modificação da atmosfera, no interior da embalagem de frutas e hortaliças, pode ser feita mesmo sem a aplicação de vácuo ou injeção de gases. Isto tem sido obtido com filmes plásticos, cuja permeabilidade deve contrabalancear a respiração do produto, a fim de criar passivamente, dentro da embalagem, uma atmosfera de equilíbrio, apropriada em termos de oxigênio e gás carbônico.

\subsubsection{Materiais de Embalagem}

A grande maioria dos trabalhos encontrados na literatura, referentes ao uso de filmes plásticos na embalagem de goiabas, utilizam filmes de polietileno comuns. Há 
pouca informação do comportamento dessa fruta quando embalada em filmes especiais.

Considerando a variabilidade nos níveis de atividade respiratória, na tolerância às concentrações de $\mathrm{O}_{2}$ e $\mathrm{CO}_{2}$ e na sensibilidade às injúrias pelo frio, o material de embalagem deveria ser feito sob medida para cada fruta ou hortaliça. Alguns materiais realmente são produzidos de forma a atender as exigências de determinados produtos. Entretanto, seria impraticável produzir um filme específico para cada produto ou situação. Por outro lado, as opções de materiais de embalagem vêm crescendo significativamente, permitindo encontrar com maior facilidade filmes com características adequadas para cada necessidade (Gorris \& Peppelenbos, 1992). Alguns materiais de embalagem que podem ser utilizados no acondicionamento de vegetais são citados a seguir:

\section{a) Filmes de Polietileno}

O polietileno é o polímero mais utilizado na embalagem de alimentos em geral. Tem a mais simples composição química de todos os polímeros e geralmente o menor custo. Pode ser classificado como polietileno de baixa densidade quando esta propriedade varia na faixa de 0,915 a $0,939 \mathrm{~g} . \mathrm{cm}^{-3}$, e polietileno de alta densidade, quando esta é de $0,940 \mathrm{~g} . \mathrm{cm}^{-3}$ ou mais. O polietileno de baixa densidade é um material bastante flexível, resistente a impacto e pouco resistente ao calor. Possui alta permeabilidade ao $\mathrm{O}_{2}$ e $\mathrm{CO}_{2}$ e baixa permeabilidade ao vapor d'água, quando comparado aos demais tipos de plásticos. É muito utilizado na embalagem de alimentos, porém, geralmente constitui-se em barreira muito intensa ao $\mathrm{O}_{2}$ e $\mathrm{CO}_{2}$ na embalagem de frutas e hortaliças que possuem alta taxa respiratória (Yam et al., 1992).

\section{b) Filmes poliolefínicos com permeabilidade seletiva}

$\mathrm{Na}$ linha de filmes poliolefinicos co-extrusados, têm sido desenvolvidos alguns materiais de alta permeabilidade a gases, específicos para manter a correta atmosfera modificada ao redor de vegetais embalados, mantidos sob refrigeração. As taxas de permeabilidade ao oxigênio destes filmes variam de 3.500 a $16.500 \mathrm{~cm}^{3} \cdot \mathrm{m}^{-2} \cdot \mathrm{dia}^{-1}$ (Cryovac Division, 1994). 
Outros desenvolvimentos em filmes poliolefinicos são as novas gerações de resinas de polietileno linear obtidas com catalisadores do tipo metaloceno, que apresentam maior taxa de permeabilidade aos gases, melhores propriedades ópticas e melhores características de termossoldagem (Brant et al., 1995).

Contudo, a taxa de respiração de muitas frutas e hortaliças é alta, e estes filmes não permitem a troca gasosa necessária, em espessuras comerciais. Uma forma encontrada de aumentar a taxa de permeabilidade a gases em filmes é a incorporação de cargas inertes, como os materiais que absorvem etileno. Desta forma, ocorre aumento na permeabilidade aos gases, embora provoque perda de transparência do material (Lee et al., 1992; Frey, 1995).

\section{c) Filmes com absorvedores de etileno}

As embalagens ativas visam controlar o teor de etileno no espaço-livre para reduzir o metabolismo, aumentando a vida de prateleira de vegetais (Sarantópoulos, 1993; Passy \& Miltz, 1995).

Filmes poliméricos, em geral polietileno contendo dispersões de minerais, também são comercializados como absorvedores de etileno. Esses filmes contêm cerca de $5 \%$ do peso em minerais, uma mistura de $\mathrm{SiO}_{2}, \mathrm{Al}_{2} \mathrm{O}_{3}$ e outros em menor proporção. De acordo com Lee et al. (1992), provavelmente, o bom desempenho desses filmes, quando aplicados no acondicionamento de vegetais com alta taxa de respiração, deve-se não somente à capacidade de absorção de etileno, como também a outras características desejáveis em uma embalagem para vegetais frescos como: taxas de permeabilidade ao $\mathrm{O}_{2}$, ao $\mathrm{CO}_{2}$ e ao etileno superiores às dos filmes convencionais, além de maior relação entre a taxa de permeabilidade ao $\mathrm{CO}_{2}$ e a taxa de permeabilidade ao $\mathrm{O}_{2}$. 


\section{INTRODUÇÃO}

A goiabeira (Psidium guajava L.) é cultivada no Brasil desde o Rio Grande do Sul até o Maranhão (Pereira, 1995). Estima-se que o país possua aproximadamente 8.800 ha cultivados com esta fruteira, destacando-se os Estados de São Paulo com 4.100 ha e Pernambuco com 1.900 ha (FNP, 1999).

No Estado de São Paulo a produção destina-se tanto para consumo in natura quanto para industrialização. A variedade mais cultivada visando comercialização in natura é a Kumagai, cujos frutos são arredondados a oblongos, com polpa de cor branca e casca lisa, de coloração verde-amarelada quando maduros (Piza Jr. \& Kavati, 1994).

A goiaba é uma fruta altamente perecível, cuja vida útil após o amadurecimento é de 1 a 2 dias (Carvalho, 1994; Durigan, 1997). Desta forma, o emprego de métodos que possibilitem retardar o amadurecimento são benéficos para ampliar o período de comercialização.

O armazenamento em baixas temperaturas tem sido considerado como o método mais eficiente para manter as qualidades da maioria dos produtos hortifrutícolas, devido aos seus efeitos de redução nos processos de respiração, transpiração, produção de etileno, amadurecimento, senescência e desenvolvimento de podridões (Handenburg et al., 1986). Invariavelmente, o abaixamento da temperatura aumenta o período de conservação. Em frutos climatéricos, como a maioria das variedades de goiaba, a redução da temperatura retarda o pico climatérico e, por conseqüência, o seu amadurecimento (Kader, 1992a).

Da mesma maneira que o abaixamento da temperatura pode conservar as frutas, em algumas situações pode ser prejudicial, em função de danos fisiológicos que podem causar. Pantástico (1975) relata que as frutas tropicais são muito sensiveis aos danos pelo frio (chilling), podendo apresentar uma série de características indesejáveis, como alterações na taxa de respiração e de produção de etileno, escurecimento da casca e polpa, irregularidade no amadurecimento, menor resistência à podridões e perda do aroma e sabor. 
As condições ótimas para a conservação de goiabas ainda não estão bem definidas, sendo encontradas muitas contradições à respeito da temperatura ideal de refrigeração desta fruta. As informações existentes são escassas e a maioria referentes a pesquisas efetuadas em países cujas condições climáticas e variedades cultivadas são diferentes das brasileiras. Wills et al. (1983) relataram que goiabas para industrialização ou para consumo in natura podem ser conservadas por duas a três semanas sob temperatura de $5^{\circ} \mathrm{C}$ a $10^{\circ} \mathrm{C}$ e $90 \%$ de umidade relativa, e que temperaturas abaixo de $5^{\circ} \mathrm{C}$ causam danos na polpa. Vasquez-Ochoa \& Colinas-Leon (1990) obtiveram os melhores resultados de conservação de goiabas quando estas foram armazenadas a $7^{\circ} \mathrm{C}$. Frutas armazenadas a $3,5^{\circ} \mathrm{C}$ apresentaram danos pelo chilling, enquanto aquelas armazenadas a $11^{\circ} \mathrm{C}$ tiveram menor período de conservação. No Brasil, segundo Carraro \& Cunha (1994), a temperatura para conservação durante o transporte dessa fruta, no caso de exportação por via marítima, deve situar-se entre 9 e $10^{\circ} \mathrm{C}$. Durigan (1997) recomenda o uso de temperatura entre 8 e $10^{\circ} \mathrm{C}$, para que haja maior segurança em evitar danos pelo chilling.

Os sintomas de danos pelo chilling em goiaba branca são inicialmente caracterizados pela opacidade da coloração verde da casca, seguida pelo aparecimento de áreas irregulares verde-pardas. A polpa, quando afetada, adquire coloração irregular com manchas escurecidas. Em estágio mais avançado do dano, toda a polpa torna-se de coloração parda a escurecida (Castro \& Sigrist, 1988). Segundo estes autores, o armazenamento a $5^{\circ} \mathrm{C}$ por um período de 15 dias é suficiente para causar o dano físiológico.

O objetivo do presente experimento foi avaliar os efeitos de diversas temperaturas de refrigeração, na conservação de goiabas ‘Kumagai'.

\section{MATERIAL E MÉTODOS}

O experimento foi conduzido no Instituto de Tecnologia de Alimentos (ITAL), em Campinas (SP).

Goiabas da variedade 'Kumagai' foram colhidas num pomar comercial do município de Valinhos, SP, em janeiro de 1998. Após a colheita, os frutos foram 
selecionados e transportados ao ITAL. Utilizou-se um lote uniforme de frutos sem defeitos, em estádio de maturação caracterizado pela mudança da cor da casca de verde escuro para verde claro e peso médio de $160 \mathrm{~g}$. Os frutos foram acondicionados em caixas de papelão ondulado e armazenados a $2,8,10$ e $12^{\circ} \mathrm{C}$ e $85-90 \%$ de umidade relativa (UR), durante 7,14 e 21 dias.

O delineamento experimental foi inteiramente casualizado, com 4 tratamentos (2, 8,10 e $12^{\circ} \mathrm{C}$ ) e 10 repetições de um fruto. Os resultados foram submetidos à análise de variância e comparação de médias pelo teste de Tukey ao nível de $5 \%$ de probabilidade.

As variáveis analisadas foram: a) perda de matéria fresca: determinada pela diferença entre a massa inicial e massa final da amostra, expressa em porcentagem da massa inicial; b) coloração da casca: avaliada pelo método visual, por uma equipe de 4 a 6 avaliadores previamente treinados, de acordo com a seguinte escala de notas: $1=$ totalmente verde; 2 = mais verde do que amarelo; 3 = verde e amarelo em quantidades iguais; $4=$ mais amarelo do que verde; $5=$ totalmente amarelo; c) danos pelo chilling: avaliados pelo método visual de acordo com a seguinte escala de notas: $1=$ isento; $2=$ ligeiro; 3 = moderado; 4 = intenso e 5 = muito intenso; d) firmeza da polpa: avaliada com penetrômetro manual Effegi FT 327, com ponteira 5/16" e os valores expressos em $\mathrm{kg}$; e) teor de sólidos solúveis: determinado em refratômetro marca Schmidt-Haensch, modelo SR-400 e os resultados expressos em ${ }^{\circ} \mathrm{Brix}$; f) acidez total titulável: determinada por titulometria de acordo com metodologia descrita por Carvalho et al. (1990) e os resultados expressos em \% de ácido cítrico; g) teor de ácido ascórbico: determinado por titulometria, de acordo com metodologia de Carvalho et al. (1990), e os resultados expressos em mg de ácido ascórbico por $100 \mathrm{~g}$ de polpa; $\mathrm{h}$ ) incidência de podridões: avaliada pela contagem do número de frutos afetados, sendo os resultados expressos em porcentagem.

As análises foram realizadas imediatamente após a colheita, visando caracterizar do lote experimental e após cada período de armazenamento, seguido de comercialização simulada de 3 dias a $25^{\circ} \mathrm{C}$ e $70-80 \%$ UR. 


\section{RESULTADOS E DISCUSSÃO}

Perda de matéria fresca: de maneira geral, a perda de matéria fresca aumentou com o aumento do período de conservação e da temperatura de armazenamento (Tabela 1). Aos 14 e 21 dias de conservação, o armazenamento a 10 ou $12^{\circ} \mathrm{C}$ resultou em maior perda de peso se comparado com o armazenamento a 2 ou $8^{\circ} \mathrm{C}$. Isso é explicável pela maior transpiração que ocorre à medida que a temperatura aumenta, em resposta ao incremento no déficit de pressão de vapor entre os tecidos da fruta e o ambiente (Woods, 1990). Entre as temperaturas 2 e $8^{\circ} \mathrm{C}$ não houve diferenças significativas para a perda de peso, ao longo dos períodos de conservação.

Tabela 1. Perda de matéria fresca de goiabas 'Kumagai' submetidas a diferentes temperaturas de armazenamento. ${ }^{x}$

\begin{tabular}{cccc}
\hline \multirow{2}{*}{ Temperatura $\left({ }^{\circ} \mathbf{C}\right)$} & \multicolumn{3}{c}{ Períodos de armazenamento (dias) ${ }^{\mathrm{y}}$} \\
\cline { 2 - 4 } & 7 & 14 & 21 \\
\hline & $3,97 \mathrm{~b}$ & $6,03 \mathrm{~b}$ & $5,83 \mathrm{~b}$ \\
8 & $3,95 \mathrm{~b}$ & $6,11 \mathrm{~b}$ & $6,13 \mathrm{~b}$ \\
10 & $4,07 \mathrm{~b}$ & $7,88 \mathrm{a}$ & $8,13 \mathrm{a}$ \\
12 & $4,67 \mathrm{a}$ & $7,23 \mathrm{a}$ & $7,64 \mathrm{a}$ \\
\hline C.V. $(\%)$ & 2,58 & 7,12 & 3,42 \\
\hline
\end{tabular}

${ }^{x}$ Médias seguidas de mesma letra na coluna não diferem entre si pelo teste de Tukey ao nivel de $5 \%$ de probabilidade.

${ }^{y}$ após cada periodo de armazenamento, as frutas foram submetidas a 3 dias de comercialização simulada a $25^{\circ} \mathrm{C}$.

Coloração: houve desenvolvimento normal de coloração da casca das frutas até 14 dias de armazenamento para os tratamentos 8,10 e $12^{\circ} \mathrm{C}$ (Tabela 2). As frutas armazenadas a $2^{\circ} \mathrm{C}$ mantiveram a evolução normal da coloração da casca até 7 dias, enquanto que aos 14 e 21 dias a coloração da casca manteve-se verde, com manchas amarelas irregulares. A irregularidade no desenvolvimento da coloração da casca constitui um dos sintomas provocados pelo frio (Chitarra \& Chitarra, 1990; Awad, 
1993). As frutas armazenadas a $8^{\circ} \mathrm{C}$ mantiveram-se mais verdes que aquelas armazenadas a 10 ou $12^{\circ} \mathrm{C}$, no final de 21 dias de refrigeração.

Tabela 2. Coloração da casca de goiabas 'Kumagai' submetidas a diferentes temperaturas de armazenamento."

\begin{tabular}{|c|c|c|c|}
\hline \multirow{2}{*}{ Temperatura $\left({ }^{\circ} \mathrm{C}\right)$} & \multicolumn{3}{|c|}{ Períodos de armazenamento (dias) ${ }^{\mathrm{x}}$} \\
\hline & 7 & 14 & 21 \\
\hline & & & \\
\hline 2 & $3,87 \mathrm{a}$ & $3,02 \mathrm{a}$ & $2,35 c$ \\
\hline 8 & $3,70 \mathrm{a}$ & $3,98 \mathrm{a}$ & $3,43 b$ \\
\hline 10 & $3,75 a$ & $4,22 a$ & $4,28 \mathrm{a}$ \\
\hline 12 & $3,78 \mathrm{a}$ & $4,23 a$ & $4,80 \mathrm{a}$ \\
\hline C.V. $(\%)$ & 9,36 & 4,27 & 18,33 \\
\hline
\end{tabular}

${ }^{\text {w }}$ Médias seguidas de mesma letra na coluna não diferem entre si pelo teste de Tukey ao nível de $5 \%$ de probabilidade.

${ }^{x}$ após cada período de armazenamento, as frutas foram submetidas a 3 dias de comercialização simulada a $25^{\circ} \mathrm{C}$.

${ }^{y}$ Escala de notas: 1 = verde, 2 = mais verde que amarelo, 3 = verde e amarelo em quantidades iguais; $4=$ mais amarelo que verde, $5=$ amarelo.

${ }^{z}$ Coloração no momento da colheita $=1,60$ (média de 10 frutos)

Danos pelo chilling: ao final de 7 dias de refrigeração, mais 3 dias de comercialização simulada, as frutas armazenadas nas diferentes temperaturas não apresentaram sintomas visíveis de injúrias pelo frio. Chitarra \& Chitarra (1990) afirmam que o aparecimento dos danos pelo chilling varia não apenas com a temperatura, mas também com o tempo de exposição da fruta à temperatura baixa. Assim, aos 14 dias, as frutas armazenadas a $2^{\circ} \mathrm{C}$ apresentaram intensos danos de chilling (Tabela 3), os quais aumentaram de intensidade aos 21 dias de conservação. Estes resultados estão de acordo com as observações de Wills et al. (1983) e Vasquez-Ochoa \& Colinas-Leon (1990), que concluíram que temperaturas demasiadamente baixas para a conservação de goiabas prejudicam as frutas. As goiabas armazenadas a $8^{\circ} \mathrm{C}$ apresentaram leves danos pelo chilling aos 14 e 21 dias, enquanto que as frutas armazenadas a 10 ou $12^{\circ} \mathrm{C}$ não sofreram 
injúrias. Os principais danos pelo chilling verificados nas frutas foram ocorrência de regiões na casca com aspecto enrugado e dificuldade de perda da coloração verde, caracterizado por áreas irregulares verde-pardas contrastando com áreas amareladas. Os sintomas de enrugamento na casca foram visíveis mesmo sob refrigeração e os demais sintomas, somente após transferência para o ambiente. Tabela 3. Dano causado pelo chilling em goiabas 'Kumagai' submetidas a
diferentes temperaturas de armazenamento ${ }^{x}$.

\begin{tabular}{cccc}
\hline \multirow{2}{*}{ Temperatura $\left({ }^{\circ} \mathrm{C}\right)$} & \multicolumn{3}{c}{ Períodos de armazenamento (dias) $^{\mathrm{y}}$} \\
\cline { 2 - 4 } & 7 & 14 & 21 \\
\hline & $1,0 \mathrm{a}$ & $4,0 \mathrm{a}$ & $5,0 \mathrm{a}$ \\
8 & $1,0 \mathrm{a}$ & $1,2 \mathrm{~b}$ & $1,5 \mathrm{~b}$ \\
10 & $1,0 \mathrm{a}$ & $1,0 \mathrm{~b}$ & $1,0 \mathrm{c}$ \\
12 & $1,0 \mathrm{a}$ & $1,0 \mathrm{~b}$ & $1,0 \mathrm{c}$ \\
\hline C.V. $(\%)$ & 3,34 & 5,34 & 2,58 \\
\hline
\end{tabular}

${ }^{x}$ Médias seguidas de mesma letra na coluna não diferem entre si pelo teste de Tukey ao nível de $5 \%$ de probabilidade.

${ }^{y}$ após cada periodo de armazenamento, as frutas foram submetidas a 3 dias de comercialização simulada a $25^{\circ} \mathrm{C}$.

${ }^{z}$ Escala de notas: 1 = isento; 2 = ligeiro dano de chilling; 3 = moderado; 4 = intenso e 5 = muito intenso.

Firmeza da polpa: não houve influência da temperatura de armazenamento sobre a firmeza de polpa das frutas nos períodos de conservação estudados (Tabela 4). Mesmo naquelas que mantiveram a coloração verde da casca, a polpa mostrou-se bastante amolecida. A firmeza da polpa foi de $3,27 \mathrm{~kg}$ nas frutas recém colhidas e chegou a valores entre 0,56 e $0,76 \mathrm{~kg}$, após 21 dias de conservação. Isto mostra que a goiaba apresenta rápida perda de firmeza ao longo do armazenamento. Portanto, outros tratamentos que evitem esta redução na consistência dos frutos devem ser testados, para que o produto suporte o transporte e a comercialização por períodos satisfatórios. 
Tabela 4. Firmeza da polpa de goiabas 'Kumagai' submetidas a diferentes temperaturas de armazenamento. ${ }^{\mathrm{x}}$

\begin{tabular}{cccc}
\hline & \multicolumn{3}{c}{ Periodos de armazenamento $(\text { dias })^{\mathrm{y}}$} \\
\hline & 7 & 14 & 21 \\
\hline 2 & $1,49 \mathrm{a}$ & $0,74 \mathrm{a}$ & $0,76 \mathrm{a}$ \\
8 & $1,41 \mathrm{a}$ & $0,90 \mathrm{a}$ & $0,60 \mathrm{a}$ \\
10 & $1,39 \mathrm{a}$ & $0,91 \mathrm{a}$ & $0,56 \mathrm{a}$ \\
12 & $1,15 \mathrm{a}$ & $0,89 \mathrm{a}$ & $0,66 \mathrm{a}$ \\
\hline C.V. $(\%)$ & 12,89 & 9,07 & 11,22 \\
\hline
\end{tabular}

${ }^{\mathrm{x}}$ Médias seguidas de mesma letra na coluna não diferem entre si pelo teste de Tukey ao nível de $5 \%$ de probabilidade.

${ }^{y}$ após cada período de armazenamento, as frutas foram submetidas a 3 dias de comercialização simulada a $25^{\circ} \mathrm{C}$.

${ }^{z}$ firmeza de polpa nas frutas recém colhidas $=3,27 \mathrm{kgf}$ (média de 10 frutos)

Teor de sólidos solúveis totais (SST): não houve diferença significativa para o teor de SST entre as temperaturas estudadas (Tabela 5). Verificou-se apenas um pequeno incremento nos valores desta variável ao longo do armazenamento.

Acidez total titulável (ATT): poucas diferenças significativas ocorreram nos teores de ATT das goiabas ao longo do experimento (Tabela 6). O pequeno decréscimo nos valores verificados aos 14 e 21 dias, nas frutas armazenadas a $2{ }^{\circ} \mathrm{C}$, pode ser explicado pela ocorrência de danos de chilling. Shewfelt \& Prussia (1993) comentam que um dos danos provocados pelo frio em frutas é o aumento desordenado na produção de etileno e respiração. Isso pode ter provocado, no presente trabalho, a utilização de grande quantidade de ácidos no processo respiratório das frutas armazenadas a $2^{\circ} \mathrm{C}$, fazendo com que estas apresentassem ATT menor do que aquelas armazenadas nas demais temperaturas. Outra possibilidade seria o fato da baixa temperatura não ter permitido o amadurecimento normal dessas frutas, uma vez que nos demais tratamentos 
Tabela 5. Teor de sólidos solúveis totais (SST) de goiabas 'Kumagai' submetidas a diferentes temperaturas de armazenamento. ${ }^{x}$

\begin{tabular}{cccc}
\hline \multirow{2}{*}{ Temperatura $\left({ }^{\circ} \mathrm{C}\right)$} & \multicolumn{3}{c}{ Períodos de armazenamento (dias) } \\
\cline { 2 - 4 } & 7 & 14 & 21 \\
\hline 2 & $6,80 \mathrm{a}$ & $7,74 \mathrm{a}$ & $7,22 \mathrm{a}$ \\
8 & $6,19 \mathrm{a}$ & $7,74 \mathrm{a}$ & $7,38 \mathrm{a}$ \\
10 & $6,90 \mathrm{a}$ & $7,32 \mathrm{a}$ & $7,32 \mathrm{a}$ \\
12 & $6,81 \mathrm{a}$ & $7,54 \mathrm{a}$ & $6,89 \mathrm{a}$ \\
\hline C.V. $(\%)$ & 11,43 & 7,67 & 8,70 \\
\hline
\end{tabular}

${ }^{x}$ Médias seguidas de mesma letra na coluna não diferem entre si pelo teste de Tukey ao nível de 5\% de probabilidade.

${ }^{y}$ após cada periodo de armazenamento, as frutas foram submetidas a 3 dias de comercialização simulada a $25^{\circ} \mathrm{C}$.

${ }^{z}$ teor de SST nas frutas recém colhidas $=6,18^{\circ}$ Brix

Tabela 6. Acidez total titulável (ATT) de goiabas 'Kumagai' submetidas a diferentes temperaturas de armazenamento. ${ }^{\mathrm{X}}$

\begin{tabular}{cccc}
\hline Temperatura $\left({ }^{\circ} \mathrm{C}\right)$ & \multicolumn{3}{c}{ Períodos de armazena mento (dias, $)^{\mathrm{y}^{\prime}}$} \\
\cline { 2 - 4 } & 7 & 14 & 21 \\
\hline 2 & $0,81 \mathrm{a}$ & $0,51 \mathrm{~b}$ & $0,44 \mathrm{~b}$ \\
8 & $0,74 \mathrm{ab}$ & $0,61 \mathrm{a}$ & $0,63^{\mathrm{a}}$ \\
10 & $0,75 \mathrm{ab}$ & $0,60 \mathrm{a}$ & $0,64^{\mathrm{a}}$ \\
12 & $0,70 \mathrm{~b}$ & $0,60 \mathrm{a}$ & $0,62^{\mathrm{a}}$ \\
\hline C.V. $(\%)$ & 11,10 & 10,40 & 9,22 \\
\hline
\end{tabular}

${ }^{x}$ Médias seguidas de mesma letra na coluna não diferem entre si pelo teste de Tukey ao nivel de $5 \%$ de probabilidade.

${ }^{y}$ após cada periodo de armazenamento, as frutas foram submetidas a 3 dias de comercialização simulada a $25^{\circ} \mathrm{C}$.

${ }^{z}$ ATT nas frutas recém colhidas $=0,45 \%$ de ácido citrico 
os teores de ATT passaram de $0,45 \%$ nas goiabas verdes recém colhidas para aproximadamente $0,60 \%$ após armazenamento e amadurecimento.

Teor de vitamina $C$ : verificou-se, de maneira geral, incremento no teor de vitamina $\mathrm{C}$ das goiabas durante a conservação (Tabela 7), em relação ao valor observado nas frutas recém colhidas $\left(69,2 \mathrm{mg} 100 \mathrm{~g}^{-1}\right)$. Estes resultados concordam com aqueles obtidos por Esteves et al. (1984), que observaram incrementos no teor de vitamina C em goiabas, durante o amadurecimento. De igual forma ao verificado para a ATT, o teor de vitamina $\mathrm{C}$ nas frutas armazenadas a $2^{\circ} \mathrm{C}$, aos 14 e 21 dias, foi menor do que $\mathrm{o}$ verificado nas demais temperaturas, provavelmente devido às disfunções provocadas pelo frio na temperatura mais baixa.

\section{Tabela 7. Teor de vitamina $C$ de goiabas 'Kumagai' submetidas a diferentes temperaturas de armazenamento ${ }^{x}$.}

\begin{tabular}{cccc}
\hline \multirow{2}{*}{ Temperatura $\left({ }^{\circ} \mathrm{C}\right)$} & \multicolumn{3}{c}{ Dias de armazenamento $^{\mathrm{y}}$} \\
\cline { 2 - 4 } & 7 & 14 & 21 \\
\hline 2 & $123,0 \mathrm{a}$ & $108,1 \mathrm{c}$ & $73,6 \mathrm{c}$ \\
8 & $123,8 \mathrm{a}$ & $140,9 \mathrm{~b}$ & $128,1 \mathrm{~b}$ \\
10 & $123,9 \mathrm{a}$ & $157,4 \mathrm{ab}$ & $131,0 \mathrm{~b}$ \\
12 & $133,1 \mathrm{a}$ & $161,9 \mathrm{a}$ & $154,0 \mathrm{a}$ \\
\hline C.V. $(\%)$ & 14,21 & 11,42 & 12,63 \\
\hline
\end{tabular}

${ }^{x}$ Médias seguidas de mesma lera na coluna não diferem entre si pelo teste de Tukey ao núvel de $5 \%$ de probabilidade.

${ }^{y}$ após cada período de armazenamento, as frutas foram submetidas a 3 dias de comercialização simulada a $25^{\circ} \mathrm{C}$.

${ }^{z}$ teor de ácido ascórbico nas goiabas recém colhidas $=69,2 \mathrm{mg} \cdot 100 \mathrm{~g}^{-1}$

Podridões: as frutas armazenadas a 2 ou $8^{\circ} \mathrm{C}$ apresentaram pequena incidência de podridões até 21 dias de armazenamento (menos de 15\% de frutas afetadas), enquanto que as armazenadas a 10 ou $12^{\circ} \mathrm{C}$, devido ao estado avançado de 
amadurecimento, foram bastante afetadas (mais de $70 \%$ de frutas afetadas), o que tornou-as impróprias para comercialização.

Foi verificado, no presente trabalho, que a temperatura de armazenamento de $2^{\circ} \mathrm{C}$ provoca danos nas frutas, sejam eles visuais, representados pelo escurecimento e enrugamento da casca, ou na composição química, representados pela redução na ATT e no teor de vitamina C. Os danos visuais não apareceram aos 7 dias e sim aos 14 dias, o que demonstra que a goiaba pode suportar a temperatura de $2^{\circ} \mathrm{C}$ por até uma semana. As temperaturas de 10 e $12^{\circ} \mathrm{C}$, conservaram as frutas por até 14 dias, sendo que aos 21 dias a sua comercialização foi afetada devido à ocorrência de podridões. A temperatura de $8^{\circ} \mathrm{C}$ foi considerada a melhor para o armazenamento da variedade em estudo, devido à baixa incidência de danos pelo chilling e de podridões e normalidade no processo de amadurecimento.

\section{CONCLUSÕES}

- Goiabas 'Kumagai' não podem ser armazenadas a $2{ }^{\circ} \mathrm{C}$ por mais do que 7 dias;

- As temperaturas de 10 ou $12^{\circ} \mathrm{C}$ não são eficientes na conservação desta variedade, para armazenamento superior a 14 dias;

- A utilização da temperatura de $8^{\circ} \mathrm{C}$ para a conservação desta variedade é a mais indicada para o armazenamento até 21 dias.

\section{REFERÊNCIAS BIBLIOGRÁFICAS}

AWAD, M. Fisiologia pós-colheita de frutos. São Paulo: Nobel, 1993. 114p.

CARRARO, A.F.; CUNHA, M.M. Manual de exportação de frutas. Brasília: FRUPEX; IICA, 1994. 254p. 
CARVALHO, C.R.L.; MANTOVANI, D.M.B.; CARVALHO, P.R.N.; MORAES, R.M.M. Análises químicas de alimentos. Campinas: ITAL, 1990. $121 \mathrm{p}$. (Manual Técnico)

CARVALHO, V.D. Qualidade e conservação pós-colheita de goiabas. Informe Agropecuário, v.17, n. 179, p.48-54, 1994.

CASTRO, J. V.; SIGRIST, J. M. M. Matéria-prima. In: MEDINA, J.C.; CASTRO,J.V.; SIGRIST, J.M.M.S.; MARTIN, Z.J.; KATO, K.; MAIA, M.L.; GARCIA, A.E.B.; LEITE, R.S.S.F. Goiaba: cultura, matéria-prima, processamento e aspectos econômicos. 2.ed. Campinas: ITAL, 1988. cap. 2, p. 121-140. (Série Frutas Tropicais, 6)

CHITARRA, M.I.F.; CHITARRA, A.B. Pós-colheita de frutas e hortaliças: fisiologia e manuseio. Lavras: ESAL, FAEPE, 1990. 320p.

DURIGAN, J.F. Colheita, conservação e embalagens. In: SIMPÓSIO BRASILEIRO SOBRE A CULTURA DA GOIABEIRA, 1., Jaboticabal, 1995. Anais. Jaboticabal: FUNEP, 1997. p.149-158.

ESTEVES, M.T.C; CARVALHO, V.D.; CHITARRA, M.I.F.; CHITARRA, A.B.; PAULA, M.B. Caracterização dos frutos de seis cultivares de goiabeiras (Psidium guajava L.) na maturação. I. Determinações fisicas e químicas. In: CONGRESSO BRASILEIRO DE FRUTICULTURA, 7., Florianópolis, 1983. Anais. Florianópolis: SBF; EMPASC, 1984. v.2, p.477-489.

FNP CONSULTORIA \& COMÉRCIO. Agrianual 99: anuário estatístico da agricultura brasileira. São Paulo, 1999. 521p.

HARDENBURG, R.E.; WATADA, A.E.; WANG, C.Y. The commercial storage of fruits, vegetables, and florist, and nursery stocks. Washington: USDA, 1986. 130p. (USDA. Agriculture Handbook, 66) 
KADER, A.A. Postharvest biology and technology: an overview. In: KADER, A.A.; KASMIRE, R.F.; MITCHELL F.G.; REID, M.S.; SOMMER, N.F.; THOMPSON, J.F. Postharvest technology of horticultural crops. Oakland: University of California, 1992a. cap.2, p.3-7.

PANTÁSTICO, E.B. Postharvest physiology, handling and utilization of tropical an subtropical fruits an vegetables. Westport: AVI Publ., 1975. 560p.

PEREIRA, F.M. Cultura da goiabeira. Jaboticabal: FUNEP, 1995. 47p.

PIZA Jr., C.T.; KAVATI, R. A cultura da goiabeira de mesa. Campinas: CATI, 1994. 28p. (CATI. Boletim Técnico, 219)

SHEWFELT, R.L.; PRUSSIA, S.E. Postharvest handling: a systems approach. New York: Academic Press, 1993. 358p.

VASQUEZ-OCHOA, R.J.; COLINAS-LEON, M.T. Changes in guavas of three maturity stages in response to temperture and relative humidy. HortScience, v.25, n. 1, p.86-87, 1990.

WILLS, R.B.H.; MULHOLLAND, E.E.; BROWN, B.I.; SCOTT, K.J. Storage of two new cultivars fo guava fruit for processing. Tropical Agriculture, v.60, p. 175-178, 1983.

WOODS, J. L. Moisture loss from fruits and vegetables. Postharvest News and Information, v.1, n.3, p.195-199, 1990. 
4. MATERIAIS DE EMBALAGEM PARA CONSERVAÇÃO REFRIGERADA DE GOIABAS 'KUMAGAI' 


\section{MATERIAIS DE EMBALAGEM PARA CONSERVAÇÃO REFRIGERADA DE GOIABAS 'KUMAGAI'}

Resumo: Goiabas da variedade Kumagai foram acondicionadas em diversos materiais de embalagem e armazenadas a $10 \pm 1^{\circ} \mathrm{C}$ e $85-90 \%$ de UR, durante $7,14,21$ e 28 dias, seguidos de 3 dias de comercialização simulada a $25 \pm 1^{\circ} \mathrm{C}$ e $70-80 \%$ UR. Os materiais de embalagem utilizados foram: filme poliolefinico com permeabilidade seletiva (PPS), filme de polietileno de baixa densidade (PEBD), filme de PEBD com incorporação de mineral (PBM) e filme poliolefinico termo-encolhível (ENC). Goiabas sem embalagem foram utilizadas como Controle. Foram determinadas as taxas de permeabilidade ao $\mathrm{O}_{2}$ e ao $\mathrm{CO}_{2}$ em cada um dos filmes, as composições gasosas no interior das embalagens e as características físicoquímicas das goiabas (cor da casca, firmeza da polpa, teor de sólidos solúveis, acidez total titulável, teor de ácido ascórbico, incidência de podridões e perda de matéria fresca). O filme PEBD, com $69 \mu \mathrm{m}$ de espessura, apresentou $\mathrm{TPO}_{2}$ de $2.115 \mathrm{~cm}^{3} \cdot \mathrm{m}^{-2} \cdot \mathrm{dia}^{-1}$ e $\mathrm{TPCO}_{2}$ de 4.434 $\mathrm{cm}^{3} \cdot \mathrm{m}^{-2} \cdot \mathrm{dia}^{-1}$, tendo induzido anaerobiose e elevada concentração de gás carbônico no interior das embalagens. Os frutos acondicionados nestas embalagens apresentaram distúrbios fisiológicos e não amadurecem normalmente após transferência para o ambiente. O filme ENC, com $15 \mu \mathrm{m}$ de espessura, apresentou $\mathrm{TPO}_{2}$ de $6.366 \mathrm{~cm}^{3} \cdot \mathrm{m}^{-2} \cdot \mathrm{dia}^{-1}$ e $\mathrm{TPCO}_{2}$ de $34.864 \mathrm{~cm}^{3} \cdot \mathrm{m}^{-2} \cdot \mathrm{dia}^{-1}$. Este filme proporcionou atmosfera de equilíbrio com $19 \%$ de $\mathrm{O}_{2}$ e $2 \%$ de $\mathrm{CO}_{2}$. Os frutos acondicionados nestas embalagens apresentaram rápida senescência e período de conservação menor que frutos sem embalagem. O filme PBM, com $24 \mu \mathrm{m}$ de espessura, apresentou $\mathrm{TPO}_{2}$ de $4.918 \mathrm{~cm}^{3} \cdot \mathrm{m}^{-2} \cdot \mathrm{dia}^{-1}$ e $\mathrm{TPCO}_{2}$ de $32.937 \mathrm{~cm}^{3} \cdot \mathrm{m}^{-2} \cdot \mathrm{dia}^{-1}$. Este filme proporcionou atmosfera de equilíbrio com $3 \%$ de $\mathrm{O}_{2}$ e $4,5 \%$ de $\mathrm{CO}_{2}$, no interior das embalagens. Os frutos acondicionados nestas embalagens puderam ser conservados até 14 dias, mantendo a coloração da casca e firmeza da polpa adequadas para consumo. $\mathrm{O}$ filme PPS, com $35 \mu \mathrm{m}$ de espessura, apresentou $\mathrm{TPO}_{2}$ de $6.827 \mathrm{~cm}^{3} \cdot \mathrm{m}^{-2} \cdot \mathrm{dia}^{-1}$ e $\mathrm{TPCO}_{2}$ de 21.969 $\mathrm{cm}^{3} \cdot \mathrm{m}^{-2} \cdot \mathrm{dia}^{-1}$. Este filme proporcionou atmosfera de equilíbrio com $0,5 \%$ de $\mathrm{O}_{2}$ e $4,5 \%$ de $\mathrm{CO}_{2}$, no interior das embalagens. Os frutos acondicionados nestas embalagens puderam ser conservados até 28 dias, mantendo suas características físico-químicas.

Palavras-chave: Psidium guajava, pós-colheita, atmosfera modificada, composição gasosa 


\section{PACKAGING MATERIALS FOR COLD STORAGE OF 'KUMAGAI' GUAVAS}

Summary: Guavas cv. Kumagai were wrapped in several packaging materials and stored at $10 \pm 1^{\circ} \mathrm{C}$ and $85-90 \% \mathrm{RH}$ during 7, 14, 21 and 28 days, followed by 3 days at $25 \pm 1{ }^{\circ} \mathrm{C}$ and $70-80 \% \mathrm{RH}$ to simulate commercial handling conditions. The packaging materials used were: polyolephinic film with selective permeability (PSP), low density polyethylene film (LDP), LDP film with mineral incorporation (LDPM) and shrink polyolephinic film (SHR). Guavas without packaging were used as Control. The gas permeability of the each film, the concentrations of $\mathrm{O}_{2}$ and $\mathrm{CO}_{2}$ inside the packagings and the physical-chemical characteristics of the guavas (skin color, firmness, total soluble solids, total titatrable acidity, ascorbic acid, decay and weight loss) were evaluated. The LDP film with $69 \mu \mathrm{m}$ of thickness presented $\mathrm{TPO}_{2}$ of $2,115 \mathrm{~cm}^{3} \cdot \mathrm{m}^{-2} \cdot \mathrm{dia}^{-1}$ and $\mathrm{TPCO}_{2}$ of $4,434 \mathrm{~cm}^{3} \cdot \mathrm{m}^{-2} \cdot \mathrm{dia}^{-1}$. It promoted anaerobic atmosphere and high $\mathrm{CO}_{2}$ concentration. Furthermore, it induced both off-flavor and physiological disorders in the fruits which caused abnormal ripening. The SHR film with $15 \mu \mathrm{m}$ of thickness presented $\mathrm{TPO}_{2}$ of $6,366 \mathrm{~cm}^{3} \cdot \mathrm{m}^{-2} \cdot \mathrm{dia}^{-1}$ and $\mathrm{TPCO}_{2}$ of $34,864 \mathrm{~cm}^{3} \cdot \mathrm{m}^{-2} \cdot \mathrm{dia}^{-1}$. This film promoted atmosphere composition of $19 \%$ of $\mathrm{O}_{2}$ and $2 \%$ of $\mathrm{CO}_{2}$. The fruits wrapped in this film presented fast senescence and smaller conservation than fruits controls. The LDPM film with $24 \mu \mathrm{m}$ of thickness presented $\mathrm{TPO}_{2}$ of $4,918 \mathrm{~cm}^{3} \cdot \mathrm{m}^{-2} \cdot \mathrm{dia}^{-1}$ and $\mathrm{TPCO}_{2}$ of 32,937 $\mathrm{cm}^{3} \cdot \mathrm{m}^{-2} \cdot \mathrm{dia}^{-1}$. This film provided atmosphere composition of $3 \%$ of $\mathrm{O}_{2}$ and $4.5 \%$ of $\mathrm{CO}_{2}$. The fruits wrapped in this film could be conserved until 14 days, keeping the skin color and firmness. The PSP film with $35 \mu \mathrm{m}$ of thickness presented $\mathrm{TPO}_{2}$ of $6,827 \mathrm{~cm}^{3} . \mathrm{m}^{-}$ ${ }^{2} \cdot \mathrm{dia}^{-1}$ and $\mathrm{TPCO}_{2}$ of $21,969 \mathrm{~cm}^{3} \cdot \mathrm{m}^{-2} \cdot \mathrm{dia}^{-1}$. This film provided atmosphere composition of $0.5 \%$ of $\mathrm{O}_{2}$ and $4.5 \%$ of $\mathrm{CO}_{2}$. The fruits wrapped in this film kept their physicalchemical characteristics until 28 days.

Key words: Psidium guajava, post-harvest, modified atmosphere, gas composition 


\section{INTRODUÇÃO}

A goiabeira (Psidium guajava L.) encontra-se atualmente muito difundida por todas as regiões tropicais e subtropicais do mundo. A goiaba destaca-se por apresentar elevado valor nutritivo e excelentes características organolépticas, tornando-a muito adequada para o consumo in natura (Carvalho, 1994).

A produção brasileira é de aproximadamente 250 mil toneladas, sendo os Estados de São Paulo e Pernambuco responsáveis por $60 \%$ e $25 \%$, respectivamente, do total produzido (FNP, 1999). Em 1995, as exportações brasileiras desta fruta foram de 123 mil toneladas, sendo a França o principal país comprador (FNP, 1997).

Segundo Proctor (1990), a goiaba situa-se no grupo das frutas tropicais que ainda apresenta um pequeno volume de exportação para o mercado Europeu, mas tem despertado grande interesse e curiosidade nos consumidores, sendo esperada a abertura e ampliação de muitos mercados. O mesmo autor salienta a necessidade do desenvolvimento de técnicas que possibilitem que os produtos tropicais sejam transportados via marítima, evitando-se assim o transporte aéreo que é muito oneroso.

As goiabas de polpa branca são as mais comercializadas no mercado in natura (FNP, 1999). Têm sido preferidas por apresentarem melhor conservação em pós-colheita e por exalarem um perfume discreto, que as torna finas e delicadas. A variedade de polpa branca mais cultivada é a Kumagai, cujos frutos são grandes, arredondados a oblongos, firmes, com casca lisa e resistente e de coloração verde-amarelada quando maduros (Piza Jr. \& Kavati, 1994). Essa é também, a principal variedade exportada pelo Brasil.

Os conhecimentos sobre a fisiologia pós-colheita da goiaba são bastante limitados, entretanto, permitem concluir que trata-se de uma fruta com padrão de respiração do tipo climatérico. Trabalhando com diferentes cultivares de P. guajava, Akamine \& Goo (1979), Singh et al. (1981), Brown \& Wills (1983), Oliveira \& Cereda (1996), Lima et al. (1998) e Mercado-Silva et al. (1998) encontraram pico de atividade respiratória entre o quarto e o nono dia após a colheita.

O emprego de atmosfera modificada, associada à refrigeração, constitui-se num importante mecanismo para retardar o amadurecimento de frutos climatéricos e 
aumentar seu período de conservação (Hardenburg et al.,1986; Chitarra \& Chitarra, 1990; Kader, 1992a; Kader, 1992b).

Carraro \& Cunha (1994) e Durigan (1997) recomendam o emprego de temperatura entre 8 e $10^{\circ} \mathrm{C}$ para armazenamento de goiabas. Atmosfera contendo $3 \%$ de $\mathrm{O}_{2}$ e $7,5-8 \%$ de $\mathrm{CO}_{2}$ tem sido citada como a mais adequada para conservação desta fruta (Monzini \& Gorini, 1973; Castro \& Sigrist, 1988).

Muitos são os trabalhos que evidenciam a eficiência do uso de atmosfera modificada na conservação pós-colheita de goiabas, diminuindo a perda de matéria fresca e retardando o amadurecimento (Khedkar et al. 1982; Adsule \& Tandon, 1983; Singh et al., 1984; Tandon et al., 1984; Augustin \& Azizah, 1988; Combrink, et al. 1990; Gaspar et al., 1996; Paro et al., 1996; Ali \& Lazan, 1997; Lima et al., 1998). Combrink et al. (1990) obtiveram beneficios no armazenamento de goiabas em embalagem de polietileno selada, durante 2 semanas, sendo que os melhores resultados foram obtidos em filmes impregnados com mineral. Paro et al. (1996) associando o uso de cera, embalagem de polietileno e refrigeração $\left(9^{\circ} \mathrm{C}\right)$, conservaram goiabas da variedade Paluma por 29 dias. De maneira semelhante, Gaspar et al. (1996) conservaram goiaba branca da variedade Kumagai por 3 semanas em embalagem selada de polietileno, sob temperatura de $8^{\circ} \mathrm{C}$.

$\mathrm{Na}$ maioria destes trabalhos, os autores utilizam filmes de polietileno comum, havendo pouca informação sobre o comportamento dessa fruta quando embalada em filmes especiais.

O polietileno é o polímero mais utilizado na embalagem de alimentos em geral. Tem a mais simples composição química de todos os polímeros e, geralmente, o menor custo. Pode ser classificado como polietileno de baixa densidade, quando esta propriedade varia na faixa de 0,915 a $0,939 \mathrm{~g} . \mathrm{cm}^{-3}$ e polietileno de alta densidade, quando esta é de $0,940 \mathrm{~g} . \mathrm{cm}^{-3}$ ou mais. O polietileno de baixa densidade é um material bastante flexível, resistente ao impacto e pouco resistente ao calor (Yam et al., 1992). Possui taxa de permeabilidade ao oxigênio entre 1.000 e $4.000 \mathrm{~cm}^{3} \cdot \mathrm{m}^{-2} \cdot \mathrm{dia}^{-1}$ e ao gás carbônico entre 3.200 e $12.2600 \mathrm{~cm}^{3} \cdot \mathrm{m}^{-2} \cdot \mathrm{dia}^{-1}$, dependendo da espessura (Sarantópoulos et al., 1996). 
$\mathrm{Na}$ linha de filmes poliolefinicos, têm sido desenvolvidos alguns materiais de alta permeabilidade a gases, específicos para manter a correta atmosfera modificada ao redor de vegetais embalados e mantidos sob refrigeração. A taxa de permeabilidade ao oxigênio destes filmes varia de 3.500 a $16.500 \mathrm{~cm}^{3} \cdot \mathrm{m}^{-2} \cdot \mathrm{dia}^{-1}$ (Cryovac Division, 1994).

Outra forma para aumentar a taxa de permeabilidade de filmes a gases é a incorporação de cargas inertes (Lee et al., 1992; Frey, 1995). Filmes poliméricos, em geral polietileno contendo dispersões de minerais, também são comercializados como absorvedores de etileno. Esses filmes contêm cerca de 5\% do peso em minerais, principalmente uma mistura de $\mathrm{SiO}_{2}$ e $\mathrm{Al}_{2} \mathrm{O}_{3}$. Com a incorporação de materiais inertes ocorre aumento nas taxas de permeabilidade a o oxigênio, ao gás carbônico e ao etileno, e na relação entre a taxa de permeabilidade ao gás carbônico e a taxa de permeabilidade ao oxigênio (Lee et al., 1992). Por outro lado, ocorre perda de transparência do material, o que normalmente prejudica seu uso em embalagens visando comercialização ao nível de varejo.

Tendo em vista a potencialidade de ampliar o período de conservação de produtos vegetais pelo emprego de atmosfera modificada, o presente trabalho teve como objetivos: a) caracterizar diversos materiais de embalagem; b) verificar os efeitos destes materiais de embalagem e de períodos de armazenamento sob refrigeração, na conservação de goiabas 'Kumagai'; c) monitorar a composição gasosa no interior das embalagens.

\section{MATERIAL E MÉTODOS}

O experimento foi realizado no Instituto de Tecnologia de Alimentos (ITAL), localizado em Campinas, SP.

Goiabas da variedade 'Kumagai' foram colhidas num pomar comercial do município de Valinhos, SP, no mês de julho de 1998. Após a colheita, os frutos foram selecionados e transportados ao ITAL, em caixas de papelão com capacidade para $3 \mathrm{~kg}$. Foram selecionados frutos sem defeitos e em estádio de maturação caracterizado pela 
mudança da cor da casca de verde-escuro para verde-claro. O peso médio dos frutos utilizados foi de $167 \mathrm{~g}$.

Antes da aplicação dos tratamentos, as goiabas foram pré-resfriadas em câmaras de refrigeração até a temperatura da polpa atingir $10^{\circ} \mathrm{C}$.

Os tratamentos consistiram no uso de diferentes materiais de embalagem e períodos de armazenamento. Os materiais de embalagem utilizados foram: filme poliolefinico com permeabilidade seletiva (PPS), filme de polietileno de baixa densidade (PEBD), filme de PEBD com incorporação de mineral (PBM) e filme poliolefinico termo-encolhível (ENC). Goiabas sem embalagem foram tomadas como Controle.

Os filmes PPS, PEBD e PBM foram utilizados na forma de sacos, que após a colocação das goiabas foram selados em seladora por impulso elétrico, marca Haramura, sem evacuação de ar. Para o acondicionamento no filme ENC, as goiabas foram colocadas em bandejas de poliestireno expandido, envolvidas com o material de embalagem e submetidas ao encolhimento do filme em túnel de ar quente. $O$ encolhimento ocorreu à temperatura média de $128^{\circ} \mathrm{C}$ durante 13 segundos com posterior resfriamento em ar forçado à temperatura ambiente, durante 5 segundos.

Após o acondicionamento nas diferentes embalagens, os frutos foram colocados em caixas de papelão ondulado e armazenados a $10 \pm 1{ }^{\circ} \mathrm{C}$ e $85-90 \%$ UR, durante 7,14 , 21 e 28 dias. Frutos sem embalagem plástica (Controle) foram submetidos às mesmas condições.

O delineamento experimental adotado foi inteiramente ao acaso, em esquema fatorial $5 \times 5$. Os fatores estudados foram materiais de embalagem (PPS, PEBD, PBM, ENC e Controle) e períodos de armazenamento (O, 7, 14, 21 e 28 dias). Foram utilizadas 5 repetições com 6 frutos por parcela, sendo cada parcela constituída por uma embalagem.

\section{Caracterização dos materiais de embalagem}

As taxas de permeabilidade ao oxigênio e ao gás carbônico foram determinadas por método de aumento da concentração, segundo procedimento descrito por Oliveira et 
al. (1996). Foram utilizadas células de difusão de gás constituídas por duas câmaras. Na câmara superior foi mantido um fluxo de gás permeante, que ao permear o corpo-deprova acumulou-se na câmara inferior, fechada para atmosfera. Em intervalos prédeterminados foram retiradas alíquotas de $300 \mu \mathrm{L}$ gás, desta câmara, para quantificação do gás permeante em cromatógrafo a gás marca Shimadzu, modelo 14A, acoplado a integrador Shimadzu modelo CR 4A, operando com detector de condutividade térmica a $150^{\circ} \mathrm{C}$, colunas Porapak $\mathrm{N}$ e Peneira molecular $13 \mathrm{X}$ a $51^{\circ} \mathrm{C}$ e injetor a $70^{\circ} \mathrm{C}$, com um fluxo de $30 \mathrm{ml} \cdot \mathrm{min}^{-1}$ de argônio, operando com detector de condutividade térmica. Os resultados de cromatografia foram analisados por um integrador, com base em curva padrão feita com gás de calibração. Todo o procedimento foi efetuado a $25^{\circ} \mathrm{C}$ e a seco. Os resultados foram corrigidos para 1 atm de gradiente de pressão parcial de gás permeante.

A área de permeação efetiva das embalagens foi determinada pelo produto das dimensões entre as linhas de selagem das embalagens. Foram medidas 5 embalagens de cada tratamento e calculada a média aritmética.

\section{Determinação da composição gasosa do espaço livre das embalagens}

Ao final de cada período de armazenamento, três embalagens de cada tratamento foram analisadas para verificar o estabelecimento da atmosfera de equilíbrio. A técnica utilizada nesta determinação constituiu-se na coleta de alíquotas de $300 \mu \mathrm{L}$ de gás do espaço livre das embalagens, através de um septo, com seringa hermética e posterior quantificação em cromatógrafo a gás com as mesmas especificações daquele utilizado na caracterização dos materiais de embalagem. Os resultados da cromatografia foram analisados com base em curvas padrões feitas com gases de calibração. Os resultados foram expressos em termos de porcentagem, em volume de gás.

\section{Avaliação das características físico-químicas das goiabas}

As características físico-químicas das goiabas foram analisada na caracterização do lote experimental e após cada período de armazenamento. Na caracterização do lote experimental realizou-se uma análise imediatamente após a colheita e outra após 
comercialização simulada de 3 dias a $25^{\circ} \mathrm{C}$ e 70-80\% UR. Após cada período de armazenamento realizou-se uma avaliação imediatamente após a refrigeração e outra após a comercialização simulada, para as variáveis coloração externa, índice de doença e perda de matéria fresca. Para as demais variáveis as avaliações foram efetuadas ao final da comercialização simulada. Nas análises não destrutivas utilizaram-se amostras de 3 frutos provenientes de cada embalagem e nas demais, amostras de 2 frutos.

As determinações realizadas foram:

a) coloração externa: determinada com auxílio de colorímetro Minolta, modelo CR300, com a seguinte configuração: sistema colorimétrico L C h, iluminante D65 e observador padrão $2^{\circ}$. Foram tomadas 2 leituras por fruta, em lados opostos de sua região equatorial e os resultados foram expressos em ângulo de cor $\left(\mathrm{h}^{\circ}\right)$, de acordo com McGuirre (1992);

b) teor de sólidos solúveis totais (SST): leitura direta em refratômetro marca SchmidtHaensch, modelo SR-400 e os resultados expressos em ${ }^{\circ} \mathrm{Brix}$;

c) acidez total titulável (ATT): determinada de acordo com metodologia descrita por Carvalho et al. (1990) e os resultados expressos em \% de ácido cítrico na polpa;

d) firmeza da polpa: determinada com auxílio de penetrômetro manual Effegi, modelo FT-327 e ponteira 5/16", tomando-se duas leituras por fruta, em lados opostos de sua região equatorial, sendo os resultados expressos em $\mathrm{kg}$;

e) teor de ácido ascórbico: determinado por titulometria, de acordo com metodologia descrita por Carvalho et al. (1990), e os resultados expressos em mg de ácido ascórbico por $100 \mathrm{~g}$ de polpa;

f) índice de doença (ID): avaliou-se a incidência e a severidade de podridões pelo método visual. O ID correspondeu ao número de frutos com alguma lesão multiplicado pela severidade das lesões, onde $0=$ sem lesões, $1=$ até $25 \%$ da área superficial afetada, $2=25-50 \%, 3=50-75 \%$ e $4=75-100 \%$. A seguinte fórmula foi utilizada: $I D=\Sigma\left(n^{\circ}\right.$ frutos com lesão x severidade) $/ \mathrm{n}^{\circ}$ de frutos da parcela.

g) perda de matéria fresca: determinada pela diferença entre a massa inicial e a massa final da amostra em balança semi-analítica Mettler Toledo, modelo PB3002, sendo os resultados expressos em porcentagem da massa inicial; 
Os dados coletados foram submetidos à análise de variância (teste F) e comparação de médias pelo teste de Tukey ao nível de 5\% de probabilidade. Os resultados de índice de doença foram transformadas segundo $\sqrt{x+0,5}$, antes da análise de variância.

\section{RESULTADOS E DISCUSSÃO}

\section{Caracterização dos materiais de embalagem}

A atmosfera de equilíbrio que se estabelece em um sistema de atmosfera modificada é função, entre outros fatores, da relação entre a quantidade de produto no interior da embalagem e sua a área de permeação (Sarantópoulos et al.,1996). Verificase que a área de permeação das embalagens utilizadas neste experimento foi semelhante para todos os tratamentos (Tabela 1). Isto possibilitou, portanto, efetuar adequada avaliação dos materiais de embalagem, uma vez que a quantidade de goiabas colocadas no interior de cada embalagem também foi constante (aproximadamente $1 \mathrm{~kg}$ por embalagem). Observando as taxas de permeabilidade ao oxigênio e ao gás carbônico encontradas para os materiais de embalagens, pode-se esperar que levarão à resultados bastante diferentes na conservação das goiabas ao longo do armazenamento, uma vez que apresentam características distintas de trocas gasosas.

Os resultados de permeabilidade obtidos para os filmes analisados estão de acordo com a literatura (Gorris \& Peppelenbos, 1992; Cryovac, 1994). Segundo Cryovac (1994), a taxa de permeabilidade ao oxigênio nos filmes poliolefínicos varia de 3.500 a $16.500 \mathrm{~cm}^{3} \cdot \mathrm{m}^{-2} \cdot \mathrm{dia}^{-1}$. As taxas de permeabilidade em filmes de polietileno de baixa densidade, com espessuras entre 25 e $50 \mu \mathrm{m}$, variam de 3.000 a $6.000 \mathrm{~cm}^{3} \cdot \mathrm{m}^{-2}$.dia ${ }^{-1}$ para o oxigênio e 10.000 a $20.000 \mathrm{~cm}^{3} \cdot \mathrm{m}^{-2} \cdot \mathrm{dia}^{-1}$ para o gás carbônico (Gorris \& Peppelenbos, 1992). De acordo com Lee et al. (1992), filmes de polietileno impregnados com minerais apresentam taxas de permeabilidade ao oxigênio e ao gás carbônico superiores às dos filmes convencionais, além de maior relação entre a taxa de permeabilidade ao gás 
carbônico e taxa de permeabilidade ao oxigênio, o que também pode ser verificado quando compara-se estes dois materiais de embalagem (Tabela 1).

Tabela 1. Características dos filmes utilizados para o acondicionamento das goiabas e área de permeação das embalagens.

\begin{tabular}{|c|c|c|c|c|}
\hline Filmes & $\begin{array}{l}\text { Espessura } \\
\qquad(\mu \mathrm{m})\end{array}$ & $\begin{array}{c}\mathrm{TPO}_{2} \\
\left(\mathrm{~cm}^{3} \cdot \mathrm{m}^{-2} \cdot \mathrm{dia}^{-1}\right)^{x}\end{array}$ & $\begin{array}{c}\mathrm{TPCO}_{2} \\
\left(\mathrm{~cm}^{3} \cdot \mathrm{m}^{-2} \cdot \mathrm{dia}^{-1}\right)^{\mathrm{y}}\end{array}$ & $\begin{array}{c}\text { Área de permeação } \\
\text { das embalagens } \\
\left(\mathrm{m}^{2}\right)\end{array}$ \\
\hline $\begin{array}{l}\text { (PPS) Poliolefínico com } \\
\text { permeabilidade seletiva }\end{array}$ & 35 & 6.827 & 21.969 & 0,112 \\
\hline $\begin{array}{l}\text { (PEBD) Polietileno de } \\
\text { baixa densidade }\end{array}$ & 69 & 2.115 & 8.434 & 0,115 \\
\hline $\begin{array}{l}\text { (PBM) Polietileno de } \\
\text { baixa densidade com } \\
\text { incorporação de mineral }\end{array}$ & 24 & 4.918 & 32.937 & 0,118 \\
\hline $\begin{array}{l}\text { (ENC) Poliolefinico } \\
\text { termo-encolhível }\end{array}$ & 15 & 6.366 & 34.864 & 0,108 \\
\hline
\end{tabular}

${ }^{\mathrm{x}} \mathrm{TPO}_{2}$ : Taxa de permeabilidade ao oxigênio em condições normais de temperatura e pressão

${ }^{y} \mathrm{TPCO}_{2}$ : Taxa de permeabilidade ao gás carbônico em condições normais de temperatura e pressão

\section{Composição gasosa do espaço livre das embalagens}

As atmosferas do interior das embalagens entraram em equilíbrio com a do ambiente entre o primeiro e o segundo período de avaliação, ou seja, entre 7 e 14 dias (Figura 1).

Nas embalagens de PPS a composição gasosa estabilizou-se ao redor de $5 \%$ de $\mathrm{CO}_{2}$ e $0,5 \%$ de $\mathrm{O}_{2}$. Esta concentração de oxigênio é considerada baixa para armazenamento prolongado de vegetais, devido aos problemas decorrentes da anaerobiose (Kader, 1986; Wills et al., 1989).

As embalagens de PEBD induziram anaerobiose em seu interior e elevada concentração de $\mathrm{CO}_{2}$ (em torno de $20 \%$ ), mostrando-se barreira excessiva à permeação destes gases. Após o $14^{\circ}$ dia de armazenamento houve redução na concentração de $\mathrm{CO}_{2}$ em PEBD (Figura 1). Possivelmente, a elevada concentração deste gás no interior da embalagem tenha facilitado sua permeação para o ambiente. Filme de PEBD de menor espessura é mais permeável, e poderia proporcionar melhor resultado em termos de 
composição gasosa, entretanto, não teria resistência mecânica suficiente para manter a integridade da embalagem. Neste caso, poder-se-ia optar por filme de polietileno linear de baixa densidade, que apresenta maior resistência mecânica (Sarantópoulos et al., 1996).
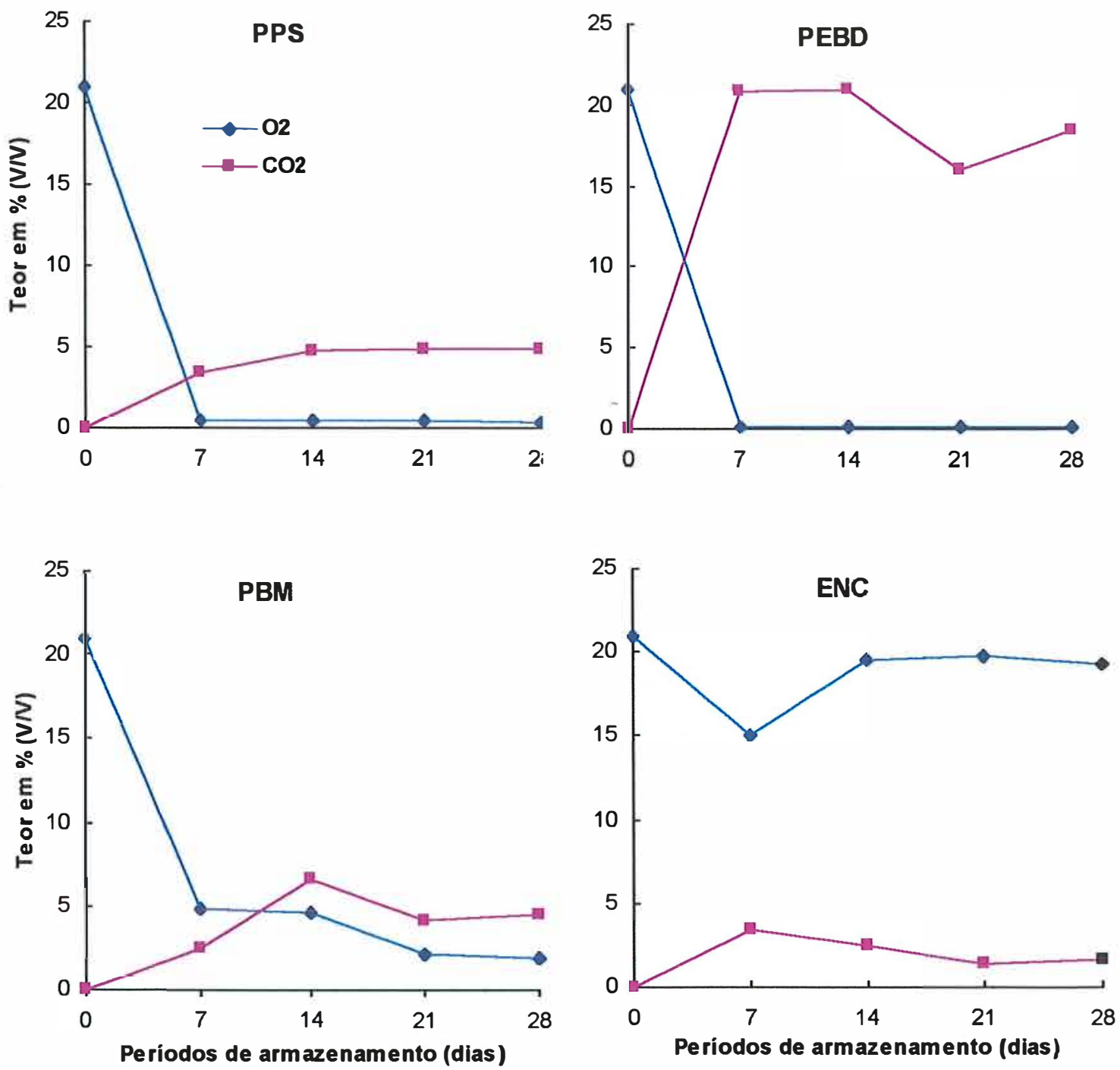

Figura 1. Evolução da composição gasosa no espaço livre de embalagens com goiabas 'Kumagai', durante armazenamento a $10^{\circ} \mathrm{C}$ e $85-90 \% \mathrm{UR}$, onde: PPS= filme poliolefínico com permeabilidade seletiva; $P E B D=$ filme de polietileno de baixa densidade; $P B M=P E B D$ com incorporação de mineral; $\mathrm{ENC}=$ filme poleolefínico termo-encolhível. 
No filme PBM as concentrações de $\mathrm{O}_{2}$ e $\mathrm{CO}_{2}$ estabilizaram-se ao redor de $3 \% \mathrm{e}$ $5 \%$, respectivamente. Estes valores estão mais próximos daqueles recomendados por Monzini \& Gorini (1973) e Castro \& Sigrist (1988), como sendo atmosfera ideal para conservação de goiabas.

O filme ENC, por ser bastante permeável, causou pouca modificação da atmosfera no interior das embalagens, ao longo do armazenamento.

\section{Características físico-químicas das goiabas}

Na Tabela 2 está resumida a análise de variância para os efeitos dos tratamentos sobre diversas variáveis físico-químicas analisadas neste experimento. Observa-se que tanto os materiais de embalagem quanto os períodos de armazenamento influenciaram de maneira significativa o comportamento das variáveis, o mesmo ocorrendo com a interação entre eles. Isto indica que os diferentes materiais de embalagem influenciaram diferentemente as variáveis analisadas ao longo do armazenamento, com exceção da acidez total titulável, cuja interação não foi significativa.

Tabela 2. Significância do teste $F$ da análise de variância para os efeitos dos tratamentos, sobre as variáveis analisadas em goiabas 'Kumagai'.

\begin{tabular}{|c|c|c|c|c|c|c|c|c|}
\hline \multirow{2}{*}{ Tratamentos e interação } & \multicolumn{8}{|c|}{ Variáveis analisadas $x$} \\
\hline & Corl & Cor 2 & SST & ATT & $\mathrm{FP}$ & $\mathrm{AA}$ & ID 1 & ID2 \\
\hline & ------- & & --.--- & gnificâ & ia de tes & $F^{y}$ & ----- & ------ \\
\hline Material de Embalagem (ME) & $* *$ & $* *$ & $* *$ & $*$ & $* *$ & $* *$ & $* *$ & $* *$ \\
\hline Periodo de armazenamento (PA) & $* *$ & $* *$ & $* *$ & $*$ & ** & $* *$ & $* *$ & $* *$ \\
\hline ME $\times$ PA & $* *$ & $* *$ & * & n.s. & $* *$ & $* *$ & $* *$ & $*$ \\
\hline Coeficiente de variação (\%) & 1,41 & 3,29 & 7,46 & 7,24 & 12,79 & 8,37 & 20,90 & 14,45 \\
\hline
\end{tabular}

x Corl = coloração extema após armazenamento; Cor2 = coloração extema após comercialização simulada; SST = teor de sólidos solúveis totais; ATT = teor de acidez total titulável; FP = firmeza da polpa; $\mathrm{AA}=$ teor de ácido ascórbico; ID1 = indice de doença após annazenamento; ID2 = indice de doença após comercialização simulada.

${ }^{y}$ n.s. = não significativo; *,* $=$ significativo ao nivel de 5 ou $1 \%$ de probabilidade, respectivamente. 
Segundo McGuirre (1992), o ângulo de cor $\left(\mathrm{h}^{\circ}\right)$ é a medida mais apropriada para expressar a variação da coloração em produtos vegetais. $\mathrm{O} \mathrm{h}^{\circ}$ é zero para cor vermelha, $90^{\circ}$ para cor amarela, $180^{\circ}$ para cor verde e $270^{\circ}$ para cor azul. Desta forma, pode-se facilmente visualizar a evolução da cor em frutos, durante o amadurecimento. Neste experimento $\mathrm{h}^{\circ}$ variou de $118,6^{\circ}$ nas goiabas recém colhidas a $91,4^{\circ}$ nos frutos do tratamento ENC, após armazenamento e comercialização simulada (Tabela 3 e Figura 2). Os frutos deste tratamento apresentaram, de maneira geral, os menores valores para

Tabela 3. Influência de embalagens e períodos de armazenamento na coloração externa de goiabas 'Kumagai' armazenadas a $10^{\circ} \mathrm{C}$ e $85-90 \%$ UR.'

\begin{tabular}{cccccc}
\hline \multicolumn{5}{c}{ Frutos avaliados imediatamente após retirados da câmara } \\
\hline Embalagens $^{y}$ & 0 & \multicolumn{6}{c}{ Períodos de armazenamento (dias) } \\
& & 7 & \multicolumn{1}{c}{14} & 21 & 28 \\
\hline PPS & 119,0 a A & 118,3 a A & 119,0 a A & 118,0 a A & 118,2 a A \\
PEBD & 119,0 a A & 118,0 a A & 118,0 ab A & 117,2 a A & 117,8 a A \\
PBM & 119,0 a A & 117,6 a AB & 116,0 b B & 115,8 a B & 116,0 a B \\
ENC & 119,0 a A & 113,2 b B & 104,8 d C & 103,8 c C & 100,8 b C \\
Controle & 119,0 a A & 115,6 ab B & 110,1 c C & 108,8 b C & 101,8 b D \\
\hline
\end{tabular}

\begin{tabular}{|c|c|c|c|c|c|}
\hline \multirow{3}{*}{ Embalagens } & \multicolumn{5}{|c|}{ Frutos avaliados após comercialização simulada ${ }^{2}$} \\
\hline & \multicolumn{5}{|c|}{ Períodos de armazenamento (dias) } \\
\hline & 0 & 7 & 14 & 21 & 28 \\
\hline PPS & 116,0 a $\mathrm{A}$ & 114,6 a $\mathrm{A}$ & 114,5 a $\mathrm{A}$ & 112,8 a $\mathrm{A}$ & 111,6 \\
\hline PEBD & 116,0 a $\mathrm{A}$ & 113,4 a $\mathrm{A}$ & 113,5 a $\mathrm{A}$ & $110,2 \mathrm{a} A$ & 114,4 \\
\hline PBM & 116,0 a $\mathrm{A}$ & $111,2 \mathrm{ab} \mathrm{AB}$ & 106,6 b BC & 103,6 b C & $\cdots$ \\
\hline ENC & $116,0 \mathrm{a} A$ & 104,8 c B & 99,4 c B & 91,4 c C & -- \\
\hline Controle & $116,0 \mathrm{a} \mathrm{A}$ & 106,4 bc B & $102,8 \mathrm{bc} \mathrm{B}$ & 94,2 c C & $-\cdots$ \\
\hline
\end{tabular}

${ }^{x}$ Médias seguidas de mesma letra minúscula na coluna e maiúscula na linha não diferem entre si, pelo teste de Tukey ao nível de $5 \%$ de probabilidade.

${ }^{y} \mathrm{PPS}=$ filme poliolefinico com permeabilidade seletiva, $\mathrm{PEBD}=$ filme de polietileno de baixa densidade, PBM=filme $\mathrm{PEBD}$ com incorporação de mineral, $\mathrm{ENC}=$ filme poliolefínico termo-encolhível

${ }^{\mathrm{z}}$ Frutos mantidos a $25^{\circ} \mathrm{Ce} 70-80 \%$ UR, durante 3 dias, após cada período de armazenamento. 

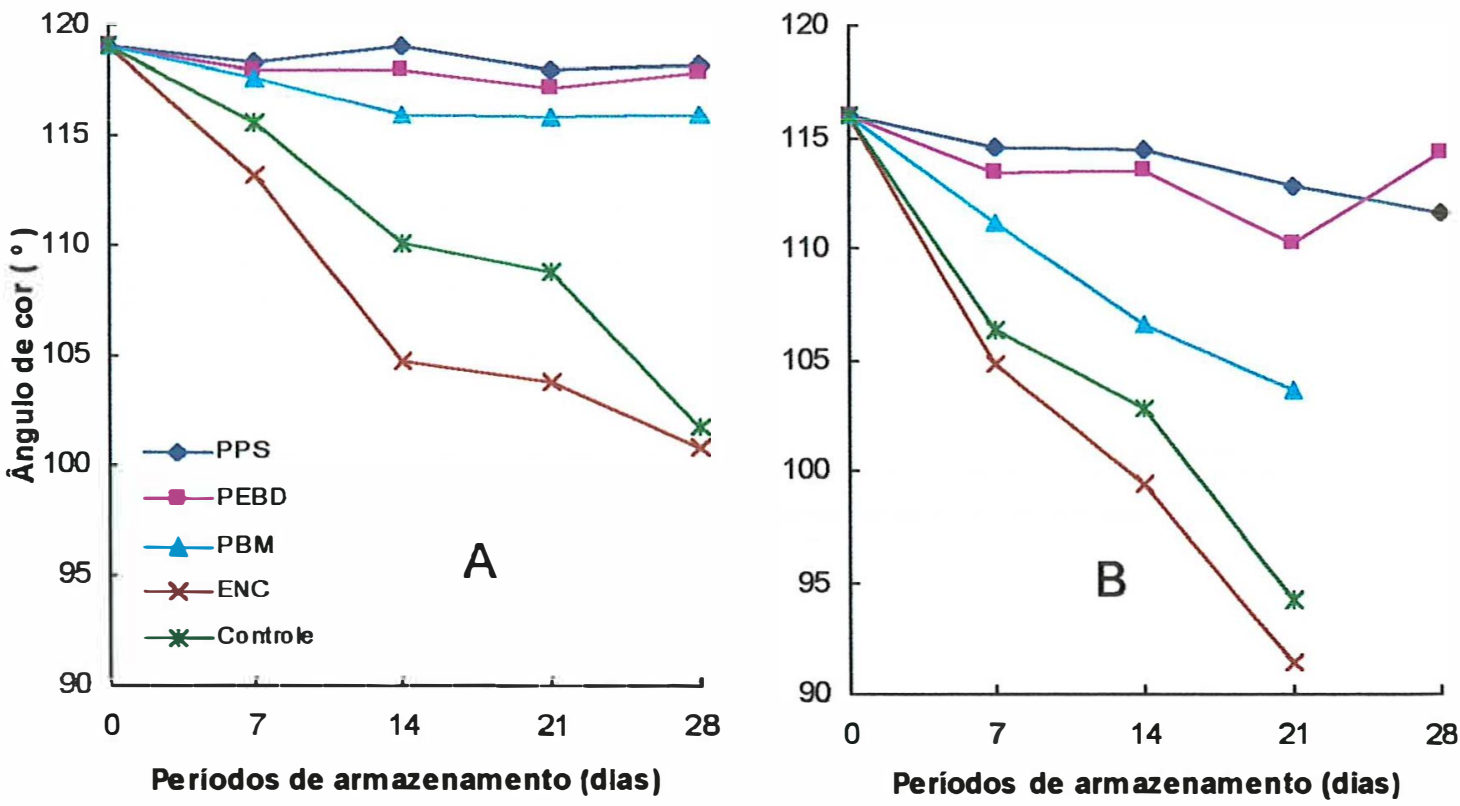

Figura 2. Influência de embalagens e períodos de armazenamento na coloração externa de goiabas 'Kumagai' armazenadas a $10^{\circ} \mathrm{C}$ e $85-90 \%$ UR, sendo (A) frutos avaliados imediatamente após retirados da câmara e (B) frutos avaliados após comercialização simulada.

$\mathrm{h}^{\circ}$ durante o armazenamento, ou seja, maior desenvolvimento da cor amarela, diferindo inclusive do Controle. Isto ocorreu, possivelmente, devido ao período de aquecimento ao qual os frutos foram submetidos durante o encolhimento do filme. Klein et al. (1990) e Lurie \& Klein (1990) também relataram a influência de tratamentos por aquecimento na diminuição no teor de clorofila da casca de maçãs e consequente perda da cor verde.

Os tratamentos PPS, PEBD e PBM foram eficientes na manutenção da coloração verde dos frutos durante o armazenamento refrigerado, não havendo diferença estatística para $\mathrm{h}^{\circ}$ entre os períodos de armazenamento e nem entre os materiais de embalagens.

Após a transferência dos frutos para condição ambiente, verificou-se manutenção nos valores de $\mathrm{h}^{\circ}$ para os tratamentos PPS e PEBD, ou seja, não ocorreu desenvolvimento da cor amarela nestes frutos, mesmo após 3 dias em condição ambiente, indicando ter havido alteração na fisiologia dos mesmos. Por outro lado, os frutos do tratamento PBM, que mantiveram a cor verde sob atmosfera modificada, desenvolveram a cor amarela normalmente. 
Ocorreu pequeno incremento no teor de SST entre as goiabas recém colhidas $(8,4$ ${ }^{\circ}$ Brix) e após 3 dias em temperatura ambiente $\left(8,8^{\circ} \mathrm{Brix}\right)$. Por outro lado, verificou-se decréscimo no teor desta variável com o aumento do tempo de armazenamento, praticamente em todos os tratamentos (Tabela 4 e Figura 3). Estes resultados estão de acordo com Pivetta et al. (1992) e Lima et al. (1998), que também verificaram diminuição no teor de SST durante a conservação de goiabas. Os frutos acondicionados no filme ENC apresentaram decréscimo mais acentuado no teor desta variável. É provável que o aquecimento tenha causado elevação na taxa respiratória e, por consequência, maior consumo de carboidratos em relação aos outros tratamentos. A influência da temperatura na elevação da taxa respiratória é evidenciada por muitos autores (Pantástico, 1975; Chitarra \& Chitarra, 1990; Kader, 1992a; Awad, 1993).

$\mathrm{O}$ teor de acidez dos frutos foi pouco influenciado pelos tratamentos (Tabela $5 \mathrm{e}$ Figura 4). Houve, de maneira geral, tendência de decréscimo na ATT com o aumento do tempo de armazenamento, o que também foi verificado por Vasquez-Ochoa \& ColinasLeon (1990), Pivetta et al. (1992), Mercado-Silva et al. (1998) e Lima et al. (1998). Wills et al. (1989) afirmaram que o teor de ácidos orgânicos normalmente decresce em frutos durante o amadurecimento, sendo esses convertidos em açúcares ou consumidos no processo respiratório, neste caso, atuando como fonte de reserva de energia.

A firmeza da polpa observada nos frutos recém colhidos foi de $3,13 \mathrm{~kg}$ e após 3 dias de amadurecimento sob condição ambiente foi de $2,77 \mathrm{~kg}$.

Verificou-se acentuada e crescente perda de firmeza nos tratamentos ENC, PBM e Controle, com o aumento no tempo de armazenamento, moderada perda no tratamento PPS e manutenção da firmeza no tratamento PEBD (Tabela 6 e Figura 5).

$\mathrm{O}$ tratamento ENC apresentou as maiores perdas na firmeza da polpa. Aos 14 dias, os frutos já encontravam-se excessivamente amolecidos, com resultado pior que o próprio Controle. É provável, que a elevada temperatura à qual os frutos ficaram expostos durante o encolhimento do filme, ainda que por poucos segundos, tenha causado algum dano fisiológico, o que promoveu elevação da taxa respiratória e conseqüente antecipação da senescência. 
Tabela 4. Influência de embalagens e períodos de armazenamento no teor de sólidos solúveis totais (SST) de goiabas 'Kumagai' armazenadas a $10^{\circ} \mathrm{C}$ e 85-90\% UR. ${ }^{\mathrm{x}}$

\begin{tabular}{|c|c|c|c|c|c|}
\hline \multirow{2}{*}{ Embalagens $\mathrm{y}^{\mathrm{y}}$} & \multicolumn{5}{|c|}{ Períodos de armazenamento (dias) $^{z}$} \\
\hline & 0 & 7 & 14 & 21 & 28 \\
\hline & $-----\cdot$ & - & SST $\left({ }^{\circ}\right.$ Brix $)$ & . & ---.- \\
\hline PPS & 8,80 a $\mathrm{A}$ & 8,20 a $\mathrm{A}$ & 9,18 a $\mathrm{A}$ & 8,62 a $A$ & 8,18 \\
\hline PEBD & 8,80 a $\mathrm{A}$ & 7,66 a $\mathrm{BC}$ & $8,36 \mathrm{ab} \mathrm{AB}$ & $7,32 \mathrm{~b} \mathrm{C}$ & 7,50 \\
\hline PBM & 8,80 a $\mathrm{A}$ & 7,98 a $\mathrm{AB}$ & 8,72 a $A B$ & 7,90 ab B & --- \\
\hline ENC & 8,80 a $\mathrm{A}$ & 8,34 a $A B$ & $7,56 \mathrm{~b} \quad \mathrm{BC}$ & 7,12 b C & --- \\
\hline Controle & 8,80 a $\mathrm{A}$ & 7,52 a $\mathrm{AC}$ & $8,32 \mathrm{ab} \quad \mathrm{AB}$ & $7,22 \mathrm{~b} \mathrm{C}$ & --- \\
\hline
\end{tabular}

${ }^{x}$ Médias seguidas de mesma letra minúscula na coluna e maiúscula na linha não diferem entre si, pelo teste de Tukey ao nível de $5 \%$ de probabilidade.

${ }^{y}$ PPS=filme poliolefinico com permeabilidade seletiva, $\mathrm{PEBD}=$ filme de polietileno de baixa densidade, $\mathrm{PBM}=$ filme $\mathrm{PEBD}$ com incorporação de mineral, $\mathrm{ENC}=$ filme poliolefinico termo-encolhível

${ }^{\mathrm{z}}$ Frutos mantidos a $25^{\circ} \mathrm{C}$ e $70-80 \%$ UR, durante 3 dias, após cada período de armazenamento.

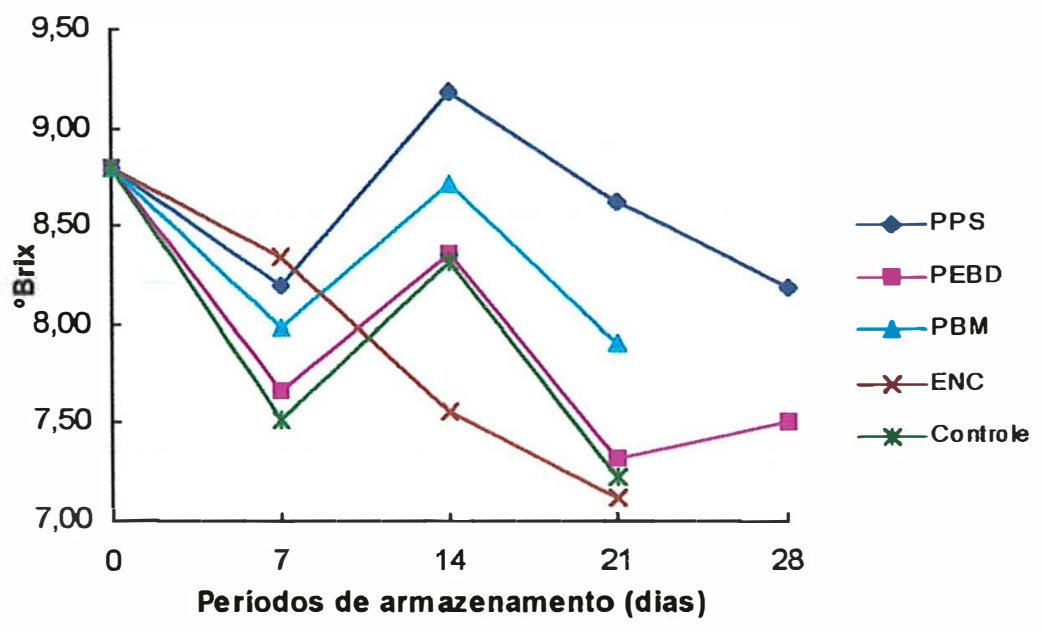

Figura 3. Influência de embalagens e períodos de armazenamento no teor de sólidos solúveis totais de goiabas 'Kumagai' armazenadas a $10^{\circ} \mathrm{C}$ e $85-90 \%$ UR, mais 3 dias a $25^{\circ} \mathrm{C}$ e $70-80 \% \mathrm{UR}$. 
Tabela 5. Influência de embalagens e períodos de armazenamento na acidez total titulável (ATT) de goiabas 'Kumagai' armazenadas a $10^{\circ} \mathrm{C}$ e $85-90 \%$ UR. ${ }^{\mathbf{x}}$

\begin{tabular}{ccccccc}
\hline \multirow{2}{*}{ Embalagens $^{y}$} & \multicolumn{6}{c}{ Períodos de armazenamento (dias) ${ }^{\mathrm{z}}$} \\
& 0 & 7 & 14 & 21 & Médias & 28 \\
\hline PPS & 0,68 & 0,68 & 0,70 & 0,65 & $0,68 \mathrm{ab}$ & 0,63 \\
PEBD & 0,68 & 0,67 & 0,69 & 0,64 & $0,67 \mathrm{ab}$ & 0,64 \\
PBM & 0,68 & 0,65 & 0,62 & 0,62 & $0,64 \mathrm{~b}$ & --- \\
ENC & 0,68 & 0,67 & 0,64 & 0,63 & $0,66 \mathrm{ab}$ & -- \\
Controle & 0,68 & 0,69 & 0,74 & 0,67 & $0,69 \mathrm{a}$ & -- \\
\hline Médias & $0,680 \mathrm{~A}$ & $0,674 \mathrm{AB}$ & $0,676 \mathrm{AB}$ & $0,643 \mathrm{~B}$ & & \\
\hline
\end{tabular}

${ }^{x}$ Médias seguidas de mesma letra minúscula na coluna e maiúscula na linha não diferem entre si, pelo teste de Tukey ao nível de $5 \%$ de probabilidade.

y PPS=filme poliolefinico com permeabilidade seletiva, $\mathrm{PEBD}=$ filme de polietileno de baixa densidade, $\mathrm{PBM}=$ filme $\mathrm{PEBD}$ com incorporação de mineral, $\mathrm{ENC}=$ filme poliolefinico termo-encolhível

${ }^{z}$ Frutos mantidos a $25^{\circ} \mathrm{C}$ e $70-80 \%$ UR, durante 3 dias, após cada período de armazenamento.

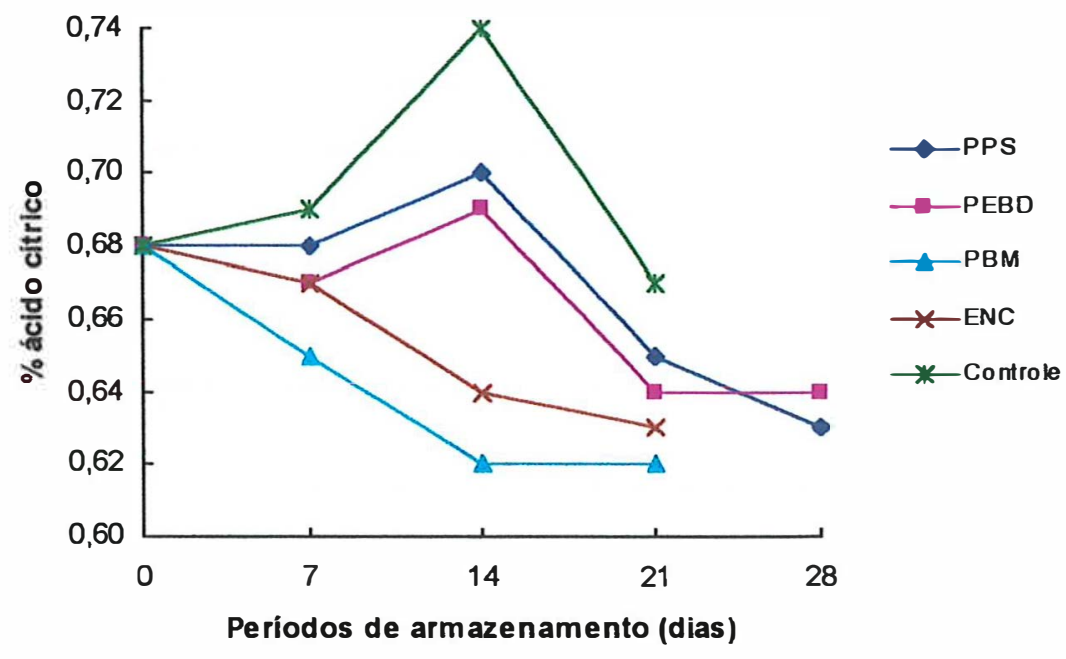

Figura 4. Influência de embalagens e períodos de armazenamento na acidez total titulável de goiabas 'Kumagai' armazenadas a $10^{\circ} \mathrm{C}$ e $85-90 \%$ UR, mais 3 dias a $25^{\circ} \mathrm{C}$ e $70-80 \%$ UR. 
Tabela 6. Influência de embalagens e períodos de armazenamento na firmeza da polpa de goiabas 'Kumagai' armazenadas a $10^{\circ} \mathrm{C}$ e $85-90 \%$ UR. ${ }^{x}$

\begin{tabular}{|c|c|c|c|c|c|}
\hline \multirow{2}{*}{ Embalagens $^{y}$} & \multicolumn{5}{|c|}{ Períodos de armazenamento (dias) ${ }^{\mathrm{z}}$} \\
\hline & 0 & 7 & 14 & 21 & 28 \\
\hline & & & & & \\
\hline PPS & 2,77 a $\mathrm{A}$ & $2,26 \mathrm{ab} B C$ & $2,58 \mathrm{~b} A B$ & 2,01 b C & 1,37 \\
\hline PERP & 2,73 a & 2,80 a & 3,34 ad & 2,44 c ${ }_{c d} B$ & 2,50 \\
\hline ENC & 2,77 a $\mathrm{A}$ & 1,83 b B & $0,89 \mathrm{~d} \mathrm{C}$ & $0,40 \mathrm{~d} \mathrm{D}$ & -- \\
\hline Controle & 2,77 a $\mathrm{A}$ & 2,12 b B & 1,39 с C & 0,74 c D & --- \\
\hline
\end{tabular}

${ }^{\mathrm{x}}$ Médias seguidas de mesma letra minúscula na coluna e maiúscula na linha não diferem entre si, pelo teste de Tukey ao nível de $5 \%$ de probabilidade.

${ }^{\gamma}$ PPS=filme poliolefinico com permeabilidade seletiva, $\mathrm{PEBD}=$ filme de polietileno de baixa densidade, PBM=filme PEBD com incorporação de mineral, ENC=filme poliolefínico termo-encolhível

${ }^{z}$ Frutos mantidos a $25^{\circ} \mathrm{C}$ e $70-80 \%$ UR, durante 3 dias, após cada período de armazenamento.

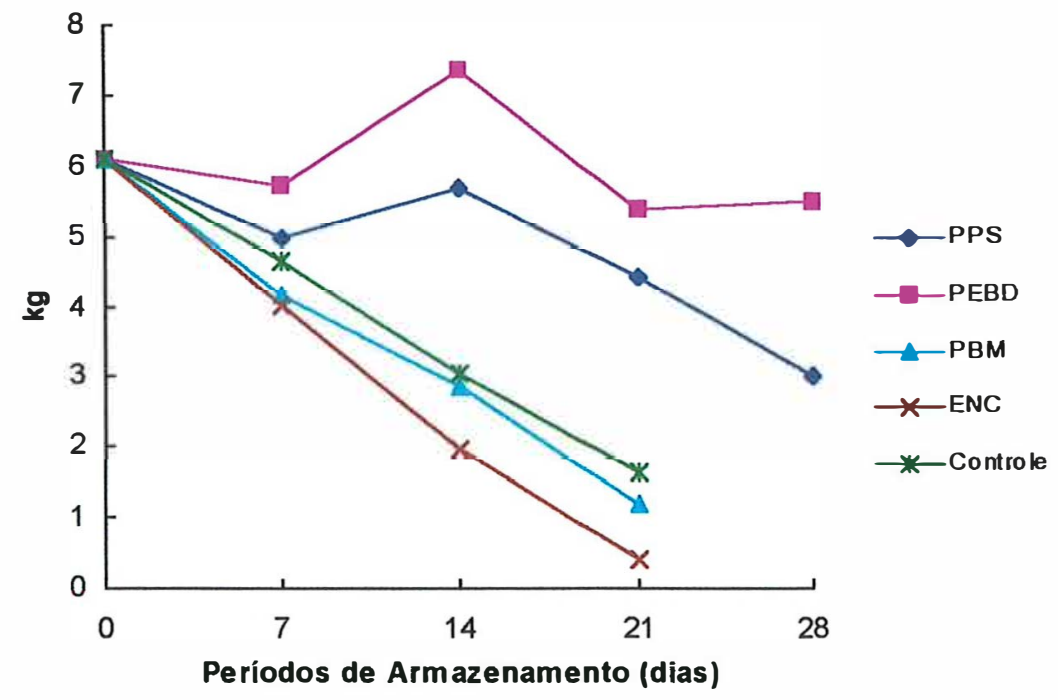

Figura 5. Influência de embalagens e períodos de armazenamento na firmeza da polpa de goiabas 'Kumagai' armazenadas a $10^{\circ} \mathrm{C}$ e $85-90 \%$ UR, mais 3 dias a $25^{\circ} \mathrm{C}$ e $70-80 \% \mathrm{UR}$. 
A modificação atmosférica proporcionada pelo filme PBM (ao redor de $2 \% \mathrm{O}_{2} \mathrm{e}$ $5 \% \mathrm{CO}_{2}$ ), parece não ter sido suficiente para manter a firmeza das goiabas, que amoleceram rapidamente quando transferidas para o ambiente. Por outro lado, as embalagens com PPS e PBM, nas quais ocorreu modificação bastante drástica da atmosfera, houve menor perda da firmeza ao longo do armazenamento.

A perda da firmeza está relacionada à degradação da parede celular pelas enzimas poligalacturonase e pectinametilesterase (Chitarra \& Chitarra, 1990; Kays, 1991). Esteves et al. (1984) verificaram redução nos teores de celulose, hemicelulose e pectina total, e aumento nos teores de pectina solúvel em goiabas, durante $\mathrm{o}$ amadurecimento. A atmosfera modificada retarda o amadurecimento, pois diminui a velocidade da perda de firmeza, bem como das demais variáveis relacionadas à senescência dos frutos (Kader, 1992b; Ali \& Lazan, 1997).

Verificou-se, de maneira geral, aumento no teor de ácido ascórbico com o progresso do amadurecimento das goiabas (Tabela 7 e Figura 6), concordando com as informações de literatura (Castro \& Sigrist, 1988; Seymour et al., 1993; Ali \& Lazan, 1997; Mercado-Silva et al., 1998). O teor de ácido ascórbico passou de $109 \mathrm{mg} .100 \mathrm{~g}^{-1}$ de polpa, nas frutas recém colhidas, para $137 \mathrm{mg} .100 \mathrm{~g}^{-1}$ após 3 dias de amadurecimento.

Nos frutos Controle verificou-se progressivo aumento no teor de vitamina $\mathrm{C}$ no decorrer do armazenamento,o que correspondeu à intensificação do amadurecimento. Comportamento semelhante foi verificado no tratamento ENC. Nos tratamentos PPS e PBM o teor de ácido ascórbico não foi influenciado pelo tempo de armazenamento. Por outro lado, os frutos embalados em PEBD perderam progressivamente a capacidade de sintetizar ácido ascórbico, mesmo após transferência para condição ambiente. Neste tratamento, o efeito foi mais intenso quanto maior o tempo de armazenamento. Possivelmente, o elevado teor de $\mathrm{CO}_{2}$ ao qual os frutos ficaram expostos no interior das embalagens, seja responsável por este distúrbio fisiológico.

Verificou-se, de maneira geral, uma elevação nos valores do índice de doença (ID) com o aumento do tempo de armazenamento (Tabela 8), o que já era esperado, em função do progresso no amadurecimento dos frutos e por conseqüência, maior suscetibilidade à ocorrência de podridões. 
Tabela 7. Influência de embalagens e períodos de armazenamento no teor de ácido ascórbico de goiabas 'Kumagai' armazenadas a $10^{\circ} \mathrm{C}$ e 85-90\% UR.

\begin{tabular}{|c|c|c|c|c|c|}
\hline \multirow{2}{*}{ Embalagens ${ }^{y}$} & \multicolumn{5}{|c|}{ Períodos de armazenamento (dias) ${ }^{\mathrm{Z}}$} \\
\hline & 0 & 7 & 14 & 21 & 28 \\
\hline \multicolumn{6}{|c|}{------ Ácido ascórbico (mg. $100 \mathrm{~g}^{-1}$ de polpa) } \\
\hline PPS & 137 a A & $151 \mathrm{aA}$ & $152 \mathrm{~b} \mathrm{~A}$ & 140 c A & 126,61 \\
\hline PEBD & 137 a A & $124 \mathrm{~b} \mathrm{AB}$ & $124 \mathrm{c} \mathrm{AB}$ & $112 \mathrm{~d} \mathrm{~B}$ & 117,56 \\
\hline PBM & 137 a A & 153 a $\mathrm{A}$ & $155 \mathrm{~b} \mathrm{~A}$ & $146 \mathrm{bc} \mathrm{A}$ & --- \\
\hline ENC & 137 a $B$ & 160 a A & $165 \mathrm{ab} A$ & $167 \mathrm{~b} \mathrm{~A}$ & $-\cdots$ \\
\hline Controle & 137 a $\mathrm{C}$ & 164 a B & 183 a $\mathrm{AB}$ & 191 a $\mathrm{A}$ & $-\cdots$ \\
\hline
\end{tabular}

${ }^{\mathrm{x}}$ Médias seguidas de mesma letra minúscula na coluna e maiúscula na linha não diferem entre si, pelo teste de Tukey ao nível de $5 \%$ de probabilidade.

y PPS=filme poliolefinico com permeabilidade seletiva, PEBD=filme de polietileno de baixa densidade, $\mathrm{PBM}=$ filme $\mathrm{PEBD}$ com incorporação de mineral, ENC=filme poliolefínico termo-encolhível

${ }^{\mathrm{z}}$ Frutos mantidos a $25^{\circ} \mathrm{C}$ e $70-80 \%$ UR, durante 3 dias, após cada período de armazenamento.

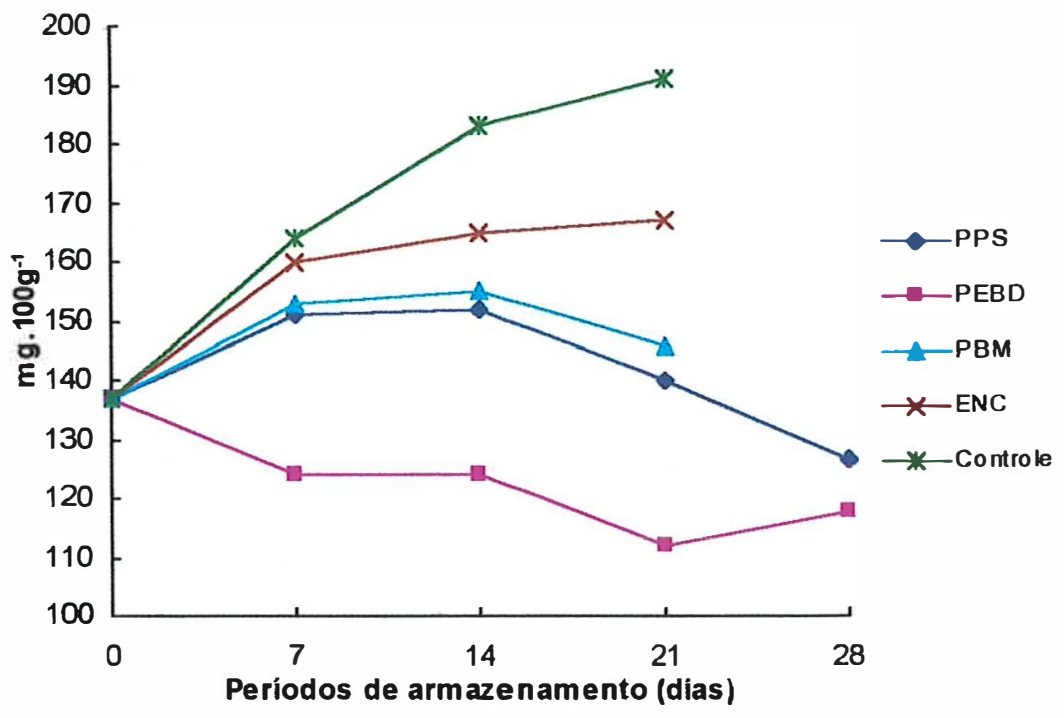

Figura 6. Influência de embalagens e períodos de armazenamento no teor de ácido ascórbico de goiabas 'Kumagai' armazenadas a $10^{\circ} \mathrm{C}$ e $85-90 \%$ UR, mais 3 dias a $25^{\circ} \mathrm{C}$ e $70-80 \% \mathrm{UR}$. 
Tabela 8. Influência de embalagens e períodos de armazenamento no índice de doença (ID) em goiabas 'Kumagai' armazenadas a $10^{\circ} \mathrm{C}$ e $85-90 \%$ UR. '

\begin{tabular}{|c|c|c|c|}
\hline \multicolumn{4}{|c|}{ Frutos avaliados imediatamente após retirados da câmara } \\
\hline \multirow{2}{*}{ Tratamentos ${ }^{y}$} & \multicolumn{3}{|c|}{ Períodos de armazenamento (dias) } \\
\hline & 14 & 21 & 28 \\
\hline & & -- ID --. & 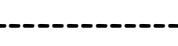 \\
\hline PPS & 0,0 a $\mathrm{A}$ & 0,0 a $A$ & $0,2 \mathrm{~b} \mathrm{~A}$ \\
\hline PEBD & 0,0 a $A$ & 0,4 a $A$ & $0,4 \mathrm{~b} \mathrm{~A}$ \\
\hline PBM & 0,0 a B & 0,0 a $B$ & 1,8 a $\mathrm{A}$ \\
\hline ENC & 0,0 a $\mathrm{C}$ & 0,6 a $B$ & 2,4 a $A$ \\
\hline \multirow[t]{2}{*}{ Controle } & $0,0 \mathrm{a} \mathrm{B}$ & 0,0 a B & 2,6 a A \\
\hline & \multicolumn{3}{|c|}{ Frutos avaliados após comercialização simulada ${ }^{z}$} \\
\hline \multirow{2}{*}{ Tratamentos } & \multicolumn{3}{|c|}{ Períodos de armazenamento (dias) } \\
\hline & 14 & 21 & 28 \\
\hline & & --- ID --. & ------- \\
\hline PPS & 0,2 a B & $2,0 \quad \mathrm{~b} \quad \mathrm{~A}$ & $2,6 \mathrm{~d} A$ \\
\hline PEBD & 0,8 a B & $2,7 \mathrm{ab} \mathrm{A}$ & $3,3 \mathrm{~cd} A$ \\
\hline PBM & 0,6 a B & $3,2 \mathrm{ab} \mathrm{A}$ & 4,4 bc $\mathrm{A}$ \\
\hline ENC & 0,8 a $\mathrm{C}$ & 4,2 a $B$ & 7,0 a $A$ \\
\hline Controle & 0,6 a $\mathrm{C}$ & $3,5 \mathrm{ab} \mathrm{B}$ & $6,0 \mathrm{ab} \mathrm{A}$ \\
\hline
\end{tabular}

${ }^{x}$ Médias seguidas de mesma letra minúscula na coluna e maiúscula na linha não diferem entre si, pelo teste de Tukey ao nivel de $\mathbf{5 \%}$ de probabilidade.

${ }^{y} \mathrm{PPS}=$ filme poliolefinico com permeabilidade seletiva, $\mathrm{PEBD}=$ filme de polietileno de baixa densidade, PBM=filme PEBD com incorporação de mineral, $E N C=$ filme poliolefinico terno-encolhível

${ }^{z}$ Frutos mantidos a $25^{\circ} \mathrm{C}$ e $70-80 \%$ UR, durante 3 dias, após cada período de armazenamento.

Os frutos acondicionados ENC apresentaram o maior ID, seguidos pelo Controle e PBM. O melhor controle das doenças foi verificado nas embalagens PPS e PEBD, cujos resultados não diferiram estatisticamente entre si.

Aos 14 dias sob refrigeração não havia frutos com lesão. Após manutenção em condição ambiente durante 3 dias, verificaram-se princípios de lesões em diversos frutos (ID $=0,2$ a 0,8 ). As lesões eram causadas, principalmente, por fungos dos gêneros Colletotrichum, Lasiodiplodia e Pestalotiopsis. 
Aos 21 dias sob refrigeração verificaram-se baixos valores de ID. Porém, após manutenção sob condição ambiente, ocorreu significativa elevação neste índice. Apenas nas embalagens de PPS o ID manteve-se relativamente baixo. Possivelmente, um menor período de comercialização simulada ou comercialização sob refrigeração, poderia contribuir para a diminuição nos valores deste índice.

Aos 28 dias sob refrigeração, apenas os tratamentos PPS e PEBD apresentaram baixos valores de ID e, após comercialização simulada, apenas o PPS.

As embalagens foram eficientes em evitar a perda de matéria fresca dos frutos durante o armazenamento, a qual manteve-se abaixo de $1 \%$ nos frutos embalados e chegou a 5,5\% naqueles do Controle (Figura 7). Durante a comercialização simulada a perda de matéria fresca manteve-se ao redor de $2 \%$, independentemente do tratamento, o que era de se esperar, pois, nesta fase as embalagens foram retiradas e, normalmente não há efeito residual da atmosfera modificada sobre a perda de matéria fresca.

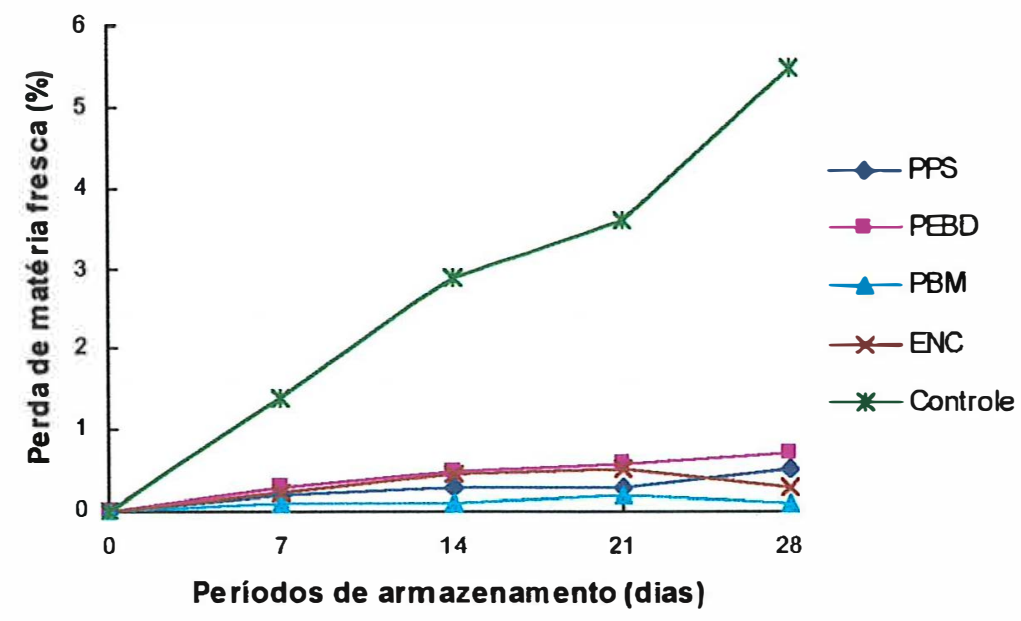

Figura 7. Influência de embalagens e periodos de armazenamento na perda de matéria fresca de goiabas 'Kumagai' armazenadas a $10^{\circ} \mathrm{C}$ e 85-90\% UR.

A perda de matéria fresca dos frutos é provocada pela perda de água em forma de vapor, pelo processo de transpiração, em conseqüência do déficit de pressão de vapor (DPV) entre os tecidos internos dos frutos e o ambiente (Woods, 1990). O DPV é tanto maior quanto mais alta a temperatura e/ou mais baixa a umidade relativa do ar. A 
utilização de filmes plásticos, associada com a refrigeração, promove aumento da umidade relativa ao redor dos frutos o que reduz o DPV e, consequentemente, a transpiração.

Os produtos vegetais são metabolicamente ativos após a colheita e a manutenção de sua atividade é fundamental para a qualidade. Para ampliar sua vida pós-colheita através de atmosfera modificada, deve-se manter o nível mínimo de seu metabolismo básico (Gorris \& Peppelenbos, 1992). A composição gasosa da atmosfera no interior da embalagem é resultado da atmosfera inicial, da troca de gases através da embalagem e da respiração do produto durante o período de armazenamento. Desta forma, a atmosfera no interior da embalagem sofre modificação, até que seja alcançado o equilíbrio entre a permeação e o gás consumido ou produzido (Zagory \& Kader, 1988; Gorris \& Pepplenbos, 1992).

$O$ filme PEBD utilizado neste experimento não atendeu às necessidades de conservação das goiabas. Por ser muito pouco permeável aos gases, provocou anaerobiose e elevada concentração de gás carbônico poucos dias após o fechamento das embalagens. Apesar da manutenção das características dos frutos (cor, firmeza e pouca incidência de podridões), verificou-se a presença lesões escuras na casca, a partir dos 21 dias de estocagem, além da ocorrência de distúrbios fisiológicos. Portanto, o filme de polietileno de baixa densidade com espessura de 69 $\mu \mathrm{m}$ (PEBD) não apresenta potencial de uso como material de embalagem para goiabas.

O filme PPS foi bastante eficiente na manutenção da qualidade das goiabas. Embora tenha mantido a concentração de oxigênio abaixo de $1 \%$, provocou apenas alterações fisiológicas discretas, com pequeno prejuízo no amadurecimento. As goiabas acondicionadas nestas embalagens apresentaram-se comercializáveis mesmo quando armazenadas por 28 dias.

Os frutos embalados em PBM mantiveram a qualidade enquanto mantidos sob refrigeração e atmosfera modificada, de maneira semelhante àqueles embalados em PPS. Entretanto, amadureceram rapidamente após transferência para o ambiente. A perda da firmeza e a incidência de podridões, verificadas após 3 dias a $25^{\circ} \mathrm{C}$, limitam o período de armazenamento em 14 dias. 
As embalagens com filme ENC resultaram em excelente apresentação visual do produto, devido ao brilho característico do material de embalagem e por ficar esticado sobre os frutos, prendendo-os na bandeja. Entretanto, este tratamento acelerou a senescência dos frutos em relação ao Controle, o que foi comprovado em todas as variáveis analisadas. Este comportamento certamente foi induzido pela alta temperatura necessária para o encolhimento do filme no túnel de ar quente. Embora o tempo de exposição à alta temperatura tenha sido curto (13 segundos), parece ter sido suficiente para acelerar o metabolismo da fiuta.

\section{CONCLUSÕES}

Para goiabas 'Kumagai' submetidas a diferentes materiais de embalagem e armazenadas a $10^{\circ} \mathrm{C}$ e $85-90 \%$ UR $\left(+3\right.$ dias a $25^{\circ} \mathrm{C}$ e $70-80 \%$ UR), podem ser feitas as seguintes conclusões:

- Filme de polietileno de baixa densidade com $69 \mu \mathrm{m}$ de espessura apresenta $\mathrm{TPO}_{2}$ de $2.115 \mathrm{~cm}^{3} \cdot \mathrm{m}^{-2} \cdot \mathrm{dia}^{-1}$ e $\mathrm{TPCO}_{2}$ de $4.434 \mathrm{~cm}^{3} \cdot \mathrm{m}^{-2} \cdot \mathrm{dia}^{-1} \mathrm{e}$, induz anaerobiose e elevada concentração de gás carbônico no interior das embalagens. Os frutos acondicionados nestas embalagens apresentam distúrbios fisiológicos e não amadurecem normalmente após transferência para o ambiente.

- Filme poliolefínico termo-encolhível com $15 \mu \mathrm{m}$ de espessura, apresenta $\mathrm{TPO}_{2}$ de $6.366 \mathrm{~cm}^{3} \cdot \mathrm{m}^{-2} \cdot \mathrm{dia}^{-1}$ e $\mathrm{TPCO}_{2}$ de $34.864 \mathrm{~cm}^{3} \cdot \mathrm{m}^{-2} \cdot \mathrm{dia}^{-1}$. Este filme proporciona atmosfera de equilíbrio com $19 \%$ de $\mathrm{O}_{2}$ e $2 \%$ de $\mathrm{CO}_{2}$. Os frutos acondicionados nestas embalagens apresentam rápida senescência e período de conservação menor que frutos sem embalagem.

- Filme de polietileno de baixa densidade com incorporação de mineral e $24 \mu \mathrm{m}$ de espessura, apresenta $\mathrm{TPO}_{2}$ de $4.918 \mathrm{~cm}^{3} \cdot \mathrm{m}^{-2} \cdot \mathrm{dia}^{-1}$ e $\mathrm{TPCO}_{2}$ de $32.937 \mathrm{~cm}^{3} \cdot \mathrm{m}^{-2} \cdot \mathrm{dia}^{-1}$. 
Este filme proporciona atmosfera de equilíbrio com $3 \%$ de $\mathrm{O}_{2}$ e $4,5 \%$ de $\mathrm{CO}_{2}$, no interior das embalagens. Os frutos acondicionados nestas embalagens podem ser conservados por até 14 dias, mantendo a coloração da casca e firmeza da polpa adequadas para consumo.

- Filme poliolefínico com permeabilidade seletiva e $35 \mu \mathrm{m}$ de espessura, apresenta $\mathrm{TPO}_{2}$ de $6.827 \mathrm{~cm}^{3} \cdot \mathrm{m}^{-2} \cdot \mathrm{dia}^{-1}$ e $\mathrm{TPCO}_{2}$ de $21.969 \mathrm{~cm}^{3} \cdot \mathrm{m}^{-2} \cdot \mathrm{dia}^{-1}$. Este filme proporciona atmosfera de equilíbrio com $0,5 \%$ de $\mathrm{O}_{2}$ e $4,5 \%$ de $\mathrm{CO}_{2}$, no interior das embalagens. Os frutos acondicionados nestas embalagens podem ser conservados por até 28 dias, mantendo suas características físico-químicas.

\section{REFERÊNCIAS BIBLIOGRÁFICAS}

ADSULE, P.G.; TANDON, D.K. The assesment of LDPE bags for enhancing self life of guava. Indian Food Packer, v.37, n.3, p.82-87, 1983.

AKAMINE, E.K.; GOO, T. Repiration and ethylene production in fruits of species and cultivars of Psidium and species of Eugenia. Journal of the American Society for Horticultural Science, v.104, n.5, p.632-635, 1979.

ALI, Z.M; LAZAN, H. Guava. In: MITRA, S.K. Postharvest physiology and storage of tropical and subtropical fruits. Wallingford: CAB International, 1997. cap.6, p.145-165.

AUGUSTIN, M.A.; AZIZAH, O. Post-harvest storage of guava (Psidium guajava L.) var. Taiwan. Pertanika, v.11, n.1, p.45-50, 1988.

AWAD, M. Fisiologia pós-colheita de frutos. São Paulo: Nobel, 1993. 114p.

BROWN, B.I.; WILLS, R.B.H. Post-harvest changes in guava fruit of different maturing. Scientia Horticulturae., v.19, n.3/4, p.237-243, 1983. 
CARRARO, A.F.; CUNHA, M.M. Manual de exportação de frutas. Brasília: FRUPEX; IICA, 1994. 254p.

CARVALHO, C.R.L.; MANTOVANI, D.M.B.; CARVALhO, P.R.N.; MORAES, R.M.M. Análises químicas de alimentos. Campinas: ITAL, 1990. 121p. (Manual Técnico)

CARVALHO, V.D. Qualidade e conservação pós-colheita de goiabas. Informe Agropecuário, v. 17, n.179, p.48-54, 1994.

CASTRO, J. V.; SIGRIST, J. M. M. Matéria-prima. In: MEDINA, J.C.; CASTRO,J.V.; SIGRIST, J.M.M.S.; MARTIN, Z.J.; KATO, K.; MAIA, M.L.; GARCIA, A.E.B.; LEITE, R.S.S.F. Goiaba: cultura, matéria-prima, processamento e aspectos econômicos. 2.ed. Campinas: ITAL, 1988. cap. 2, p. 121-140. (Série Frutas Tropicais, 6)

CHITARRA, M.I.F.; CHITARRA, A.B. Pós-colheita de frutas e hortaliças: fisiologia e manuseio. Lavras: ESAL, FAEPE, 1990. 320p.

COMBRINK, J.C.; KOCK,S.L.; VAN EEDEN, C. Effect of post-harvest treatment and packaging on the keeping quality of fresh guava fruit. Acta Horticulturae, n.275, p.639-645, 1990.

CRYOVAC DIVISION. New controlled permeability produce packaging preserves flavors and extends shelf life. Ontario, 1994. 15p.

DURIGAN, J.F. Colheita, conservação e embalagens. In: SIMPÓSIO BRASILEIRO SOBRE A CULTURA DA GOIABEIRA, 1., Jaboticabal, 1995. Anais. Jaboticabal: FUNEP, 1997. p.149-158.

ESTEVES, M.T.C; CARVALHO, V.D.; CHITARRA, M.I.F.; ChITARRA, A.B.; PAULA, M.B. Caracterização dos frutos de seis cultivares de goiabeiras (Psidium guajava L.) na maturação. I. Determinações fisicas e químicas. In: CONGRESSO 
BRASILEIRO DE FRUTICULTURA, 7., Florianópolis, 1983. Anais. Florianópolis: SBF; EMPASC, 1984. v.2, p.477-489.

FNP CONSULTORIA \& COMÉRCIO. Agrianual 97: anuário estatístico da agricultura brasileira. São Paulo, 1997. 435p.

FNP CONSULTORIA \& COMÉRCIO. Agrianual 99: anuário estatístico da agricultura brasileira. São Paulo, 1999. 521p.

FREY, T.D. High gas permeability structures for fresh-cut produce packaging. In: MAPACK'95, Anaheim, 1995. Proceedings. Herndon: Institute of Packaging Professionals, 1995. p.23-25.

GASPAR, J.W.; COUTO, F.A.A.; SALOMÃO, L.C.; FINGER, L.L.; CARDOSO, A.A. Effect of low temperature and plastic films on post-harvest life of guava (Psidium guajava L). Acta Horticulturae, n.452, p.107-114, 1997.

GORRIS, L.G.M.; PEPPELENBOS, H.W. Modified Atmosphere and vacuum packaging to extend the shelf life of respiring food products. HortTechnology, v.2, n.3, p.303-309, 1992.

HARDENBURG, R.E.; WATADA, A.E.; WANG, C.Y. The commercial storage of fruits, vegetables, and florist, and nursery stocks. Washington: USDA, 1986. 130p. (USDA. Agriculture Handbook, 66)

KADER, A.A. Biochemical and physiological basis for effects of controlled and modified atmospheres on fruits and vegetables. Food Technology, v.40, n.5, p.99104. 1986.

KADER, A.A. Postharvest biology and technology: an overview. In: KADER, A.A.; KASMIRE, R.F.; MITCHELL F.G.; REID, M.S.; SOMMER, N.F.; THOMPSON, J.F. Postharvest technology of horticultural crops. Oakland: University of California, 1992a. cap.2, p.3-7. 
KADER, A.A. Modified atmospheres and low-pressure systems during transport and storage. In: KADER, A.A.; KASMIRE, R.F.; MITCHELL F.G.; REID, M.S.; SOMMER, N.F.; THOMPSON, J.F. Postharvest technology of horticultural crops. Oakland: University of California, 1992b. cap.11, p.58-64.

KAYS, S.J. Postharvest physiology of perishable plant products. New York: AVI Publ., 1991. 526p.

KHEDKAR, D.M.; ANSARWADKAR, K.W.; DABHADE, R.S.; BALLAL, A.L. Extension of storage life of guava var. L-49. Indian Food Packer, v.36, n.2, p.49$52,1982$.

KLEIN, J.D.; LURIE, S.; BEN-AIRE, R. Quality and cell wall components of 'Anna' and 'Granny Smith' aplles treated with heat, calcium and ethylene. Journal of the American Society for Horticultural Science, v.115, n.6, p. 954-958, 1990.

LEE, D.S.; HAGGAR, P.E.; YAM, K.L. Application of ceramic-filled polymeric films for packaging fresh produce. Packaging Technology and Science, v. 5, n. 1, p.2730, 1992.

LIMA, M.A.; DURIGAN, J.F.; TOSTES, D.R.D. Avaliação do comportamento respiratório de goiabas 'Pedro Sato' e a influência de diferentes embalagens na sua conservação sob refrigeração (compact disc). In: CONGRESSO BRASILEIRO DE CIÊNCIA E TECNOLOGIA DE ALIMENTOS, 16., Rio de Janeiro, 1998. Anais. Rio de Janeiro: SBCTA, 1998.

LURIE, S.; KLEIN, J.D. Heat treatments of ripening apples: diferential effects on physiology na biochemistry. Physiologia Plantarum, v.78, n.2, p.181-186, 1990.

McGUIRRE, R.G. Reporting of objective color measurents. HortScience, v.27, n.12, p.1254-1255, 1992. 
MERCADO-SILVA, E; BENITO-BAUTISTA, P.; GARCIA-VELASCO, M.A. Fruit development, harvest index and ripening changes of guavas produced in central Mexico. Postharvest Biology and Technology, v.13, n.2, p.143-150, 1998.

MONZINI, A.; GORINI, F.L. Controlled atmosphere storage of citrus, grapes and others fruit. Freddo, v.27, n.6, p.27-31, 1973.

OLIVEIRA, L.M.; ALVES, R.M.V.; SARANTÓPOUlOS, C.I.G.L., PADUlA, M.; GARCIA, E.E.C.; COLTRO, L. Ensaios para avaliação de embalagens plásticas flexíveis. Campinas: ITAL, CETEA, 1996. 219p.

OLIVEIRA, M.A.; CEREDA, M.P. Determinação da curva de respiração na póscolheita dos frutos de goiaba híbrida (branca) (Psidium guajava) variedade Kumagai. In CONGRESSO BRASILEIRO DE FRUTICULTURA, 14., Curitiba, 1996. Resumos. Londrina: IAPAR, 1996. p.239.

PANTÁSTICO, E.B. Postharvest physiology, handling and utilization of tropical an subtropical fruits an vegetables. Westport: AVI Publ., 1975. 560p.

PARO, R.M.; KANESIRO, M.A.B.; JERÔNIMO, E.M.; TOSTES, D.R.D. Conservação pós-colheita de frutos de goiabeira (Psidium guajava $\mathrm{L}$ ), empregando-se tratamento com cera, embalagens plásticas, em associação com armazenamento refrigerado. In: CONGRESSO BRASILEIRO DE FRUTICULTURA, 14., Curitiba, 1996. Resumos. Londrina: IAPAR, 1996. p.238.

PIVETTA, K.F.L.; DURIGAN, J.F.; PEREIRA, F.M. Efeito de dois tipos de cera na conservação pós-colheita de frutos de goiabeira (Psidium guajava L.). Revista Brasileira de Fruticultura, v.14, n.3, p.241-243, 1992.

PIZA Jr., C.T.; KAVATI, R. A cultura da goiabeira de mesa. Campinas: CATI, 1994. 28p. (CATI. Boletim Técnico, 219) 
PROCTOR, F.J. The European Community market for tropical fruit and factors limiting growth. Acta Horticulturae, n.269, p.29-39, 1990.

SARANTÓPOULOS, C.I.G.L.; ALVES, R.M.V.; OLIVEIRA, L.M.; GOMES, T.C. Embalagens com atmosfera modificada. Campinas: ITAL, CETEA, 1996. 114p.

SEYMOUR, G.B.; TAYLOR, J.E.; TUCKER,G.A. Biochemistry of fruit ripening. London: Chapman \& Hall, 1993. 454p.

SINGH, B.P.; SINGH, H.K.; CHAUAN, K.S.; Effect of post-harvest calcium treatments on the storage life of guava fruits. Indian Journal of Agricultural Science, v.51, n.1, p.44-47, 1981.

SINGH, R.V.; JOSHI, M.C.; RAM, H.B.; BISHT, N.S. Effect of wax coating and prepackaging on the storage behavior of guava cv. allahabad safeda. Indian Food Packer, v.38, n.6, p.80-85, 1984.

TANDON, D.K.; ADSULE.P.G;; KALRA, S.K. Effect of certain post-harvest treatments on the shelf life of guava fruits. Indian Journal of Horticulture, v.41, n.1, p.88-92, 1984 .

VASQUEZ-OCHOA, R.J.; COLINAS-LEON, M.T. Changes in guavas of three maturity stages in response to temperture and relative humidy. HortScience, v.25, n. 1, p.86-87, 1990.

WILLS, R.B.H.; McGLASSON, W.B.; GRAHAM, D.; LEE, T.H.; HALL, E.G. Postharvest: an introduction to the physiology and handling of fruit and vegetables. 3.ed. New York: AVI Publ., 1989. 174p.

WOODS, J. L. Moisture loss from fruits and vegetables. Postharvest News and Information, v.1, n.3, p.195-199, 1990. 
YAM, K.L.; PAIK, J.S.; LAI, C.C. Packaging part III: Materials. In: HUI, Y.H. (Ed.) Encyclopedia of food science and technology. Chichester: John Wiley, 1992. v.3, p.1978-1982.

ZAGORY, D.; KADER, A.A. Modified atmosfere packaging of fresh produce. Food Technology, v.42, n.9, p.70-77, 1988. 
5. CARACTERÍSTICAS SENSORIAIS DE GOIABAS 'KUMAGaI' SUBMETDAS A DIFERENTES MATERIAIS DE EMBALAGEM E ARMAZENAMENTO REFRIGERADO 


\section{CARACTERÍSTICAS SENSORIAIS DE GOIABAS 'KUMAGAI' SUBMETIDAS A DIFERENTES MATERIAIS DE EMBALAGEM E ARMAZENAMENTO REFRIGERADO}

Resumo: Goiabas da variedade Kumagai foram acondicionadas em diversos materiais de embalagem e armazenadas a $10 \pm 1^{\circ} \mathrm{C}$ e $85-90 \%$ de UR, durante $7,14,21$ e 28 dias, seguidos de 3 dias de comercialização simulada a $25 \pm 1{ }^{\circ} \mathrm{C}$ e $70-80 \%$ UR. Os materiais de embalagem utilizados foram: filme poliolefinico com permeabilidade seletiva (PPS), filme de polietileno de baixa densidade (PEBD), filme de PEBD com incorporação de mineral (PBM) e filme poliolefínico termo-encolhível (ENC). Goiabas sem embalagem foram utilizadas como Controle. Foram determinadas as composições gasosas no interior das embalagens e as características sensoriais das goiabas (coloração da casca, textura da polpa, odor e sabor estranhos e qualidade global). O filme PEBD induziu anaerobiose e elevada concentração de gás carbônico no interior das embalagens, alterações fisiológicas que impediram o amadurecimento normal dos frutos, além de alterações no odor e no sabor dos mesmos. O filme ENC apresentou baixa capacidade de modificar a atmosfera no interior das embalagens e os frutos sofreram rápida perda da cor verde, da textura e da qualidade global. O filme PBM proporcionou atmosfera de equilíbrio com $3 \%$ de $\mathrm{O}_{2}$ e $4,5 \%$ de $\mathrm{CO}_{2}$ no interior das embalagens e manutenção das características sensoriais dos frutos por 14 dias. O filme PPS proporcionou atmosfera de equilíbrio com $0,5 \%$ de $\mathrm{O}_{2}$ e $4,5 \%$ de $\mathrm{CO}_{2}$ e, foi eficiente na manutenção da cor verde da casca, textura da polpa e qualidade global dos frutos, até 28 dias de armazenamento.

Palavras-chave: Psidium guajava, pós-colheita, conservação, atmosfera modificada 


\section{SENSORIAL CHARACTERISTICS OF 'KUMAGAI' GUAVAS SUBMITTED TO DIFFERENT PACKAGING MATERIALS AND COLD STORAGE}

Summary: Guavas cv. Kumagai were wrapped in several packaging materials and stored at $10 \pm 1^{\circ} \mathrm{C}$ and $85-90 \% \mathrm{RH}$ during $7,14,21$ and 28 days, followed by 3 days at $25 \pm 1{ }^{\circ} \mathrm{C}$ and $70-80 \% \mathrm{RH}$ to simulate commercial handling conditions. The packaging materials used were: polyolephinic film with selective permeability (PSP), low density polyethylene film (LDP), LDP film with mineral incorporation (LDPM) and shrink

polyolephinic film (SHR). Guavas without packaging were used as Control. The concentrations of $\mathrm{O}_{2}$ and $\mathrm{CO}_{2}$ inside the packagings and the sensorial characteristics of the guavas (skin color, pulp texture, off-flavor and overall quality) were evaluated. The LDP film promoted anaerobic atmosphere and high $\mathrm{CO}_{2}$ concentration. Furthermore, it induced both off-flavor and physiological disorders in the fruits which caused abnormal ripening. The SHR film presented low capacity to modify the atmosphere inside the packagings and the fruits lost rapidly the skin green color, pulp texture and overall quality. The LDPM film provided atmosphere composition of $3 \%$ of $\mathrm{O}_{2}$ and $4.5 \%$ of $\mathrm{CO}_{2}$ and the fruits kept their sensorial characteristics for 14 days. The PSP film provided atmosphere composition of $0.5 \%$ of $\mathrm{O}_{2}$ and $4.5 \%$ of $\mathrm{CO}_{2}$. This atmosphere was efficient in keeping the skin green color, pulp texture and overall quality of the fruits for 28 days. Key words: Psidium guajava, post-harvest, storage life, modified atmosphere

\section{INTRODUÇÃO}

A goiabeira (Psidium guajava L.) é originária da América do Sul e encontra-se atualmente muito difundida por todas as regiões tropicais e subtropicais do mundo. Destaca-se entre as frutas tropicais por apresentar elevado valor nutritivo e boas características organolépticas, tornando-a muito adequada para o consumo in natura (Carvalho, 1994). Entretanto, a goiaba constitui-se numa fruta altamente perecível, o que causa elevadas perdas em pós-colheita, tanto em termos de quantidade quanto de qualidade. 
O emprego de refrigeração associado à atmosfera modificada tem sido importante recurso na conservação de produtos hortícolas. Em frutos climatéricos, como a goiaba (Akamine \& Goo, 1979; Singh et al. 1981; Brown \& Wills, 1983; Lima et al., 1998; Mercado-Silva et al., 1998), o abaixamento da temperatura retarda o pico climatérico e, por consequência, o amadurecimento (Hardenburg et al., 1986; Kader, 1992a). A temperatura recomendada para o armazenamento de goiabas tem sido entre 8 e $10^{\circ} \mathrm{C}$ (Castro \& Sigrist, 1988; Carraro \& Cunha, 1994; Durigan, 1997).

A diminuição do nível de $\mathrm{O}_{2}$ ao redor de frutos e hortaliças reduz a taxa respiratória (Kader, 1986; Wills et al., 1989) e a produção de etileno, bem como a sensibilidade do produto à ação do mesmo (Burg \& Burg, 1967). Elevadas concentrações de $\mathrm{CO}_{2}$ também reduzem a taxa respiratória de frutos e hortaliças e podem diminuir, promover ou não causar efeito na produção de etileno, dependendo do produto e da concentração (Kader, 1986). Os níveis críticos de $\mathrm{O}_{2}$ e de $\mathrm{CO}_{2}$ tolerados pelos vegetais variam principalmente em função do produto e do tempo de exposição (Kader, 1986; Wills et al., 1989).

Muitos são os trabalhos que evidenciam a eficiência do uso de embalagens plásticas na conservação de goiabas, diminuindo a perda de matéria fresca e retardando o a madurecimento (Yagi, 1976; Khedkar et al. 1982; Adsule \& Tandon, 1983; Singh et al., 1984; Tandon et al., 1984; Augustin \& Azizah, 1988).

Combrink et al. (1990) obtiveram beneficios no armazenamento de goiabas em embalagem de polietileno selada durante 2 semanas, sendo que os melhores resultados foram obtidos em filmes impregnados com mineral. Paro et al. (1996), associando o uso de cera, embalagem de polietileno e refrigeração $\left(9^{\circ} \mathrm{C}\right)$, conservaram goiabas 'Paluma' por 29 dias. De maneira semelhante, Gaspar et al. (1997) preservaram goiabas 'Kumagai' por 3 semanas a $8^{\circ} \mathrm{C}$, utilizando embalagem de polietileno selada.

A aplicação de métodos de conservação de frutas e hortaliças, visa basicamente a manutenção da qualidade. $\mathrm{O}$ conceito de qualidade é bastante abrangente e subjetivo, porém, considerando as exigências do consumidor, os principais atributos de qualidade são aparência, cor, textura, sabor e odor. Estes componentes da qualidade são classificados como atributos sensoriais e não podem ser avaliados pelos métodos 
laboratoriais de análises físico-químicas. Por serem avaliações subjetivas, cuja análise exige treinamento de provadores e metodologia específica, estes atributos nem sempre são avaliados nos trabalhos de pós-colheita (Chitarra \& Chitarra, 1990).

Tendo em vista importância dos atributos sensoriais como componentes da qualidade, o presente trabalho teve por objetivo avaliar os efeitos de diferentes materiais de embalagem e períodos de armazenamento nas características sensoriais de goiabas 'Kumagai', durante o armazenamento refrigerado.

\section{MATERIAL E MÉTODOS}

O experimento foi realizado no Instituto de Tecnologia de Alimentos (ITAL), localizado em Campinas, SP.

Goiabas da variedade 'Kumagai' foram colhidas num pomar comercial do município de Valinhos, SP, no mês de julho de 1998. Após a colheita, os frutos foram selecionados e transportados ao ITAL, em caixas de papelão com capacidade para $3 \mathrm{~kg}$. Foram selecionados frutos sem defeitos e em estádio de maturação caracterizado pela mudança da cor da casca de verde-escuro para verde-claro. $\mathrm{O}$ peso médio dos frutos utilizados foi de 167 gramas.

Antes da aplicação dos tratamentos, as goiabas foram pré-resfriadas em câmaras de refrigeração até a temperatura da polpa atingir $10^{\circ} \mathrm{C}$.

Os tratamentos consistiram no uso de diferentes materiais de embalagem e períodos de armazenamento. Os materiais de embalagem utilizados foram: filme poliolefinico com permeabilidade seletiva (PPS), filme de polietileno de baixa densidade (PEBD), filme de PEBD com incorporação de mineral (PBM) e filme poliolefinico termo-encolhível (ENC). Goiabas sem embalagem foram tomadas como Controle.

Os filmes PPS, PEBD e PBM foram utilizados na forma de sacos, que após a colocação das goiabas, foram selados em seladora por impulso elétrico, marca Haramura, sem evacuação de ar. Para o acondicionamento no filme ENC, as goiabas foram colocadas em bandejas de poliestireno expandido, envolvidas com o material de 
embalagem e submetidas ao encolhimento do filme em túnel de ar quente. $O$ encolhimento ocorreu à temperatura média de $128^{\circ} \mathrm{C}$ durante 13 segundos com posterior resfriamento em ar forçado à temperatura ambiente, durante 5 segundos.

Após o acondicionamento nas diferentes embalagens, os frutos foram colocados em caixas de papelão ondulado e armazenados a $10 \pm 1^{\circ} \mathrm{C}$ e $85-90 \% \mathrm{UR}$, durante 7,14 , 21 e 28 dias. Frutos sem embalagem plástica (Controle) foram submetidos às mesmas condições.

$\mathrm{O}$ delineamento experimental adotado foi inteiramente ao acaso, em esquema fatorial $5 \times 5$. Os fatores estudados foram materiais de embalagem (PPS, PEBD, PBM, ENC e Controle) e períodos de armazenamento $(0,7,14,21$ e 28 dias). Foram utilizadas 5 repetições com 6 frutos por parcela, sendo cada parcela constituída por uma embalagem.

As características dos materiais de embalagem utilizados e as áreas de permeação das embalagens, após o acondicionamento dos frutos, são mostradas na Tabela 1.

Tabela 1. Características dos materiais de embalagem utilizados no acondicionamento das goiabas e área de permeação das embalagens.

\begin{tabular}{lcccc}
\hline Materiais de embalagem & $\begin{array}{c}\text { Espessura } \\
(\mu \mathrm{m})\end{array}$ & $\begin{array}{c}\mathrm{TPO}_{2} \\
\left(\mathrm{~cm}^{3} \cdot \mathrm{m}^{-2} \cdot \mathrm{dia}^{-1}\right)^{\mathrm{x}}\end{array}$ & $\begin{array}{c}\mathrm{TPCO}_{2} \\
\left(\mathrm{~cm}^{3} \cdot \mathrm{m}^{-2} \cdot \mathrm{dia}^{-1}\right)^{\mathrm{y}}\end{array}$ & $\begin{array}{c}\text { Área de permeação } \\
\text { das embalagens } \\
\left(\mathrm{m}^{2}\right)\end{array}$ \\
\hline $\begin{array}{l}\text { (PPS) Poliolefinico com } \\
\text { permeabilidade seletiva } \\
\text { (PEBD) Polietileno de }\end{array}$ & 35 & 6.827 & 21.969 & 0,112 \\
$\begin{array}{l}\text { baixa densidade } \\
\text { (PBM) Polietileno de } \\
\text { baixa densidade com } \\
\text { incorporação de mineral }\end{array}$ & 69 & 2.115 & 8.434 & 0,115 \\
$\begin{array}{l}\text { (ENC) Poliolefinico } \\
\text { termo-encolhivel }\end{array}$ & 15 & 4.918 & 32.937 & 0,118 \\
\hline
\end{tabular}

${ }^{\mathrm{x}} \mathrm{TPO}_{2}$ : Taxa de permeabilidade ao oxigênio em condições normais de temperatura e pressão

${ }^{y} \mathrm{TPCO}_{2}$ : Taxa de permeabilidade ao gás carbônico em condições normais de temperatura e pressão

Ao final de cada período de armazenamento, foram realizadas análises da composição gasosa do espaço livre das embalagens, para verificar o estabelecimento da 
atmosfera de equilíbrio. Foram coletadas amostras de gás do interior das embalagens e injetadas em cromatógrafo marca Shimadzu, modelo 14A. Os resultados foram expressos em porcentagem de volume de gás.

As características sensoriais das goiabas foram analisadas na caracterização do lote experimental e após cada período de armazenamento. Na caracterização do lote experimental realizou-se uma análise imediatamente após a colheita e outra após comercialização simulada de 3 dias a $25 \pm 1{ }^{\circ} \mathrm{C}$ e $70-80 \%$ UR. Da mesma forma, após cada período de armazenamento, realizou-se uma avaliação imediatamente após a refrigeração e outra após a comercialização simulada. Cada tratamento foi representado por uma amostra de 5 goiabas (uma de cada embalagem). Estas foram apresentadas aos provadores, inicialmente inteiras e posteriormente em pedaços, para degustação. As amostras foram identificadas com códigos aleatórios, que variaram de uma análise para outra.

As avaliações foram realizadas por uma equipe constituída de 12 provadores, sendo eles técnicos de laboratórios e estagiários do próprio ITAL. Todas as análises foram realizadas em uma sala ampla, bem iluminada e ventilada, no horário das 10 as 11 horas da manhã, às terças e sextas-feiras. Para composição da equipe foram selecionadas pessoas não fumantes, com habilidade para detectar variações nos atributos de qualidade da goiaba e com disponibilidade de horário nas datas previamente agendadas.

Antes do início do experimento os provadores foram familiarizados com as definições das escalas, mediante várias sessões de treinamento. Foram oferecidos materiais de referência representando os diferentes pontos das escalas de notas, conforme descrição a seguir.

a) coloração externa: foram apresentadas, aos provadores, goiabas representando os diversos pontos da escala de cores, que variou de 1 a 5 . A nota 1 (totalmente verde) foi representada por goiabas em estádio imaturo de desenvolvimento, com casca verdeescura e a nota 5 (totalmente amarela) foi representada por goiabas em estádio muito avançado de amadurecimento (sobremadura).

b) odor estranho: foram colhidas goiabas em diferentes estádios de amadurecimento, embaladas em filme muito pouco permeável e armazenadas sob refrigeração até 
apresentarem odor característico de fermentado. Amostras destas goiabas e de outras recém colhidas foram oferecidas aos provadores, a fim de caracterizar o tipo de odor que se desejava identificar. Foram provadas goiabas verdes e goiabas maduras.

c) sabor estranho: foi adotada metodologia semelhante àquela utilizada para odor estranho, uma vez que neste caso desejava-se identificar sabor de fruta fermentada.

d) textura: foram oferecidas aos provadores goiabas com diferentes graus de perda de textura. A goiaba com textura completa correspondeu aproximadamente àquela com casca totalmente verde da escala de coloração externa, sendo sua textura muito crocante, dura, ainda inadequada para consumo. Moderada perda de textura foi representada por fruta cuja polpa já havia perdido a característica de crocância, porém apresentava ainda alguma resistência ao ser pressionada entre os dentes. Completa perda de textura foi representada por goiaba sobremadura, excessivamente amolecida, inadequada para consumo.

e) qualidade global: as notas foram atribuídas considerando-se a presença de fatores que depreciam a qualidade da fruta como: odor e sabor estranhos, perda de brilho, murchamento, amassamento, podridões, amadurecimento irregular, sobrematuração, etc. A ausência desses fatores implicava em atribuição de nota máxima para a amostra (ótima) e a presença de um ou vários deles a ponto de caracterizar a amostra como inadequada para comercialização, implicava em atribuição da pior nota (péssima).

Para medir a intensidade de cada atributo, foram utilizadas escalas estruturadas de 1 a 5 (Figura 1 ).

Os resultados das avaliações foram anotados em fichas apropriadas (Figura 1), tabulados e analisados estatisticamente. Inicialmente testou-se a homogeneidade das variâncias através do teste de Hartley. Como não se constatou heterogeneidade das variâncias ao nível de $\alpha=0,05 \%$, procedeu-se a análise da variância (teste $\mathrm{F}$ ) e comparação de médias pelo teste de Tukey ao nível de $5 \%$ de probabilidade. 


\section{FICHA DE AVALIAÇ̃̃O}

PROJETO: Conservação pós-colheita de goiabas pelo uso de atmosfera modificada e refrigeração PROVADOR: DATA :.........................

INSTRUÇÕES: Por favor, prove cada amostra e atribua suas notas de acordo com a escala em anexo. Anote os valores na tabela abaixo.

\begin{tabular}{|l|c|c|c|c|c|}
\hline \multirow{2}{*}{ VARIÁVEIS } & \multicolumn{5}{c|}{ AMOSTRAS } \\
\cline { 2 - 6 } & A & B & C & D & E \\
\hline COR & & & & & \\
\hline ODOR & & & & & \\
\hline SABOR & & & & & \\
\hline QEXTURA & & & & & \\
\hline
\end{tabular}

OBSERVAÇÕES:

\section{ESCALAS DE NOTAS:}

\section{Coloração externa}

$1=$ totalmente verde

$2=$ mais verde do que amarela

$3=$ verde e amarela em quantidades iguais

$4=$ mais amarela do que verde

$5=$ totalmente amarelo

\section{Odor estranho}

$1=$ isento

$2=$ ligeiro

$3=$ moderado

$4=$ intenso

$5=$ muito intenso
Textura da polpa

$1=$ textura completa

$2=$ ligeira perda da textura

$3=$ moderada perda da textura

$4=$ intensa perda da textura

$5=$ completa perda da textura

Qualidade global

l= ótima

$2=$ boa

$3=$ razoável

$4=$ ruim

$5=$ péssima

\section{Sabor estranho}

$1=$ isento

$2=$ ligeiro

$3=$ moderado

$4=$ intenso

$5=$ muito intenso

Figura 1. Ficha de avaliação e escalas de notas utilizadas para análise sensorial de goiabas. 


\section{RESULTADOS E DISCUSSÃO}

As atmosferas do interior das embalagens entraram em equilíbrio com o ambiente nos primeiros 7 dias de armazenamento, mantendo-se estáveis até o $28^{\circ}$ dia. As composições observadas nas atmosferas de equilíbrio no interior das embalagens são mostradas na Figura 2.

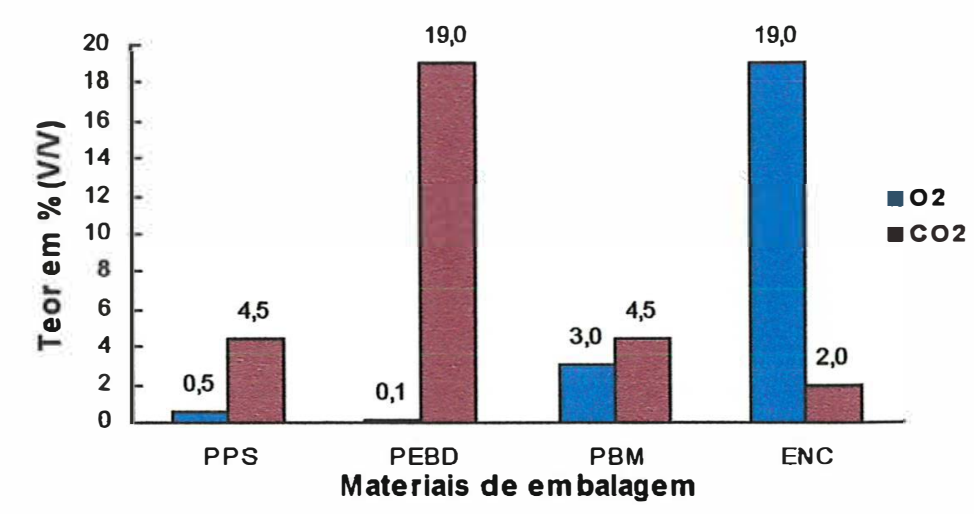

Figura 2. Atmosfera de equilíbrio no interior de embalagens com 6 goiabas 'Kumagai', sem evacuação de ar, estocadas a $10^{\circ} \mathrm{C}$. PPS=filme poliolefínico com permeabilidade seletiva, $\mathrm{PEBD}=$ filme de polietileno de baixa densidade, PBM=filme PEBD com incorporação de mineral, ENC=filme poliolefínico termo-encolhível.

O filme de PEBD induziu anaerobiose no interior das embalagens e elevada concentração de $\mathrm{CO}_{2}$, constituindo-se em excessiva barreira à permeação destes gases. $\mathrm{O}$ filme PPS também provocou intensa modificação da composição gasosa no interior da embalagem, que estabilizou-se em $0,5 \%$ e $4,5 \%$ de $\mathrm{O}_{2}$ e $\mathrm{CO}_{2}$, respectivamente. No filme PBM, as concentrações de $\mathrm{O}_{2}$ e $\mathrm{CO}_{2}$ estabilizaram-se em $3 \%$ e 4,5\%, respectivamente, níveis estes próximos daqueles recomendados para o armazenamento de goiabas (Monzini \& Gorini, 1973; Castro \& Sigrist, 1988). O filme ENC, por ser bastante permeável, causou menor modificação da atmosfera no interior das embalagens durante o armazenamento, a qual estabilizou-se em $19 \%$ de $\mathrm{O}_{2}$ e $2 \%$ de $\mathrm{CO}_{2}$.

$\mathrm{Na}$ Tabela 2 está resumida a análise de variância para os efeitos dos tratamentos, sobre a coloração externa, textura da polpa e qualidade global das goiabas analisadas 
neste experimento. Observa-se que tanto os materiais de embalagem quanto os períodos de armazenamento influenciaram de maneira significativa o comportamento das variáveis, o mesmo ocorrendo com a interação entre eles. Isto indica que os diferentes materiais de embalagem influenciaram diferentemente as variáveis analisadas, ao longo do armazenamento.

Tabela 2. Significância do teste $F$ da análise de variância para os efeitos dos tratamentos sobre as variáveis coloração externa, textura da polpa $\mathrm{e}$ qualidade global, analisadas em goiabas 'Kumagai'.

\begin{tabular}{|c|c|c|c|c|c|c|}
\hline \multirow{2}{*}{ Tratamentos e interação } & \multicolumn{2}{|c|}{ Coloração Externa } & \multicolumn{2}{|c|}{ Textura da Polpa } & \multicolumn{2}{|c|}{ Qualidade Global } \\
\hline & $I^{x}$ & II & $\mathrm{I}$ & II & I & Il \\
\hline & ------ & ------ & Significât & de teste $F$ & ------ & --.--- \\
\hline Material de Embalagem (ME) & $* *$ & $* *$ & $* *$ & $* *$ & $* *$ & $* *$ \\
\hline Período de armazenamento (PA) & $* *$ & $* *$ & $* *$ & $* *$ & $* *$ & $* *$ \\
\hline$M E \times P A$ & $* *$ & $* *$ & $* *$ & $* *$ & $* *$ & $* *$ \\
\hline Coeficiente de variação (\%) & 14,64 & 11,59 & 21,28 & 17,18 & 30,36 & 23,24 \\
\hline
\end{tabular}

x $\mathrm{I}=$ frutos analisados imediatamente após armazenamento refrigerado; $\mathrm{II}=$ frutos analisados após armazenamento refrigerado seguido de comercialização simulada de 3 dias a $25^{\circ} \mathrm{Ce}$ - 70-80\% UR.

$y * *=$ significativo ao nível de $1 \%$ de probabilidade.

Os resultados das avaliações de coloração da casca dos frutos após cada período de armazenamento e após a comercialização simulada, são apresentados na Tabela 3 e na Figura 3. Verifica-se que o tratamento ENC promoveu as maiores perdas da coloração verde da casca dos frutos, superando inclusive o Controle. Neste tratamento, o amarelecimento foi intenso, mesmo sob refrigeração. Após 7 dias de armazenamento, seguido de comercialização simulada, os frutos deste tratamento já apresentavam-se mais amarelos do que verdes. $\mathrm{O}$ aquecimento ao qual foram submetidos durante o encolhimento do filme, parece ter acentuado a degradação da clorofila e/ou síntese de carotenóides nos frutos deste tratamento. 
Tabela 3. Influência de embalagens e períodos de armazenamento na coloração externa de goiabas 'Kumagai' armazenadas a $10^{\circ} \mathrm{C}$ e $85-90 \%$ UR w'.

\begin{tabular}{|c|c|c|c|c|c|}
\hline \multicolumn{6}{|c|}{ Frutos avaliados imediatamente após retirados da câmara } \\
\hline \multirow{2}{*}{ Embalagens ${ }^{x}$} & \multicolumn{5}{|c|}{ Períodos de armazenamento (dias) } \\
\hline & 0 & 7 & 14 & 21 & 28 \\
\hline & & --.---.-- & -- Nota ${ }^{y}$ & 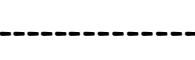 & -.--.-- \\
\hline PPS & $1,61 \mathrm{a} \mathrm{A}$ & 1,88 b A & $1,50 \mathrm{~d} A$ & $1,81 \mathrm{c} \mathrm{A}$ & $1,64 \mathrm{c} \mathrm{A}$ \\
\hline PEBD & 1,61 a $\mathrm{A}$ & $1,65 \mathrm{~b} A$ & $1,71 \mathrm{~cd} \mathrm{~A}$ & $1,88 \mathrm{c} \mathrm{A}$ & $1,79 \mathrm{c} \mathrm{A}$ \\
\hline PBM & $1,61 \mathrm{a} \mathrm{B}$ & $2,05 \mathrm{ab} \mathrm{A}$ & $2,07 \mathrm{cA}$ & $2,00 \mathrm{c} \mathrm{AB}$ & $2,00 \mathrm{c} \mathrm{AB}$ \\
\hline ENC & 1,61 a D & 2,48 a $\mathrm{C}$ & 3,07 a $\mathrm{B}$ & $3,50 \mathrm{a} \quad \mathrm{B}$ & 4,14 a $\mathrm{A}$ \\
\hline Controle & 1,61 a $C$ & $2,43 \mathrm{ab} \mathrm{B}$ & $2,57 \mathrm{~b} \quad \mathrm{~B}$ & $2,63 \mathrm{~b} \quad \mathrm{~B}$ & $3,57 \mathrm{~b} \quad \mathrm{~A}$ \\
\hline
\end{tabular}

Frutos avaliados após comercialização simulada ${ }^{\mathrm{z}}$

\begin{tabular}{|c|c|c|c|c|c|}
\hline \multirow{2}{*}{ Embalagens } & \multicolumn{5}{|c|}{ Períodos de armazenamento (dias) } \\
\hline & 0 & 7 & 14 & 21 & 28 \\
\hline PPS & 2,17 a $B$ & $2,60 \mathrm{c} A B$ & $2,50 \mathrm{c} B$ & $2,61 \mathrm{~d} A B$ & $3,00 \mathrm{c} \mathrm{A}$ \\
\hline PEBD & 2,17 a $\mathrm{AB}$ & $1,95 \mathrm{~d} \mathrm{~B}$ & $2,17 \mathrm{c} \mathrm{AB}$ & $2,44 \mathrm{~d} \mathrm{~A}$ & $2,14 \mathrm{~d} A B$ \\
\hline PBM & 2,17 a $\mathrm{D}$ & 2,90 bc C & $3,00 \mathrm{~b} \mathrm{BC}$ & $3,39 \mathrm{c} \mathrm{B}$ & 4,29 b A \\
\hline ENC & 2,17 a $\mathrm{C}$ & 3,60 a $\mathrm{B}$ & 3,89 a $\mathrm{B}$ & 4,94 a $\mathrm{A}$ & 5,00 a A \\
\hline Controle & 2,17 a $\mathrm{D}$ & 3,10 b C & 3,56 a $\mathrm{C}$ & $4,06 \mathrm{~b} \quad \mathrm{~B}$ & 5,00 a A \\
\hline
\end{tabular}

${ }^{w}$ Médias seguidas de mesma letra minúscula na coluna e maiúscula na linha não diferem entre si, pelo teste de Tukey ao nivel de $5 \%$ de probabilidade.

${ }^{x}$ PPS=filme poliolefinico com permeabilidade seletiva, $\mathrm{PEBD}=$ filme de polietileno de baixa densidade, $\mathrm{PBM}=$ filme $\mathrm{PEBD}$ com incorporação de mineral, $\mathrm{ENC}=$ filme poliolefinico termo-encolhivel .

${ }^{y}$ Escala de notas: $1=$ totalmente verde, $2=$ mais verde do que amarelo, $3=$ verde e amarelo em quantidades iguais, $4=$ mais amarelo do que verde, $5=$ totalmente amarelo.

${ }^{z}$ Frutos mantidos a $25^{\circ} \mathrm{C}$ e $70-80 \%$ UR, durante 3 dias, após cada periodo de armazenamento.

A mudança de cor em frutos durante o amadurecimento ocorre devido à degradação da clorofila, que possibilita a visualização de pigmentos previamente presentes no tecido, principalmente $\beta$-caroteno. Entretanto, em muitas espécies, a degradação da clorofila é acompanhada da biossíntese de um ou mais pigmentos, usualmente antocianinas e carotenóides (Chitarra \& Chitarra, 1990; Awad, 1993; 
Tucker, 1993). Segundo estes autores, os mecanismos precisos da degradação da clorofila e da síntese de carotenóides, durante o amadurecimento de frutos, ainda não são bem conhecidos.
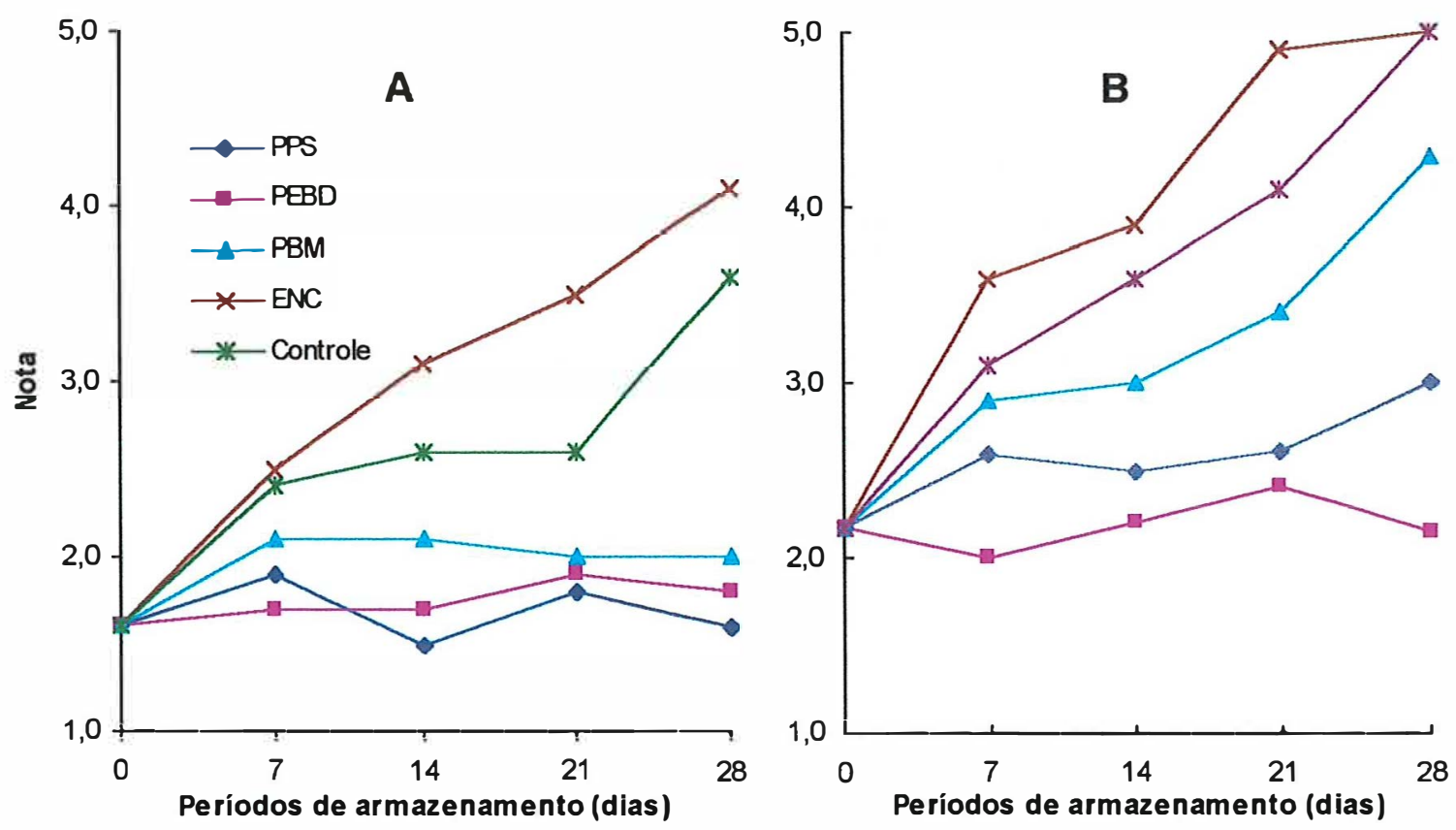

Figura 3. Coloração externa de goiabas 'Kumagai', submetidas a diferentes embalagens e períodos de armazenamento a $10^{\circ} \mathrm{C}$ e $85-90 \% \mathrm{UR}$ (A), mais 3 dias a $25^{\circ} \mathrm{C}$ e $70-80 \% \mathrm{UR}$ (B).

Os tratamentos PPS e PEBD foram eficientes na manutenção da cor verde dos frutos. Ao final de 28 dias de conservação, a coloração dos frutos não diferiu estatisticamente daqueles recém colhidos ( 0 dia). Comparando-se os gráficos A e B da Figura 3, verifica-se que a coloração dos frutos acondicionados em PEBD sofreu pouca evolução após transferência para o ambiente, nos diferentes períodos de armazenamento. Isto indica, que a condição de armazenamento à qual os frutos deste tratamento foram submetidos, induziram alteração na fisiologia dos mesmos, impedindo o amadurecimento normal. Esta irregularidade no amadurecimento pode estar ligada à alta concentração de $\mathrm{CO}_{2}$ e baixa de $\mathrm{O}_{2}$ gerada dentro da embalagem, que provavelmente 
causou danos irreversíveis às células e à rota metabólica de síntese de etileno (Wills et al., 1989).

Os frutos submetidos ao tratamento PBM também mantiveram a cor verde da casca durante o armazenamento refrigerado, porém, desenvolveram rapidamente a cor amarela quando transferidos para o ambiente. Ao final de 21 de armazenamento seguidos de comercialização simulada, os frutos apresentaram predominância da cor amarela.

Os resultados das avaliações de textura da polpa são mostrados na Tabela 4 e na Figura 4. Verifica-se que as maiores perdas da textura ocorreram nos tratamentos ENC e Controle. A partir de 7 dias de armazenamento, seguidos ou não de comercialização simulada, os valores de textura diferiram estatisticamente dos frutos recém colhidos (0 dia).

O tratamento PPS foi o mais eficiente na manutenção da textura da polpa durante o armazenamento refrigerado. As notas atribuídas para perda da textura, após cada período de armazenamento, seguidos de comercialização simulada, não diferiram estatisticamente entre si, indicando que houve manutenção deste atributo de qualidade ao longo do armazenamento.

Nos frutos acondicionados em PEBD verificou-se baixa, porém, crescente perda da textura durante o armazenamento, com valores superiores aos daqueles acondicionados em PPS. Por outro lado, houve pouca alteração nos valores de textura após transferência para o ambiente, indicando que os frutos não continuaram o processo normal de amadurecimento. Certamente, a condição de anaerobiose, associada ao elevado teor de $\mathrm{CO}_{2}$ no interior da embalagem, causou distúrbio fisiológico, o que impediu o amolecimento normal dos tecidos.

O filme PBM promoveu resultados intermediários de perda da textura dos frutos, sem ocorrência de dano fisiológico aparente.

Geralmente a perda de textura dos frutos durante o amadurecimento é devida à degradação das paredes celulares. Os polímeros de carboidratos representam 90 a $95 \%$ dos componentes da parede celular e podem ser agrupados em celulose, hemiceluloses e pectinas (Tucker, 1993). Com o amadurecimento ocorre a ação de duas enzimas 
principais, poligalacturonase e pectinametilesterase, que são responsáveis pela degradação da parede celular (Chitarra \& Chitarra, 1990).

Tabela 4. Influência de embalagens e períodos de armazenamento na textura da polpa de goiabas 'Kumagai' armazenadas a $10^{\circ} \mathrm{C}$ e $85-90 \%$ UR '

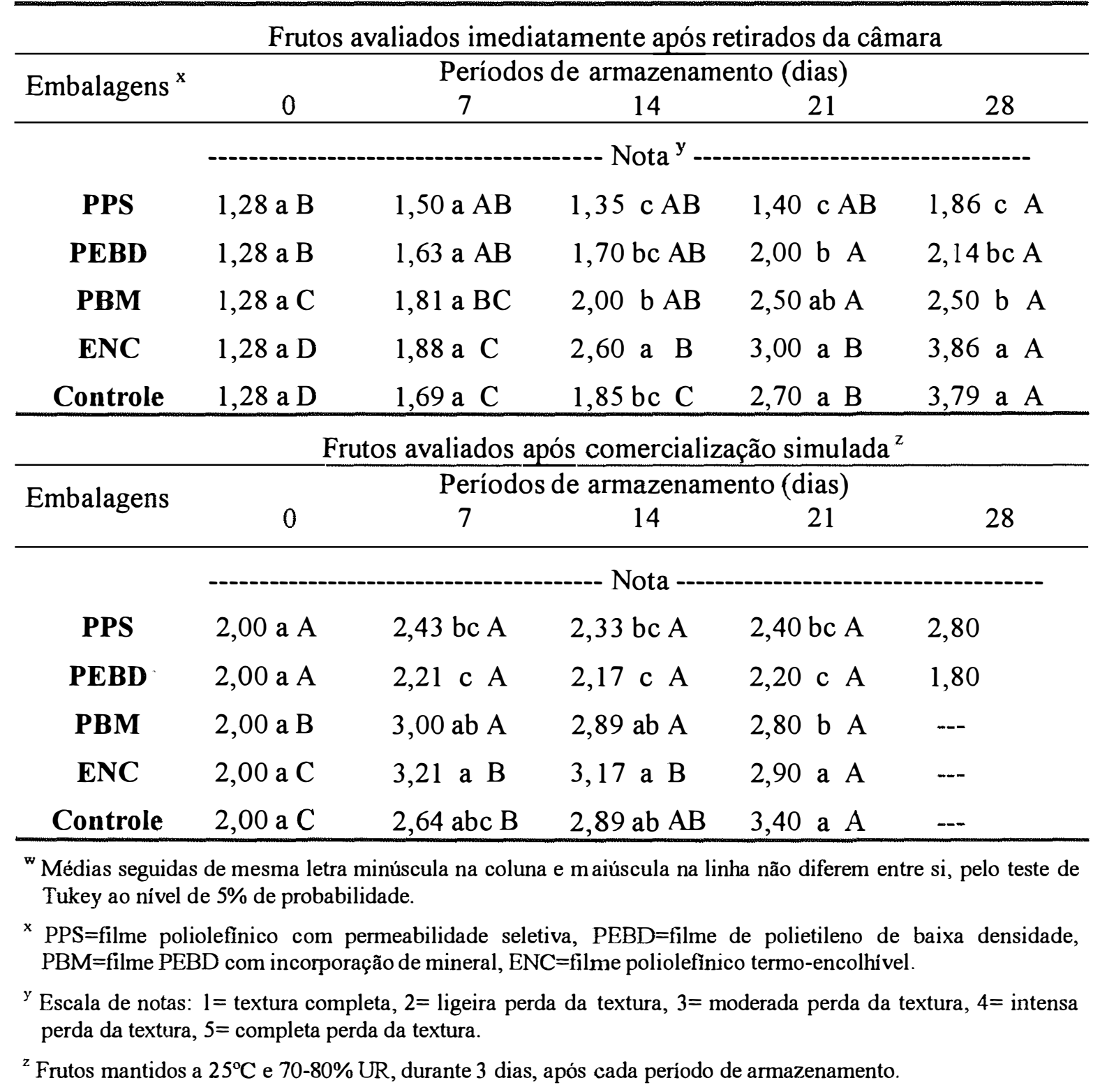



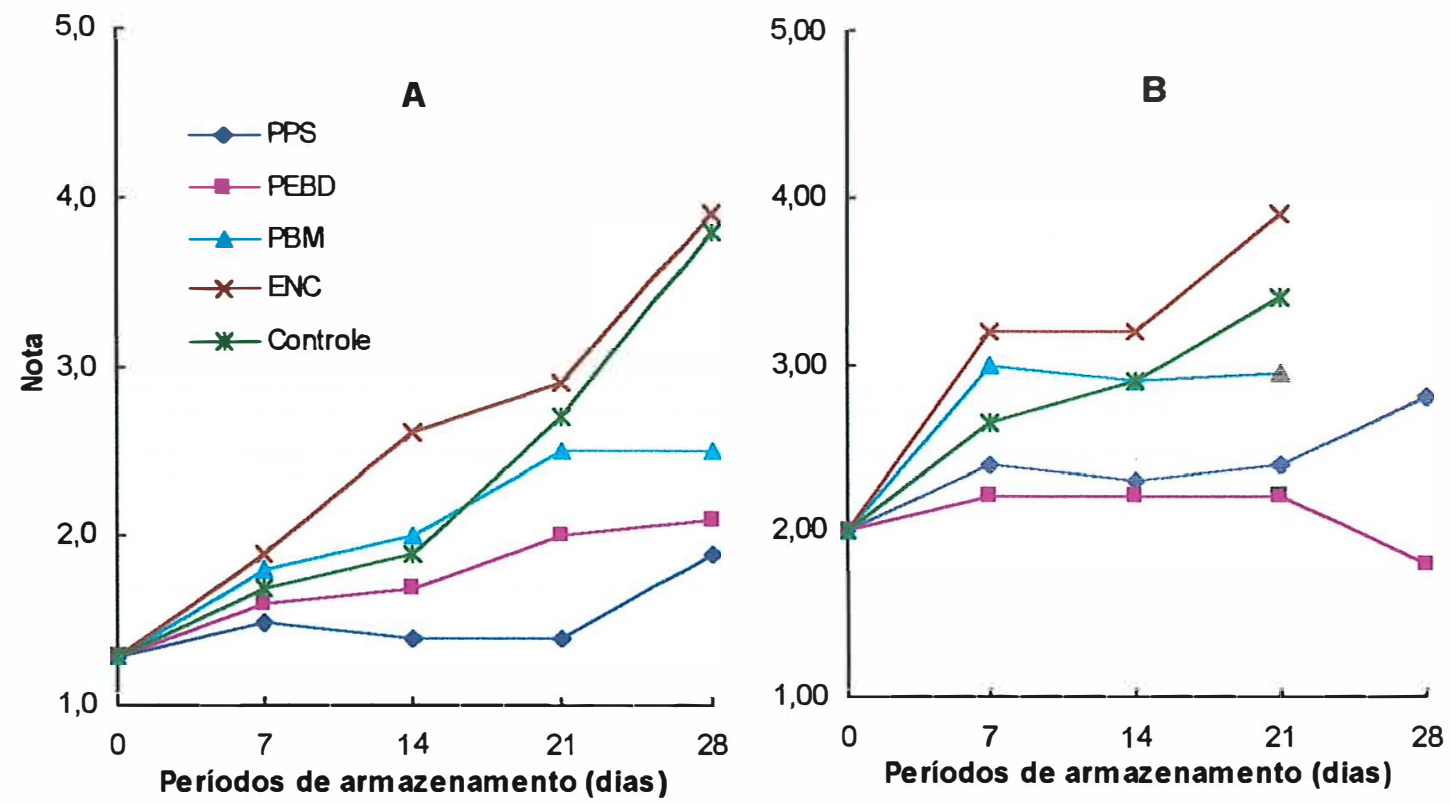

Figura 4. Textura da polpa em goiabas 'Kumagai', submetidas a diferentes embalagens e períodos de armazenamento a $10^{\circ} \mathrm{C}$ e $85-90 \% \mathrm{UR}(\mathrm{A})$, mais 3 dias a $25^{\circ} \mathrm{C}$ e $70-80 \%$ UR (B).

Verificou-se presença de odor e sabor de fermentado nos frutos acondicionados em PEBD a partir dos 14 dias de armazenamento, que foram intensificando-se até o final do armazenamento (Tabelas 5 e 6). No caso de odor, os valores foram maiores logo após a retirada das embalagens, com tendência de decréscimo após 3 dias sob condição ambiente. Por outro lado, o sabor de fermentado manteve-se intenso mesmo após transferência para o ambiente.

Nos frutos acondicionados em PPS e PBM identificaram-se valores baixos para presença de odor estranho em algumas das avaliações. Após a comercialização simulada este atributo mostrou-se ausente nos frutos destes tratamentos. Em nenhuma avaliação foi identificado sabor de fermentado nestes frutos.

Nos frutos dos tratamentos ENC e Controle não identificou-se odor e nem sabor estranhos. 
Tabela 5. Odor estranho em goiabas 'Kumagai' acondicionadas em PPS, PEBD e PBM e armazenadas a $10^{\circ} \mathrm{C}$ e $85-90 \%$ UR.

Frutos avaliados imediatamente após retirados da câmara

\begin{tabular}{|c|c|c|c|c|c|}
\hline \multirow[t]{2}{*}{ Embalagens ${ }^{x}$} & \multicolumn{5}{|c|}{ Períodos de armazenamento (dias) } \\
\hline & 0 & 7 & 14 & 21 & 28 \\
\hline PPS & 1 & 1 & 1.1 & 1,5 & 1 \\
\hline PEBD & 1 & 1 & 1,5 & 2,5 & 3,5 \\
\hline PBM & 1 & 1 & 1 & 1 & 1,3 \\
\hline
\end{tabular}

Frutos avaliados após comercialização simulada ${ }^{z}$

\begin{tabular}{cccccc}
\hline \multirow{2}{*}{ Embalagens } & \multicolumn{5}{c}{ Períodos de armazenamento (dias) } \\
& 0 & 7 & 14 & 21 & 28 \\
\hline & & & & & \\
PPS & 1 & 1 & 1 & 1 & 1 \\
PEBD & 1 & 1 & 1,3 & 2,2 & 2,5 \\
PBM & 1 & 1 & 1 & 1 & 1 \\
\hline
\end{tabular}

${ }^{x}$ PPS $=$ filme poliolefinico com permeabilidade seletiva, $P E B D=$ filme de polietileno de baixa densidade, PBM=filme PEBD com incorporação de mineral.

${ }^{y}$ Escala de notas: $1=$ =isento; $2=$ ligeiro; $3=$ moderado; $4=$ intenso; $5=$ muito intenso.

${ }^{\mathrm{z}}$ Frutos mantidos a $25^{\circ} \mathrm{C}$ e $70-80 \%$ UR, durante 3 dias, após cada período de armazenamento.

Tabela 6. Sabor estranho em goiabas 'Kumagai', acondicionadas em polietileno de baixa densidade (PEBD) e armazenadas a $10^{\circ} \mathrm{C}$ e $85-90 \% \mathrm{UR}$.

\begin{tabular}{|c|c|c|c|c|c|}
\hline & \multicolumn{5}{|c|}{ Períodos de armazenamento (dias) } \\
\hline & 0 & 7 & 14 & 21 & 28 \\
\hline & & --- & ota ${ }^{x}$ & & \\
\hline $\begin{array}{l}\text { Frutos avaliados imediatamente } \\
\text { após retirados da câmara }\end{array}$ & 1 & 1 & 1,5 & 2,3 & 3,3 \\
\hline $\begin{array}{l}\text { Frutos avaliados após } \\
\text { comercialização simulada }\end{array}$ & 1 & 1 & 1,6 & 2,9 & --- \\
\hline
\end{tabular}

${ }^{x}$ Escala de notas: 1=isento; 2=ligeiro; 3=moderado; 4=intenso; 5=muito intenso.

${ }^{y}$ Frutos mantidos a $25^{\circ} \mathrm{C}$ e $70-80 \%$ UR, durante 3 dias, após cada período de armazenamento. 
As maiores perdas da qualidade global foram observadas no tratamentos ENC e Controle (Tabela 7 e Figura 5), devido à perda da cor verde da casca, redução da textura da polpa e presença de podridões, após transferência para o ambiente. Os frutos acondicionados em PEBD também apresentaram elevada perda da qualidade global, porém, devido à presença de odor e sabor estranhos. O acondicionamento em PBM proporcionou manutenção da qualidade global durante o armazenamento refrigerado,

Tabela 7. Influência de embalagens e períodos de armazenamento na qualidade global de goiabas 'Kumagai' armazenadas a $10^{\circ} \mathrm{C}$ e $85-90 \%$ UR '

\begin{tabular}{|c|c|c|c|c|c|}
\hline \multicolumn{6}{|c|}{ Frutos avaliados imediatamente após retirados da câmara } \\
\hline \multirow{2}{*}{ Embalagens ${ }^{x}$} & \multicolumn{5}{|c|}{ Períodos de armazenamento (dias) } \\
\hline & \multicolumn{2}{|r|}{7} & 14 & 21 & \multirow[t]{2}{*}{28} \\
\hline & ----------- & ------------- & ---- Nota ${ }^{y}$-- & 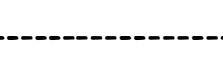 & \\
\hline PPS & 2,10 a $\mathrm{A}$ & 1,93 a $\mathrm{A}$ & $2,20 \mathrm{ab} \mathrm{A}$ & 2,41 a $\mathrm{A}$ & 2,57 bc $A$ \\
\hline PEBD & 2,10 a B & 2,00 a B & 2,75 a $B$ & 2,82 a $\mathrm{B}$ & 4,29 a $A$ \\
\hline PBM & $2,10 \mathrm{a} \mathrm{A}$ & 1,71 a $A$ & 1,45 b A & 1,41 b A & $2,21 \subset \mathrm{A}$ \\
\hline ENC & 2,10 a $B$ & 1,71 a $B$ & 1,65 b B & $2,09 \mathrm{ab} B$ & 3,71 a $A$ \\
\hline \multirow[t]{2}{*}{ Controle } & $2,10 \mathrm{a} B$ & $1,64 \mathrm{a} \mathrm{B}$ & 1,45 b B & $2,00 \mathrm{ab} \mathrm{B}$ & $3,43 \mathrm{ab} A$ \\
\hline & \multicolumn{5}{|c|}{ Frutos avaliados após comercialização simulada ${ }^{2}$} \\
\hline \multirow{2}{*}{ Embalagens } & \multicolumn{5}{|c|}{ Períodos de armazenamento (dias) } \\
\hline & \multicolumn{2}{|r|}{7} & \multicolumn{2}{|c|}{$14 \quad 21$} & 28 \\
\hline PPS & 1,50 a BC & $1,50 \mathrm{~b} \quad \mathrm{BC}$ & $1,40 \mathrm{c} \quad \mathrm{C}$ & $2,21 \mathrm{c} A \mathrm{~B}$ & 3,00 c A \\
\hline PEBD & 1,50 a $C$ & $1,71 \mathrm{ab} \mathrm{C}$ & 1,70 bc $\mathrm{C}$ & $2,93 \mathrm{abcB}$ & $4,64 \mathrm{ab} A$ \\
\hline PBM & 1,50 a $C$ & $1,93 \mathrm{ab} \mathrm{BC}$ & $2,10 \mathrm{abcBC}$ & $2,50 \mathrm{bc} \mathrm{B}$ & $4,64 \mathrm{ab} A$ \\
\hline ENC & 1,50 a $C$ & 2,50 a $\mathrm{B}$ & 2,75 a $\mathrm{B}$ & 3,64 a $A$ & 4,14 b A \\
\hline Controle & 1,50 a $\mathrm{D}$ & $2,14 \mathrm{ab} C D$ & $2,40 \mathrm{ab} \mathrm{BC}$ & $3,07 \mathrm{ab} \mathrm{B}$ & 5,00 a A \\
\hline \multicolumn{6}{|c|}{$\begin{array}{l}\text { wédias seguidas de mesma letra minúscula na coluna e maiúscula na linha não diferem entre si, pelc } \\
\text { teste de Tukey ao nível de } 5 \% \text { de probabilidade. }\end{array}$} \\
\hline \multicolumn{6}{|c|}{$\begin{array}{l}\text { × } \mathrm{PPS}=\text { filme poliolefínico com permeabilidade seletiva, } \mathrm{PEBD}=\text { filme de polietileno de baixa densidade } \\
\mathrm{PBM}=\text { filme } \mathrm{PEBD} \text { com incorporação de mineral, } \mathrm{ENC}=\text { filme poliolefinico termo-encolhivel. }\end{array}$} \\
\hline \multicolumn{6}{|c|}{${ }^{y}$ Escala de notas: $1=$ ótima, $2=$ boa, $3=$ razoável, $4=$ ruim, $5=$ péssima } \\
\hline & 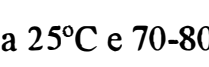 & & & & \\
\hline
\end{tabular}



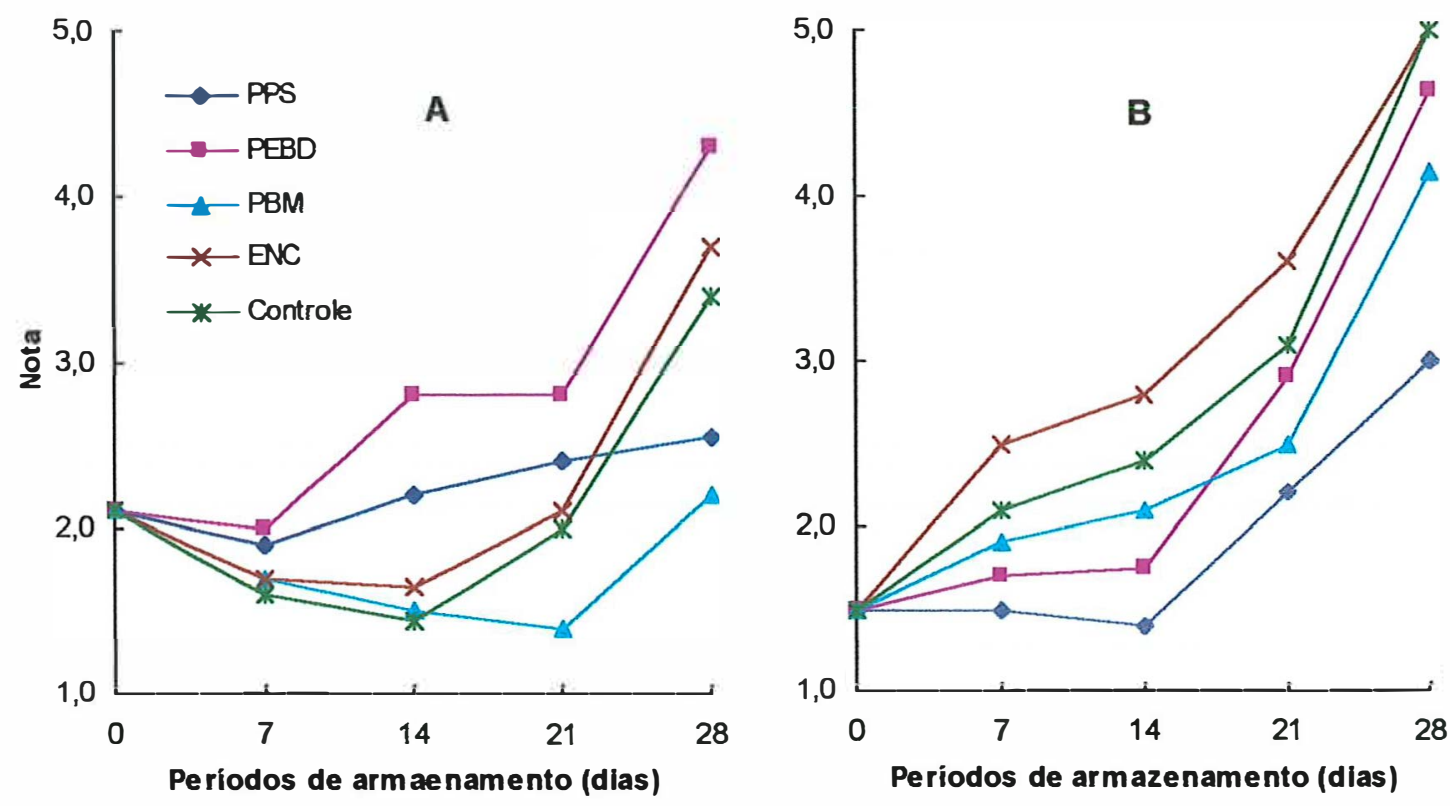

Figura 5. Qualidade global de goiabas 'Kumagai', submetidas a diferentes embalagens e períodos de estocagem a $10^{\circ} \mathrm{C}$ e $85-90 \% \mathrm{UR}$ (A), mais 3 dias a $25^{\circ} \mathrm{C}$ e $70-80 \%$ UR (B). Para mais informações veja Tabela 7.

entretanto, após transferência para o ambiente as goiabas perderam a coloração verde rapidamente. Os melhores resultados foram obtidos pelo acondicionamento em PPS, onde os frutos mantiveram a qualidade tanto na câmara de armazenamento, quanto após transferência para o ambiente.

O filme de polietileno de baixa densidade com $69 \mu$ de espessura (PEBD) induziu anaerobiose e elevada concentração de gás carbônico no interior da embalagem e, por consequência, provocou alteração na fisiologia das goiabas, que impediu 0 amadurecimento normal e resultou alterações no odor e no sabor das mesmas. As goiabas acondicionadas nestas embalagens apresentaram-se comercializáveis apenas até o $7^{0}$ dia de armazenamento. $\mathrm{O}$ uso de filme de polietileno com menor espessura seria mais permeável aos gases, contudo, a menor resistência do material poderia comprometer a integridade da embalagem. Neste caso, poderia se optar por filme de 
polietileno de baixa densidade com cadeia linear, que apresenta maior resistência mecânica (Sarantópoulos et al., 1996).

O tratamento ENC (filme poliolefinico termo-encolhível) apresentou baixa capacidade de modificação da atmosfera no interior da embalagem e não retardou a senescência das goiabas. A passagem pelo túnel de ar quente para encolhimento do filme parece ter sido a principal causa do comportamento negativo deste tratrmento, que apresentou desempenho pior do que o Controle (sem embalagem plástica).

$\mathrm{O}$ acondicionamento de goiabas em filme de polietileno de baixa densidade com incorporação de mineral (PBM) não provocou alterações no sabor, no aroma nem na fisiologia dos frutos, indicando que a composição gasosa de $2 \%$ de $\mathrm{O}_{2}$ e $5 \%$ de $\mathrm{CO}_{2}$ é adequada para a conservação de goiabas. Verificou que os frutos mantiveram a qualidade enquanto mantidos sob atmosfera modificada e refrigeração, porém, amadureceram rapidamente após a transferência para 0 ambiente. As goiabas apresentaram qualidade adequada para consumo até 28 dias, se mantidas sob refrigeração e atmosfera modificada, e até 14 dias se comercializadas em condição ambiente. Entretanto, este material de embalagem apresenta aspecto opaco, devido à presença dos minerais, o que limita seu uso como embalagem de varejo. Uma opção, seria o uso de um filme com boa aparência para embalagem de varejo e que possibilite atmosfera semelhante àquela obtida neste tratamento. Desta forma, não haveria necessidade de retirar as goiabas da embalagem para a comercialização.

As goiabas acondicionadas e PPS (filme poliolefinico com permeabilidade seletiva) apresentaram os melhores res:ytados de qualidade global ao final de 28 dias de armazenamento seguido de comercialização simulada. Apesar da baixa concentração de oxigênio no interior das embalagens $(<1 \%)$, não verificou-se ocorrência de distúrbio fisiológico, nas condições deste experimento. É possível que isto se deva ao fato da concentração de $\mathrm{CO}_{2}$ não ter sido demasiadamente alta. $\mathrm{O}$ filme PPS apresenta, também, boas características para ser utilizado em embalagem de varejo (aparência, soldabilidade e possibilidade de impressão), apresentando potencial para uso na comercialização de goiabas. 


\section{CONCLUSÕES}

Para goiabas 'Kumagai' submetidas a diferentes materiais de embalagem e armazenadas a $10^{\circ} \mathrm{C}$ e $85-90 \%$ UR ( +3 dias a $25^{\circ} \mathrm{C}$ e70-80\% UR), podem ser feitas as seguintes conclusões:

- O filme PEBD induz anaerobiose e elevada concentração de gás carbônico no interior das embalagens, alterações fisiológicas que impedem o amadurecimento normal dos frutos, além de alterações no odor e no sabor dos mesmos.

- O filme ENC apresenta baixa capacidade de modificar a atmosfera no interior das embalagens e os frutos sofrem rápida perda da cor verde, da textura e da qualidade global.

- O filme PBM proporciona atmosfera de equilíbrio com $3 \%$ de $\mathrm{O}_{2}$ e $4,5 \%$ de $\mathrm{CO}_{2}$, no interior das embalagens e manutenção das características sensoriais dos frutos por até 14 dias de armazenamento.

- O filme PPS proporciona atmosfera de equilíbrio com $0,5 \%$ de $\mathrm{O}_{2}$ e $4,5 \%$ de $\mathrm{CO}_{2}$, no interior das embalagens e, é eficiente na manutenção da cor da casca, textura da polpa e qualidade global dos frutos, por até 28 dias de armazenamento.

\section{REFERÊNCIAS BIBLIOGRÁFICAS}

AKAMINE, E.K.; GOO, T. Repiration and ethylene production in fruits of species and cultivars of Psidium and species of Eugenia. Journal of the American Society for Horticultural Science, v. 104, n.5, p.632-635, 1979.

AUGUSTIN, M.A.; AZIZAH, O. Post-harvest storage of guava (Psidium guajava L.) var. Taiwan. Pertanika, v.11, n.1, p.45-50, 1988. 
AWAD, M. Fisiologia pós-colheita de frutos. São Paulo: Nobel, 1993. 114p.

BROWN, B.I.; WILLS, R.B.H. Post-harvest changes in guava fruit of different maturing. Scientia Horticulturae., v. 19, n.3/4, p.237-243, 1983.

BURG, S.P.; BURG, E.A. Molecular requeriments for the biological activity of ethylene. Plant Physiology, v.42, p.144, 1967.

CARRARO, A.F.; CUNHA, M.M. Manual de exportação de frutas. Brasília: FRUPEX; IICA, 1994. 254p.

CARVALHO, V.D. Qualidade e conservação pós-colheita de goiabas. Informe Agropecuário, v.17, n.179, p.48-54, 1994.

CASTRO, J. V.; SIGRIST, J. M. M. Matéria-prima. In: MEDINA, J.C.; CASTRO,J.V.; SIGRIST, J.M.M.S.; MARTIN, Z.J.; KATO, K.; MAIA, M.L.; GARCIA, A.E.B.; LEITE, R.S.S.F. Goiaba: cultura, matéria-prima, processamento e aspectos econômicos. 2.ed. Campinas: ITAL, 1988. cap. 2, p. 121-140. (Série Frutas Tropicais, 6)

CHITARRA, M.I.F.; CHITARRA, A.B. Pós-colheita de frutas e hortaliças: fisiologia e manuseio. Lavras: ESAL, FAEPE, 1990. 320p.

COMBRINK, J.C.; KOCK,S.L.; VAN EEDEN, C. Effect of post-harvest treatment and packaging on the keeping quality of fresh guava fruit. Acta Horticulturae, n.275, p.639-645, 1990.

CRYOVAC DIVISION. New controlled permeability produce packaging preserves flavors and extends shelf life. Ontario, 1994. 15p.

DURIGAN, J.F. Colheita, conservação e embalagens. In: SIMPÓSIO BRASILEIRO SOBRE A CULTURA DA GOIABEIRA, 1., Jaboticabal, 1995. Anais. Jaboticabal: FUNEP, 1997. p.149-158. 
GASPAR, J.W.; COUTO, F.A.A.; SALOMÃO, L.C.; FINGER, L.L.; CARDOSO, A.A. Effect of low temperature and plastic films on post-harvest life of guava (Psidium geajava L). Acta Horticulturae, n.452, p. 107-114, 1997.

HARDENBURG, R.E.; WATADA, A.E.; WANG, C.Y. The commercial storage of fruits, vegetables, and florist, and nursery stocks. Washington: USDA, 1986. 130p. (USDA. Agriculture Handbook, 66)

KADER, A.A. Biochemical and physiological basis for effects of controlled and modified atmospheres on fruits and vegetables. Food Technology, v.40, n. 5, p.99104. 1986.

KADER, A.A. Postharvest biology and technology: an overview. In: KADER, A.A.; KASMIRE, R.F.; MITCHELL F.G.; REID, M.S.; SOMMER, N.F.; THOMPSON, J.F. Postharvest technology of horticultural crops. Oakland: University of California, 1992a. cap.2, p.3-7.

KHEDKAR, D.M.; ANSARWADKAR, K.W.; DABHADE, R.S.; BALLAL, A.L. Extension of storage life of guava var. L-49. Indian Food Packer, v.36, n.2, p. 49$52,1982$.

LEE, D.S.; HAGGAR, P.E.; YAM, K.L. Application of ceramic-filled polymeric films for packaging fresh produce. Packaging Technology and Science, v.5, n. 1, p.27$30,1992$.

LIMA, M.A.; DURIGAN, J.F.; TOSTES, D.R.D. Avaliação do comportamento respiratório de goiabas 'Pedro Sato' e a influência de diferentes embalagens na sua conservação sob refrigeração (compact disc). In: CONGRESSO BRASILEIRO DE CIÊNCIA E TECNOLOGIA DE ALIMENTOS, 16., Rio de Janeiro, 1998. Anais. Rio de Janeiro: SBCTA, 1998. 
MERCADO-SILVA, E.; BENITO-BAUTISTA, P.; GARCIA-VELASCO, M.A. Fruit development, harvest index and ripening changes of guavas produced in central Mexico. Postharvest Biology and Technology, v.13, n.2, p.143-150, 1998.

MONZINI, A.; GORINI, F.L. Controlled atmosphere storage of citrus, grapes and others fruit. Freddo, v.27, n.6, p.27-31, 1973.

PARO, R.M.; KANESIRO, M.A.B.; JERÔNIMO, E.M.; TOSTES, D.R.D. Conservação pós-colheita de frutos de goiabeira (Psidium guajava L), empregando-se tratamento com cera, embalagens plásticas, em associação com armazenamento refrigerado. In: CONGRESSO BRASILEIRO DE FRUTICULTURA, 14., Curitiba, 1996. Resumos. Londrina: IAPAR, 1996. p. 238.

SARANTÓPOULOS, C.I.G.L.; ALVES, R.M.V.; OLIVEIRA, L.M; GOMES, T.C. Embalagens com atmosfera modificada. Campinas: ITAL, CETEA, 1996. 114p.

SINGH, B.P.; SINGH, H.K.; CHAUAN, K.S.; Effect of post-harvest calcium treatments on the storage life of guava fruits. Indian Journal of Agricultural Science, v. 51, n. 1, p.44-47, 1981.

SINGH, R.V.; JOSHI, M.C.; RAM, H.B.; BISHT, N.S. Effect of wax coating and prepackaging on the storage behavior of guava cv. allahabad safeda. Indian Food Packer, v.38, n.6, p.80-85, 1984.

TANDON, D.K.; ADSULE.P.G.; KALRA, S.K. Effect of certain post-harvest treatments on the shelf life of guava fruits. Indian Journal of Horticulture, v. 41, n. 1, p.88-92, 1984.

TUCKER, G.A. Introduction. In: SEYMOUR, G.B.; TAYLOR, J.E.; TUCKER,G.A. Biochemistry of fruit ripening. London: Chapman \& Hall, 1993. cap. 1, p. 1-52. 
WILlS, R.B.H.; McGlASSON, W.B.; GRAHAM, D.; LEE, T.H.; HALL, E.G. Postharvest: an introduction to the physiology and handling of fruit and vegetables. 3.ed. New York: AVI Publ., 1989. 174p.

YAGI, M.I. Preliminary post-harvest studies on guava fruit. Sudan Journal Food Science, n. 8, p.68-73, 1976. 


\section{CONCLUSÕES GERAIS}

Do estudo de diferentes temperaturas e materiais de embalagem para conservação de goiabas 'Kumagai', obteve-se as seguintes conclusões gerais:

\section{a) com relação à temperaturas de armazenamento}

- Goiabas 'Kumagai' não podem ser armazenadas a $2^{\circ} \mathrm{C}$ por mais do que 7 dias.

- As temperaturas de 10 ou $12^{\circ} \mathrm{C}$ não são eficientes na conservação desta variedade, para armazenamento superior a 14 dias.

- A utilização da temperatura de $8^{\circ} \mathrm{C}$ para a conservação desta variedade é a mais indicada para o armazenamento até 21 dias.

b) com relação à caracterização dos materiais de embalagem

- Filme de polietileno de baixa densidade com $69 \mu \mathrm{m}$ de espessura (PEBD) apresenta $\mathrm{TPO}_{2}$ de $2.115 \mathrm{~cm}^{3} \cdot \mathrm{m}^{-2} \cdot \mathrm{dia}^{-1}$ e $\mathrm{TPCO}_{2}$ de $4.434 \mathrm{~cm}^{3} \cdot \mathrm{m}^{-2} \cdot \mathrm{dia}^{-1}$.

- Filme poliolefinico termo-encolhível com $15 \mu \mathrm{m}$ de espessura (ENC) apresenta $\mathrm{TPO}_{2}$ de $6.366 \mathrm{~cm}^{3} \cdot \mathrm{m}^{-2} \cdot \mathrm{dia}^{-1}$ e $\mathrm{TPCO}_{2}$ de $34.864 \mathrm{~cm}^{3} \cdot \mathrm{m}^{-2} \cdot \mathrm{dia}^{-1}$.

- Filme de polietileno de baixa densidade com incorporação de mineral e $24 \mu \mathrm{m}$ de espessura (PBM), apresenta $\mathrm{TPO}_{2}$ de $4.918 \mathrm{~cm}^{3} \cdot \mathrm{m}^{-2} \cdot \mathrm{dia}^{-1}$ e $\mathrm{TPCO}_{2}$ de 32.937 $\mathrm{cm}^{3} \cdot \mathrm{m}^{-2} \cdot \mathrm{dia}^{-1}$.

- Filme poliolefinico com permeabilidade seletiva e $35 \mu \mathrm{m}$ de espessura (PPS), apresenta $\mathrm{TPO}_{2}$ de $6.827 \mathrm{~cm}^{3} \cdot \mathrm{m}^{-2} \cdot \mathrm{dia}^{-1}$ e $\mathrm{TPCO}_{2}$ de $21.969 \mathrm{~cm}^{3} \cdot \mathrm{m}^{-2} \cdot \mathrm{dia}^{-1}$ 
c) com relação à atmosfera de equilíbrio no interior das embalagens com goiabas 'Kumagai', armazenadas a $10^{\circ} \mathrm{C}$ e $85-90 \%$ UR

- O filme PEBD induz anaerobiose e elevada concentração de gás carbônico (20\%).

- O filme ENC proporciona atmosfera de equilíbrio com $19 \%$ de $\mathrm{O}_{2}$ e $2 \%$ de $\mathrm{CO}_{2}$.

- O filme PBM proporciona atmosfera de equilíbrio com $3 \%$ de $\mathrm{O}_{2}$ e $4,5 \%$ de $\mathrm{CO}_{2}$.

- O filme PPS proporciona atmosfera de equilíbrio com $0,5 \%$ de $\mathrm{O}_{2}$ e $4,5 \%$ de $\mathrm{CO}_{2}$.

d) com relação à conservação das goiabas, submetidas aos diferentes materiais de embalagem e períodos de armazenamento a $10^{\circ} \mathrm{C}$ e $85-90 \%$ UR $\left(+3\right.$ dias a $25^{\circ} \mathrm{C}$ e $70-80 \%$ UR)

- Frutos acondicionados em PEBD apresentam alterações fisiológicas que impedem o amadurecimento normal, além de alterações no odor e no sabor.

- Frutos acondicionados em ENC apresentam rápida senescência, caracterizada principalmente pela perda da cor verde e da textura da polpa e incidência de podridões.

- Frutos acondicionados em PBM podem ser conservados por 14 dias, mantendo as características fisico-químicas e sensoriais adequadas para consumo.

- Frutos acondicionados em PPS podem ser conservados por 28 dias, mantendo as características físico-químicas e sensoriais adequadas para consumo. 


\section{REFERÊNCIAS BIBLIOGRÁFICAS}

ADSULE, P.G.; TANDON, D.K. The assesment of LDPE bags for enhancing self life of guava. Indian Food Packer, v.37, n.3, p.82-87, 1983.

AKAMINE, E.K.; GOO, T. Repiration and ethylene production in fruits of species and cultivars of Psidium and species of Eugenia. Journal of the American Society for Horticultural Science, v. 104, n.5, p.632-635, 1979.

ALI, Z.M.; LAZAN, H. Guava. In: MITRA, S.K. Postharvest physiology and storage of tropical and subtropical fruits. Wallingford: $C A B$ International, 1997. cap.6, p. 145-165.

AUGUSTIN, M.A.; AZIZAH, O. Post-harvest storage of guava (Psidium guajava L.) var. Taiwan. Pertanika, v.11, n. 1, p.45-50, 1988.

AWAD, M. Fisiologia pós-colheita de frutos. São Paulo: Nobel, 1993. 114p.

BRANT, P.; MICHIELS, D.J.; HALLE, R.W.; ERDERLY, T.C. Modified atmosphere packaging quality: the value of metallocen resins. In: MAPACK'95, Anaheim, 1995. Proceedings. Herndon: Institute of Packaging Professionals IoPP, 1995. p.10-11.

BROWN, B.I.; WILLS, R.B.H. Post-harvest changes in guava fruit of different maturing. Scientia Horticulturae., v.19, n.3/4, p.237-243, 1983.

BURG, S.P.; BURG, E.A. Molecular requeriments for the biological activity of ethylene. Plant Physiology, v.42, p. 144, 1967. 
CARRARO, A.F.; CUNHA, M.M. Manual de exportação de frutas. Brasília: FRUPEX; IICA, 1994. 254p.

CARVALHO, C.R.L.; MANTOVANI, D.M.B.; CARVALHO, P.R.N.; MORAES, R.M.M. Análises químicas de alimentos. Campinas: ITAL, 1990. $121 \mathrm{p}$. (Manual Técnico)

CARVALHO, V.D. Qualidade e conservação pós-colheita de goiabas. Informe Agropecuário, v.17, n.179, p.48-54, 1994.

CASTRO, J. V.; SIGRIST, J. M. M. Matéria-prima. In: MEDINA, J.C.; CASTRO,J.V.; SIGRIST, J.M.M.S.; MARTIN, Z.J.; KATO, K.; MAIA, M.L.; GARCIA, A.E.B.; LEITE, R.S.S.F. Goiaba: cultura, matéria-prima, processamento e aspectos econômicos. 2.ed. Campinas: ITAL, 1988. cap. 2, p. 121-140. (Série Frutas Tropicais, 6)

CHITARRA, M.I.F.; CHITARRA, A.B. Pós-colheita de frutas e hortaliças: fisiologia e manuseio. Lavras: ESAL, FAEPE, 1990. 320p.

COMBRINK, J.C.; KOCK,S.L.; VAN EEDEN, C. Effect of post-harvest treatment and packaging on the keeping quality of fresh guava fruit. Acta Horticulturae, n.275, p.639-645, 1990.

CRYOVAC DIVISION. New controlled permeability produce packaging preserves flavors and extends shelf life. Ontario, 1994. 15p.

DURIGAN, J.F. Colheita, conservação e embalagens. In: SIMPÓSIO BRASILEIRO SOBRE A CULTURA DA GOIABEIRA, 1., Jaboticabal, 1995. Anais. Jaboticabal: FUNEP, 1997. p.149-158.

ESTEVES, M.T.C; CARVALHO, V.D.; CHITARRA, M.I.F.; CHITARRA, A.B.; PAULA, M.B. Caracterização dos frutos de seis cultivares de goiabeiras (Psidium guajava L.) na maturação. I. Determinações físicas e químicas. In: CONGRESSO 
BRASILEIRO DE FRUTICULTURA, 7., Florianópolis, 1983. Anais. Florianópolis: SBF; EMPASC, 1984. v.2, p.477-489.

FNP CONSULTORIA \& COMÉRCIO. Agrianual 97: anuário estatístico da agricultura brasileira. São Paulo, 1997. 435p.

FNP CONSULTORIA \& COMÉRCIO. Agrianual 99: anuário estatístico da agricultura brasileira. São Paulo, 1999. 521 p.

FREY, T.D. High gas permeability structures for fresh-cut produce packaging. In: MAPACK'95, Anaheim, 1995. Proceedings. Herndon: Institute of Packaging Professionals, 1995. p.23-25.

GASPAR, J.W.; COUTO, F.A.A.; SALOMÃO, L.C.; FINGER, L.L.; CARDOSO, A.A. Effect of low temperature and plastic films on post-harvest life of guava (Psidium guajava L). Acta Horticulturae, n.452, p. 107-114, 1997.

GORRIS, L.G.M.; PEPPELENBOS, H.W. Modified Atmosphere and vacuum packaging to extend the shelf life of respiring food products. HortTechnology, v.2, n.3, p.303-309, 1992.

HARDENBURG, R.E.; WATADA, A.E.; WANG, C.Y. The commercial storage of fruits, vegetables, and florist, and nursery stocks. Washington: USDA, 1986. 130p. (USDA. Agriculture Handbook, 66)

KADER, A.A. Biochemical and physiological basis for effects of controlled and modified atmospheres on fruits and vegetables. Food Technology, v.40, n.5, p.99104. 1986.

KADER, A.A. Postharvest biology and technology: an overview. In: KADER, A.A.; KASMIRE, R.F.; MITCHELL F.G.; REID, M.S.; SOMMER, N.F.; THOMPSON, J.F. Postharvest technology of horticultural crops. Oakland: University of California, 1992a. cap.2, p.3-7. 
MERCADO-SILVA, E.; BENITO-BAUTISTA, P.; GARCIA-VELASCO, M.A. Fruit development, harvest index and ripening changes of guavas produced in central Mexico. Postharvest Biology and Technology, v.13, n.2, p.143-150, 1998.

MONZINI, A.; GORINI, F.L. Controlled atmosphere storage of citrus, grapes and others fruit. Freddo, v.27, n.6, p.27-31, 1973.

OLIVEIRA, L.M.; ALVES, R.M.V.; SARANTÓPOUlOS, C.I.G.L., PADULA, M.; GARCIA, E.E.C.; COLTRO, L. Ensaios para avaliação de embalagens plásticas flexíveis. Campinas: ITAL, CETEA, 1996. 219p.

OLIVEIRA, M.A.; CEREDA, M.P. Determinação da curva de respiração na póscolheita dos frutos de goiaba híbrida (branca) (Psidium guajava) variedade Kumagai. In CONGRESSO BRASILEIRO DE FRUTICULTURA, 14., Curitiba, 1996. Resumos. Londrina: IAPAR, 1996. p.239.

PANTÁSTICO, E.B. Postharvest physiology, handling and utilization of tropical an subtropical fruits an vegetables. Westport: AVI Publ., 1975. 560p.

PARO, R.M.; KANESIRO, M.A.B.; JERÔNIMO, E.M.; TOSTES, D.R.D. Conservação pós-colheita de frutos de goiabeira (Psidium guajava L), empregando-se tratamento com cera, embalagens plásticas, em associação com armazenamento refrigerado. In: CONGRESSO BRASILEIRO DE FRUTICULTURA, 14., Curitiba, 1996. Resumos. Londrina: IAPAR, 1996. p.238.

PASSY, N.; MILTZ, J. The application of active packaging for the extension of food shelf-life. In: WORLD CONFERENCE ON PACKAGING, 9., Bruxelas, 1995. Proceedings. Bruxelas: IAPRI, 1995. p.305-320.

PEREIRA, F.M. Cultura da goiabeira. Jaboticabal: FUNEP, 1995. 47p. 
PIVETTA, K.F.L.; DURIGAN, J.F.; PEREIRA, F.M. Efeito de dois tipos de cera na conservação pós-colheita de frutos de goiabeira (Psidium guajava L.). Revista Brasileira de Fruticultura, v.14, n.3, p.241-243, 1992.

PIZA Jr., C.T.; KAVATI, R. A cultura da goiabeira de mesa. Campinas: CATI, 1994. 28p. (CATI. Boletim Técnico, 219)

PROCTOR, F.J. The European Community market for tropical fruit and factors limiting growth. Acta Horticulturae, n.269, p.29-39, 1990.

SARANTÓPOULOS, C.I.G.L. Embalagens ativas. Informativo CETEA, v.5, n. 1, p.79, 1993.

SARANTÓPOULOS, C.I.G.L.; ALVES, R.M.V.; OLIVEIRA, L.M.; GOMES, T.C. Embalagens com atmosfera modificada. Campinas: ITAL, CETEA, 1996. 114p.

SEYMOUR, G.B.; TAYLOR, J.E.; TUCKER,G.A. Biochemistry of fruit ripening. London: Chapman \& Hall, 1993. 454p.

SHEWFELT, R.L.; PRUSSIA, S.E. Postharvest handling: a systems approach. New York: Academic Press, 1993. 358p.

SINGH, B.P.; SINGH, H.K.; CHAUAN, K.S.; Effect of post-harvest calcium treatments on the storage life of guava fruits. Indian Journal of Agricultural Science, v.51, n. 1, p.44-47, 1981.

SINGH, R.V.; JOSHI, M.C.; RAM, H.B.; BISHT, N.S. Effect of wax coating and prepackaging on the storage behavior of guava cv. allahabad safeda. Indian Food Packer, v.38, n.6, p.80-85, 1984.

TANDON, D.K.; ADSULE.P.G.; KALRA, S.K. Effect of certain post-harvest treatments on the shelf life of guava fruits. Indian Journal of Horticulture, v.41, n. 1, p.88-92, 1984. 
TUCKER, G.A. Introduction. In: SEYMOUR, G.B.; TAYLOR, J.E.; TUCKER,G.A. Biochemistry of fruit ripening. London: Chapman \& Hall, 1993. cap.1, p.1-52.

VASQUEZ-OCHOA, R.J.; COLINAS-LEON, M.T. Changes in guavas of three maturity stages in response to temperture and relative humidy. HortScience, v.25, n. 1, p.86-87, 1990.

WILLS, R.B.H.; McGLASSON, W.B.; GRAHAM，D.; LEE，T.H.; HALL，E.G. Postharvest: an introduction to the physiology and handling of fruit and vegetables. 3.ed. New York: AVI Publ., 1989. 174p.

WILLS, R.B.H.; MULHOLLAND, E.E.; BROWN, B.I.; SCOTT, K.J. Storage of two new cultivars fo guava fruit for processing. Tropical Agriculture, v.60, p.175-178, 1983.

WOODS, J. L. Moisture loss from fruits and vegetables. Postharvest News and Information, v.1, n.3, p.195-199, 1990.

YAGI, M.I. Preliminary post-harvest studies on guava fruit. Sudan Journal Food Science, n.8, p.68-73, 1976.

YAM, K.L.; PAIK, J.S.; LAI, C.C. Packaging part III: Materials. In: HUI, Y.H. (Ed.). Encyclopedia of food science and technology. Chichester: John Wiley, 1992. v.3, p.1978-1982.

YANG, S.F. Biosynthesis and action of ethylene. HortScience, v.20, n. 1, p.41, 1985.

ZAGORY, D.; KADER, A.A. Modified atmosfere packaging of fresh produce. Food Technology, v.42, n.9, p.70-77, 1988. 